\title{
Blutuntersuchungen nach der Arnethschen Methode im allgemeinen und in der Tuberkulose im spe- ziellen. 102 von uns untersuchte Fälle.
}

\author{
Von \\ K. Dluski, und M. Rospedzihowski. \\ Chefarzt. f. Assistent.
}

Trotz der fortwährend vervollkommneten physikalischen Untersuchungsmethoden der Lungentuberkulose begegnen wir oft Fälle, die die ersten Stadien der Krankheit betreffen und welche, was die Diagnose anbelangt, uns in grosse Zweifel setzen. Die gegenwärtige bakteriologische Diagnostik leistet uns ebenfalls keine genügende Sicherheit.

Dies lässt sich sowohl von den subkutanen Tuberkulin-Injektionen nach der Kochschen Schule, als auch von den neuen Arten der Tuberkulin-Anwendung zu diagnostischen Zwecken nach Pirquet, Wolff-Eisner, Moro, oder auch von dem Opsoninindex sagen. Sie bilden den Gegenstand einer enormen Streitfrage hinsichtlich der klinischen Ergebnisse und sie leisten uns endlich keine sichere Gewäbr für das Voneinanderscheiden aktiver und latenter Herde, was sowohl für den Kranken wie auch für den Arzt von hohem Werte ist. Abgesehen von der Wichtigkeit einer zeitig gestellten Diagnose, stösst die Klinik der Lungentuberkulose vielfach auf die mit dem Verlanfe der Krankheit verbundenen Ungewissheiten und Schwierigkeiten. Es ist wohl zwecklos, darüber zu sprechen. Es entsteht die Frage ob wir in der von Arneth aufgestellten und allseitig von ihm bearbeiteten Untersuchungsmethode, die er bei einer ganzen Reihe von Infektionskrankheiten angewandt hat, nämlich in den hämatologischen Untersuchungen, nicht die entsprechenden, wichtigen Hinweisungen finden und somit die bisherigen Lücken ergänzen können. 
Die A rneth sche Methode ist allgemein bekannt, dem ungeachtet wollen wir sie in kurzen Worten wiederholen. Sie betrifft eine Art von weissen Blutkörperchen, das sind die Neutrophilen. Ibr Ausgangspunkt war der Umstand, dass das lediglich quantitative Untersuchen der weissen Blutkörperchen als Grundlage zum Bestimmen der Ansteckungsschwere wie des Krankheitsverlaufes ungenügend und schwankend ist. Eine solche Rolle sollen Untersuchungen der qualitativen Verhältnisse von neutrophilen Leukozyten ergänzen.

Die Grundlage der Arnethschen Untersuchungen bildet, wie bekannt, einerseits die Metschnikoffsche Theorie, nach welcher die aus dem Zerfalle der weissen Blutkörperchen sich herausbildenden Antikörper als Waffe des Organismus gegen die Infektion oder Intoxikation hervortreten; andererseits die allmählige Entwickelung der Myelozyten und der jungen, einkernigen, neutrophilen Zellen (deren einzigen Ursprung nach Arneth das Knochenmark bildet) zu reifen, die mehr und mehr differenzierte Kerne besitzen. Daher die Folgerung, dass der Organismus sich gegen Infektion oder Intoxikation wehrt, in erster Linie dank dem Zerfalle, der an Antikörpern inhaltsreichsten mehrkernigen Zellen. An die Stelle der letzteren treten nun infolge erhöhter Produktion der blutbildenden Organe junge Zellen, welche die erwähnten Antikörper in geringerer Zahl enthalten. Auf dieser Grundlage schuf Arneth, dank seinem erfinderischen Geiste, das bekannte normale Blutbild eines erwachsenen, gesunden Menschen, welches er als das Durchschnittsmass von fünfzehn Untersuchungen entwickelte; wir erinnern an das oben Erwähnte bei der weiteren Besprechung dieses Gegenstandes.

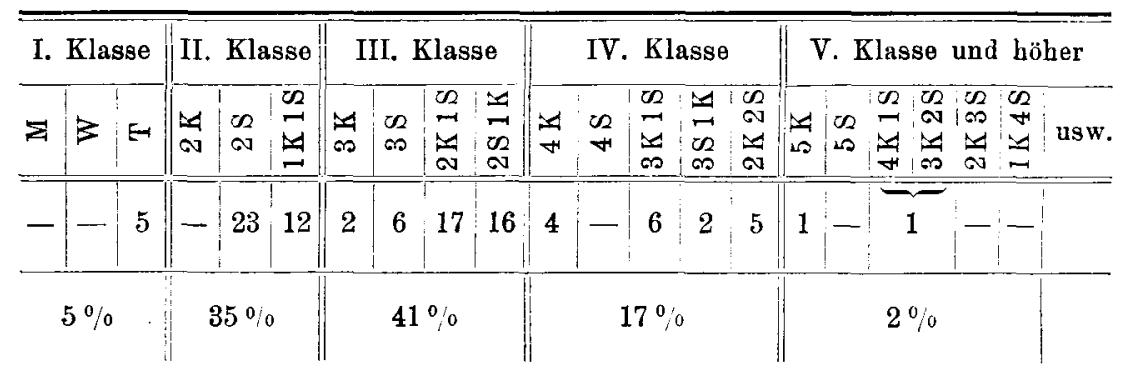

Wir müssen von rornherein bemerken, dass dieses Bild keineswegs ein unveränderliches, festes Blutbild liefert. Im Gegenteil, es schwankt vielmehr bei einzelnen Individuen und unter Einwirkung verschiedener Faktoren ${ }^{1}$, sogar rein physiologischer Natur, selbst bei

1) Monographie, S. 183. 
ebendemselben Individuum. Wir können, uns auf Arneth berufend, als ein drastisches Beispiel dieser Beweglichkeit des Bildes, die Unbeständigkeit des Blutbildes eines gebärenden Weibes oder eines Neugeborenen anführen. Auf diesen Umstand legen wir ein grosses Gewicht bezüglich der Einwürfe, welche deswegen Arneth trafen. Arneth berücksichtigt die Beweglichkeit seines Bildes gewissermassen bis zu dem Grade, dass er das Verschieben desselben um $15 \%$ nach links als eine die normalen Grenzen keineswegs überschreitende Erscheinung ansieht. Selbstverständlich kommen bei pathologischen Zuständen diese Veränderungen in breiteren Grenzen vor. Aus der Grundidee, dass die mehrkernigen, älteren Zellen die grösste Zahl von Antikörpern besitzen und dass die jüngeren, sich quantitativ vergrössernd, die ersteren im Kampfe vertreten sollen, folgt der logische Schluss: Die Verschiebung des normalen Blutbildes nach links weisst auf krankhafte Zustände des Organismus hin. Hier drängen sich unwillkürlich zwei Bemerkungen auf. Die erste lautet: kommt die Bildung der Antikörper, einenachgewiesene Tatsache - nach Metschnik off, durch den Zerfall von weissen Blutkörperchen zustande oder geschieht dies nach Buchner dank ihrer Sekretion. Dies letztere ist endgültig noch nicht erwiesen worden. Die zweite Bemerkung hob Esser (20) hervor, nämlich ob ein Massenzerfall der mehrkernigen Zellen deshalb stattfinden kann, weil diese gerade weniger widerstandsfähig als die jungen Zellen sind. Aber darauf kommt es nicht an.

Angenommen, die Metschnikoffsche Theorie wäre der Ausgangspunkt für den Kampf des menschlichen Organismus mit Mikroorganismen und deren Produkten, so fragen wir uns, was für ein Verhältnis nach Arneth zwischen dem Blutbilde und dem pathologischen Zustande des Organismus besteht. Bei einer ganzen Menge angestellter Untersuchungen findet Arneth in infektiösen Krankheiten mit Ausnahme des Tetanus und der Landryschen Paralyse ${ }^{1}$ ) eine mehr oder weniger grosse Verschiebung seines Blutbildes nach links. Dies bedeutet gar nicht, dass die einzelnen Krankheiten eine grössere Verschiebung nach links der ihnen eigentümlich entsprechenden Schwere der Infektion wie der Intoxikation erweisen sollten. Eine gegebene Krankheit als Infektionsintensität kann bei ganz schwerem Verlauf ein besseres Blutbild zeigen, wie eine andere von Natur aus leichtere, z. B. Masern, Scharlach. Mit anderen Worten es ist kein

1) Wie bekannt, erklärt Arneth diesen Umstand auf die Weise, dass in diesen Krankheiten Nervenzellen von Toxinen angegriffen werden und dass die Leukozyten daran gar keinen Anteil haben. 
obligatorischer Parallelismus zwischen der Infektionsschwere des Organismus und der Beschädigung des Bildes (der Verschiebung nach links).

Anders gesagt, besitzt jede infektiöse Krankheit ihr eigentümliches Blutbild. Es hängt dies vom Wesen der Infektion selbst ab. Als ein herrorragendes Beispiel, dass die Krankheiten ein ihnen eigentümliches Blutbild haben, können wir zwei für den menschlichen Organismus höchst gefährliche Krankheiten, wie Anaemia perniciosa und Leukaemia anführen, von denen die erste gar keine Veränderungen im Neutrophilensystem hervorruft, die zweite dagegen regelrecht zu den schwersten Störungen desselben führt. Auf diesen Umstand legen wir ein grosses Gewicht, denn andernfalls treten Missverständnisse bezüglich der grundsätzlichen Fragen auf, die die Arnethsche Theorie anbelangen.

Nach diesen allgemeinen Bemerkungen gehen wir zur Betrachtung der zahlreichen von Arneth und einer ganzen Reihe anderer Autoren angestellten Lntersuchungen über, welche vor allem verschiedene infektiöse Krankheiten und endlich die Tuberkulose betreffen. Auf diese Weise gewinnen unsere eigenen Untersuchungen und deren Ergebnisse eine bessere Erklärung.

Eine reichhaltige Literatur über Arneth sowie die lebhafte Polemik, welche in den Spalten der Fachpresse entstand, beweisst. schon an und für sich, dass es sich um eine Frage ron grosser Bedeutung handelt. Aus der bisherigen uns zugänglichen Literatur geht hervor, dass die Arnethsche Theorie sowohl grundsätzliche Gegner, wie Pollitzer und Hiller, als auch absolute oder relative Anhänger besitzt. Was die Gegner anbetrifft, müssen wir bemerken, dass man sich mit Hämatologie besonders beschäftigen müsste, um sich ein begrïndetes Urteil von ihren eigenen Theorien, contra Arneth zu rerschaffen, was jedoch den Bereich unserer Arbeit uiberschreiten würde. Ziehen wir dennoch die ganze Theorie Pollitzers in Erwägung, so müssen wir eingestehen, dass sie in der Auffassung der Entwickelung von mehrkernigen Zellen gänzlich abgesondert und höchst eigentümlich ist; trotzdem sie sich auf zahlreiche wissenschaftliche Untersuchungen und Nachforschungen stützt, findet sie, soweit uns bekannt ist, keine Anhänger. Es ist möglich, dass sich das ganze Bild A rneths dem Auge Pollitzers als ein künstliches von der Fixation des Präparates abhängiges Produkt vorstellt. Es ist ferner ebenfalls möglich, dass für das Auge Pollitzers keine einkernige Zellen vorhanden sind; nach seiner Behauptung beläuft. sich die Zahl der Kerne auf wenigstens 4-5, sie kann aber auch 15 und noch mehr betragen. Weshalb aber sollen wir andererseits 
nicht als wahrscheinlicher annehmen, dass so viele Augen bei der Blutuntersuchung den gesamten Zellenkomplex des Arnethschen Bildes, von den einkernigen Myelozyten angefangen, die verschiedenen Gestalten der Kërndifferenzierung bis zu den fünfkernigen übergehend, tatsächlich sahen und sehen? Warum sehen die Augen dieser zahlreichen Forscher die Differenzierung der Kerne nicht als ein künstliches, bei der Fixierung des Präparates entstandenes Produkt an?

Wir möchten also, auf Grund elgener Erfahrung, mehr 'oder weniger mit den Ergebnissen Arneths übereinstimmend, die Beurteilung der Pollitzerschen Theorie durch Weidenreich als begründet annehmen. Weidenreich schreibt ausdrücklich: „dass die gelapptkernigen (polymorphen) Formen sich in kontinuierlicher Reihe aus den kompaktkernigen (mononukleären) entwickeln und dass diese letzteren wirklich einheitliche und nicht segmentierte Kerne sind, halte ich für eine absolut gesicherte Tatsache" (40).

Geradezu entgegengesetzter Meinung wie Pollitzer ist Hiller, welcher nachweist, dass man in dem grössten. Teile der neutrophilen Leukozyten durchschnittlich $80 \%$ einkerniger Gebilde begegnet; der Rest setzt sich aus zweikernigen Leukozyten zusammen und nur $0,5-0,8 \%$ der Leukozyten besitzt drei Kerne.

Auf den Untersuchungen Erbs, Uskoffs und hauptsächlich Grawitz sich stützend, beweist Hiller, dass die neutrophilen Leukozyten keineswegs ihre einzige Ursprungsquelle unbedingt aus dem Knochenmarke haben müssen, sondern sie können auch aus anderen Organen hervorgehen; andererseits können auch vielkernige Formen nicht nur aus Myelozyten, sondern auch aus kleinen Lymphozyten entstehen. Auf Grund seiner Untersuchungen kommt Hiller zum Schluss: "Die von Arneth zuerst beschriebenen Veränderungen an den Kernen der neutrophilen Leukozyten unter pathologischen Verhältnissen sind nicht durch das Zugrundegehen alter und das Neuauftreten junger Zellen entstanden, sondern es sind im wesentlichen Bewegungserscheinungen, die die Vereinfachung der Kernfigur bewirken" (27). Diese Theorie wurde heftig von Zelenski angegriffen, welcher ebenfalls auf Grund eigener Untersuchungen behauptet, die Hillerschen Anschauungen seien irrtümlich; er meint, dass, wenn wir uns nicht lediglich zum Untersuchen des Kernes allein, sowie nur auf eine Färbungsmethode beschränken, so gewahren wir, dass parallel $\mathrm{zu}$ der Formdifferenzierung eine Reihe von Veränderungen in der ganzen Zelle entsteht, was man auf keinen Fall durch Bewegungserscheinungen erklären kann". - Eine Autorität wie Pappenheim beweist ebenfalls, dass ebenso riel- 
kernige wie einkernige Leukozyten zur Bewegung in gleicher Weise befähigt sind und die letzteren während der Bewegungen einkernig bleiben; dass weiter infolgedessen die Polymorphie nicht unbedingt ein Ausdruck der Bewegung sein braucht und dass zwischen den Myelozyten und den vielkernigen Leukozyten eine ganze Kette von Übergangsformen besteht. Andererseits schreibt er, dass: „Kernpolymorphose Ausdruck einer Umwälzung im inneren Bau der Zelle ist, die ihrerseits wieder mit grösster Wahrscheinlichkeit eine Folge der fortschreitenden Alterung oder besser der Reifung ist." (27) Unsererseits könnten wir hinzufügen, dass die Erklärung der Kernpolymorphose von neutrophylen Leukozyten durch ihre Befähigung zur selbständigen Bewegung uns auch aus dem Grunde zweifelhaft zu sein scheint, weil die Lymphozyten ebenfalls, wie die neusten Untersuchungen z. B. Grawitz's erwiesen, diese Fäbigkeit besitzen, ihre Kerne aber trotzdem rund bleiben. Es ergibt sich daraus, dass die Kernform, so weit uns aus der uns zugänglichen, die A rnethsche Methode betreffenden Literatur bekannt ist, in keinem kausalen Zusammenhange mit der Bewegung der Leukozyten steht. Die Theorien Pollitzers uud Grawitz-Hillers fanden mit Ausnahme Brugschs und Bourmoffs keine Anbänger. Wir wollen uns jetzt mit Arneth und mit seinen sowie seiner Anhänger Resultate beschäftigen. Als Ausgangspunkt nehmen wir seine Theorie und das neutrophile Blutbild.

Wie wir schon einmal erwähnt haben, behauptet Arneth, dass jede infektiöse Krankheit ein ihr eigentümliches Blutbild besitzen soll, das abhängig von der Infektionsschwere und dem Krankheitsverlaufe, entsprechenden Art Veränderungen unterliegt. Jeder Infektions- und Intoxikationstypus hat sein ihm bis zu einem gewissen Grade eigenes Vernichtungsbild der weissen Blutkörperchen. Andererseits nimmt Arneth an, dass die den Parallelismus zwischen dem Grade der neutrophilen Beschädigung und der Infektions- oder Intoxikationsschwere beeinflussenden Faktoren, solche Faktoren sind wie künstliche Immunisierung, angeborene Immunität usw. Im Zusammenhange mit dem Charakter und dem Verlaufe der Krankheit folgen neben qualitativen auch Veränderungen in der allgemeinen Zahl der weissen Blutkörperchen, welche samt dem Blutbilde ein Index für die benachteiligte oder vermehrte Tätigkeit des Knochenmarkes bilden. Von hier stammt die Arnethsche Klassifikation in Isonormozytose, Isohyper(leuko)zytose und Isohypo(leuko)zytose oder Anisonormozytose, Anisohyper(leuko)zy tose und Anisohypo(leuko)zytose. Diese Klassifikation erklärt sich von selbst.

Wenn wir die einzelnen Krankheiten betrachten, so wird die 
Rolle des Blutbildes vom klinischen Standpunkte als ein zuverlässiges Kennzeichen für die Diagnose der Krankheit, für die Orientierung in ihrem Verlaufe und für die Prognose sehr wichtig sein. Von einem solchen Standpunkte ausgehend, stellen wir die grundsätzliche Frage, was für und wie weit reichende Schlussfolgerungen lassen sich in dieser Richtung nach der Arnethschen Blutuntersuchungsmethode ziehen.

Wenden wir uns zu den einzelnen Untersuchungen A rneths selbst und beginnen wir mit dem Verhalten des Blutbildes bei Neubildungen, beim Karzinom. Auf Grund der von ihm selbst sowie von anderen Autoren angestellten Untersuchungen gibt Arne th zu, dass diese Frage sich als böchst verwirrt darstellt, zweitens, dass das Blutbild sowie die Leukozytose sehr veränderlich ist und dass beide in keinem unmittelbaren Zusammenhange mit der allmählichen durch Neubildungen hervorgerufenen Kachexie stehen und endlich, dass die Leukozytenzahl wie das Blutbild normal sein können. Auf diesen Umstand legt Grawitz als Beweis gegen die Arneth sche Theorie starken Nachdruck. In den zwei ersten von den zwölf durch Arneth untersuchten Fällen sehen wir wirklich eine Hyperleukozytose $(10,000$ und 10,500), die neutrophilen Bilder sind dagegen normal, trotzdem - hierauf möchten wir besonders verweisen - in dem ersten, eine 62jährige Frau mit Adenoma des Blinddarmes betreffenden Falle, die Temperatur sich monatelang auf $39^{\circ}$ erhielt und die Kachexie schon weit fortgeschritten war.

Wir übergehen die nächstfolgenden 7 Fälle, wo die Neutrophilenzahl in den ersten zwei Klassen zwischen $49 \%-78 \%$ schwankt, die Leukozytenzahl aber höchst unbeständig ist, denn sie beträgt 5000 bis 17000 . Dagegen steigen in den drei letzten Fällen, die alle mit dem Tode endigten, die Neutrophilen auf $82 \%-87 \%$ in den ersten zwei Klassen. Unwillkürlich fällt der Umstand auf, dass die Leukozytenzahl in diesen drei Fällen von Karzinom, welche einen tödlichen Ausgang nahmen, in den ersten zwei Klassen geringer war als bei zwei leichten Masernerkrankungen, die schon in wenigen Tagen geheilt wurden (Fall 35 und 36 in der Arneths Monographie). Gewiss kann man wie Arneth behaupten, dass jede Infektionskrankheit ihr eigentümliches Blutbild besitzt. Dieses kann also in einer so leichten, nach wenigen Tagen zur Genesung führenden Krankheit, wie Masern deutlich schlechter sein, als in bösartigen Geschwïlsten, welche durch allmähliche Kachexie den Organismus zum Exitus letalis führen. Es ist aber auch in einem solchen Falle gar nicht klar, weshalb das Blutbild in derselben Krankheit, dem Krebs, einmal normal, ein zweites Mal dagegen stark nach links verschoben ist. Arneth gibt 
selbst $\mathrm{zu}$, dass, um diese Mannigfaltigkeit der Blutbilder beim Karzinom zu erklären, eine andere Ursache gesucht werden muss als das blosse Einwirken der Karzinomtoxine, nämlich: die Bösartigkeit der Geschwulst, die Lokalisierung und der anatomische Bau, der Zerfall, die Metastasen, die Komplikationen usw. (5). Wenn wir annehmen, dass die Bösartigkeit eines gegebenen Krankheitsprozesses in einem unmittelbaren Zusammenhange mit der Toxinwirkung steht, so gibt es hier eine Begriffsverwirrung. Wenn nicht der Krebs an und für sich, sondern der Zerfall, die Metastasen usw. einen schädlichen Einfluss auf das gesamte Blutsystem haben sollen, so kann andererseits eine monatelang bei erhöhter Körperwärme andauernde Kachexie (Fall I) ebenfalls auf gleiche Weise ungünstig einwirken.

Als Erklärung der Beschädigung des Blutsystems bleiben also einzig die Komplikationen und nicht das Wesen der Krankheit selbst, wie z. B.: Hypostatische Pneumonie (Fall X) oder Perforation des Colon transversum (5). Wenn wir uns damit einverstanden erklären, so müssen wir auch annehmen, dass der Krebs selbst eine Nebenrolle spielt. Aus den genauen Zusammenstellungen der Arneth schen Krebsuntersuchungen lässt sich wirklich der Schluss ziehen, dass das Karzinom als ein solches, obgleich es durch seine Langwierigkeit zur Kachexie führen würde, kein eigentümliches Blutbild besitzt und dass die Komplikationen, welche diesen Krankheitsvorgang begleiten. die wichtigsten Faktoren sind. Auf die Frage, weshalb es so ist, finden wir keine Antwort.

Was das Verhältnis der Infektionsschwere zu den Veränderungen im Blutssystem anbelangt, so müssen wir, zum Blutbilde bei einer ganzen Reihe Infektionskrankheiten ükergehend, noch einmal die Stützpunkte der Arneth schen Theorie mit Nachdruck hervorheben. Arneth spricht ausdrücklich von der "Schwere der Veränderungen des Blutbildes", bei leicht verlaufenden Infektionskrankheiten, wie Masern, Varizellen, Mumps und umgekehrt bei schwer verlaufenden: Gelenkrheumatismus, Erysipl, Tuberkulose usw. erhalten wir ein nicht allzusehr beschädigtes Blutbild. Unabhängig von der Annahme einer solchen Vorausetzung erscheint nun die Frage, weshalb in dem Verlaufe einer und derselben Krankheit "das neutrophile Blutbild immerfort seiner Besserung entgegengeht, während die klinischen Symptome an Schwere immer mehr zunehmen (Arneth)." Wir finden keinen Beweis, um einen solchen Mangel an Parallelismus begründen zu können. Der Autor selbst sagt zwar auch „wir konnten nur in relativ wenig Fällen eine völlige Symmetrie zwischen dem klinischen Verlauf und den Vorgängen im neutrophilen Blutbilde konstatieren", 
Eine solche Behauptung steht aber im Widerspruche mit seiner eigenen Theorie. Dieser Mangel an Parallelismus steht im Widerspruch mit den Voraussetzungen Arneths und hauptsächlich mit dem Umstand, dass bei den Infektions- und Intoxikationsprozessen eine bedeutende Menge reifer Zellen, die die grösste Anzahl Antikörper besitzen, zugrunde gehen muss; das Bild sollte also beträchlich nach links verschoben sein. Ein solcher Vorbehalt, der einerseits so viele Abweichungen von der Grundidee, anderseits eine so grosse Disproportion zwischen den Veränderungen im Blutbilde und dem Verlaufe der Infektion selbst erlaubt, stellt unwillkürlich die Frage, ob die unter dem Einflusse der Infektion oder Intoxikation in Blutbilde vorkommenden Veränderungen vom klinischen Standpunkte aus als massgebend für die Diagnose respektive für die Prognose angesehen werden können. Wir sehen, dass in den Untersuchungen Arneths selbst in dieser Hinsicht gewisse Zweifel vorkommen. Die Tuberkulose lassen wir zurzeit beiseite und gehen, die einzelnen Fälle näher betrachtend, zu anderen Infektionskrankheiten über. Nehmen wir z. B. den Fall 30 (1) Kniegelenkrheumatismus, gleichzeitig mit Angina follicularis und Endocarditis. Aus dem Bilde vom 13. I. ersieht man, dass das Blutbild, welches $48 \%$ Neutrophilen in zwei ersten Klassen enthielt, während die Temperatur bis $38,4^{\circ}$ reichte, besser war als das am 15. I. mit $53 \%$ in denselben ersten zwei Klassen; die Körperwärme kehrte schon am 14. I. in die normalen Grenzen zurück. Gewiss der Unterschied ist nicht gross, aber das Blutbild hatte sich jedenfalls bei Temperaturherabsetzung verschlechtert anstatt sich zu verbessern. Ein Widerspruch kommt ebenfalls beim Fall 29 (1) Kniegelenkrheumatismus und eine frische Endocarditis, vor. Wir sehen nämlich während der Verschlimmerung der Krankheit an 21. II. $190358 \%$ Neutrophilen in der I. und II. Klasse, später folgt eine Remission, daraufhin stellt sich ein Rückfall ein und zwar mit einer Temperaturerhöhung bis zu $38,9 \%$, ihm folgt ein zweiter Rückfall mit Affektion verschiedener Artikulationen. Im Augenblick, wo "alle Mittel versagen" und das Fieber mit einer fast unmerklichen fünf tägigen Remission (29. III. bis 2. IV.) bis zum 13. IV. dauerte, finden wir in dem Blutbilde vom 5. IV. 38\% Neutrophilen in der I. und II. Klasse. (ES findet sich zwar ein Myolozyt, der am 21. II. nicht dagewesen war.) Jedenfalls ist eine Verschiebung der Bilder um 20\% nach rechts bei einem solchen Krankheitsverlaufe völlig unklar. Ebenfalls unverständlich sind für uns zwei Blutbilder bei den Varizellen. Nr. 32: Martin, 1 Jahr alt, gut ernährt, erwies in wenigen Stunden nach dem Erscheinen des Ausschlags $90 \%$ Neutrophilen in der I. und II. Klasse bei 7200 Leukozyten. 
Dagegen finden wir beim Fall 34 - Gustav, drei Jahre alt, an rechtsseitiger Knochentuberkulose leidend, allerdings sehr gut ernährt - mehrere Stunden nach dem Erscheinen des Ausschlags nur $69 \%$ in der I. und II. Klasse bei 16200 Leukozyten. Woher kann ein so grosser Unterschied stammen? Sollte die Knochentuberkulose allerdings mit einer granulierenden "fast nicht eiternder Wunde" eine gutartige Komplikation der Varizellen sein? Gehen wir weiter, nehmen wir als Beispiel die Masern. Fall Nr. 39: K. Georg, 18 Jahr alt, nach Arneth "mittelschwer", erwies am Höhepunkte des Ausschlags $96 \%$ in den ersten zwei Klassen bei 7700 Leukozyten; dagegen zeigt der Fall 36, welcher einen 32jährigen Mann betrifft und welcher als "bedeutend schwerer" angesehen wird und bei gleichzeitiger allgemeinen Intoxikation, Milzödem, Diazoreaktion usw. nur $92 \%$ in der I. und II. Klasse (zwar gewahren wir einen Myelozyt, was bei Georg nicht der Fall war). Derselbe Kranke besitzt eine bedeutende Leukopenie von 2400 Leukozyten. Der erste leichtere Fall zeigt bei Temperaturherabsetzung in der I. und II. Klasse $89 \%$ (in der I. Klasse $35 \%$ ), dagegen erweist der zweite schwerere Fall $85 \%$ (in der I. Klasse allein 14\%). Arneth selbst deutet auf den Widerspruch hin zwischen dem "sehr leichten" Krankheitsbilde Nr. 37 mit $81 \%$ Neutrophilen in der I. und II. Klasse und dem Bilde Nr. 38 mit $78^{\circ} \%$. Es sei nebenbei bemerkt, dass wir hier nach bestandener Superinfektion sowie neben dem Lrscheinen einer Otitis media $55 \%$ in der I. und II. Klasse finden. Wir könnten viele solcher Beispiele anführen. Es wäre noch zum Schlusse die Erysipel zu erwähnen. Wir finden beim Fall 41 in der I. und II. Klasse $86 \%$ (in der I. Klasse allein $39 \%$ ), während die Körperwärme $37,6^{\circ}$ beträgt; indessen zeigt Fall Nr. 43 bei einer Temperaturerhöhung bis zu $40^{\circ}$ in der I. und II. Klasse nur $67 \%$ (in der I. Klasse allein nur 19\%), trotz einer schon sieben Jahre dauernden „chronischen Eiterung des Beckenknochens", die allein, mit Arneths Behauptung übereinstimmend, ausreichend wäre, um das Blutbild bedeutend zu beeinträchtigen. Abgesehen von dem Widerspruch zwischen diesen beiden Fällen, ist der Umstand merkwürdig, dass wir in den ersten zwei Klassen, nach 14 Tagen seit gänzlicher Genesung, $66^{\%} \%$ Neutrophilen finden, mit anderen Worten nur um $1 \%$ weniger, als am Höhepunkte der Infektion. Man müsste aber daraus schliessen, dass die Erysipel keine Veränderungen im Blute hervorrief und dass dieselben dank der langwierigen Eiterung des Beckenknochens bereits vor der Entstehung der Krankheit vorhanden waren. Wenn wir jedoch eine solche Voraussetzung annehmen möchten, so müssten wir uns die Frage stellen, weshalb der Fall 41, welcher während des Genesens - 2 Wochen 
nach dem Erscheinen des Ausschlags -, „eine gewisse Überreifung des Bildes" erwies, am Beginne der Infektion in den ersten zwei Klassen $86 \%$, am Ende dagegen 35\% Neutrophilen enthält. Wenn also im Falle 41 die Erysipel "auf dem Höhepunkte des Krankheitsprozesses bedeutende Veränderungen im Blutbilde", wie sich Arneth ausdrückt, hervorzurufen imstande ist, so würden wir im Falle 43 bei einer schwer verlaufenden, durch eine sieben Jahre lang dauernde Eiterung komplizierte Frysipel erwarten, dass das Blutbild um vieles schlechter als im Falle 41 sich gestalten wird. Einstweilen geschieht es urngekehrt und dieser Umstand ist für uns ganz und gar unverständlich. Mehr Beispiele wollen wir nicht anführen.

Wenn wir bei Arneth Ergebnissen begegnen, die sich nicht in den Kreis seiner Theorien ziehen lassen, so wird es uns nicht wundern, dass wir bei verschiedenen Autoren, welche nach seiner Methode Blutuntersuchungen unternahmen, keineswegs klare Resultate treffen. Es ist selbstverständlich, dass verschiedene Autoren auch verschiedene normale Blutbilder erhalten müssen, was rom persönlichen Gutdünken jedes einzelnen Forschers abhängt, und auf diesen Umstand legt Arneth einen starken Nachdruck. Resultate, die für uns unverständlich bleiben, treffen wir aber selbst bei einem und demselben Forscher, obgleich dieser zur Formstellung und zum Bestimmen der Kernzahl nach einer gegebenen Färbungsart gewöhnt, sowie überhaupt mit den Untersuchungsmethoden gut bekannt ist. Hier also ist die Quelle der mannigfaltigen und verschiedenartigen Schlüsse $\mathrm{zu}$ suchen. Von Brougsch und Bourmoff angefangen, welche, auf den Untersuchungen Hillers und teilweise auch Pollitzers fussend, Arneths Grundsatz - nämlich die zum Reifwerden der Zellen verhältnismässige Kerndifferenzierung „als auf falschen Voraussetzungen aufgebaut" verwerfen (nach ihnen sollen $80-95 \%$ Neutrophilen einkernig sein) bis auf Zelenski, Bochenski, Kotbe, Orland, Wolff u. a., welche nicht nur den Inhalt der Arnethschen Methode bestätigen, sondern ihr auch eine wichtige klinische Bedeutung hinsichtlich der Diagnose und Prognose zuschreiben. Brougsch und Bourmoff fanden zwar bei Infektionskrankheiten eine Verschiebung des neutrophilen Blutbildes nach links, die aber der Stärke sowie dem Verlaufe der Krankheit gar nicht gleichlaufend war. Abgesehen davon, dass dieselben Forscher in einer ganzen Reihe von Infektionskrankheiten (Erysipel, Scharlach, Rheumatismus) bedeutend bessere Blutbilder feststellten, als z. B. bei einer chronischen Bronchitis, fanden sie in denselben Krankheiten die Blutbilder geradezu paradox, z. B. in drei Fällen von Lungenentzündung „eine mässige Verschiebung 
nach links auf der Fieberhöhe eine längere Zeit nach der Krise". Aus diesem Grunde sehen sie in ihren Schlussfolgerungen die ganze Arnethsche Methode als unbrauchbar für die klinische Diagnose und Prognose an. Die ganze Methode betrachten sie als eine "auf schwankendem Boden stehende Hypothese" (17).

Woher eine solche Mannigfaltigkeit von Anschauungen? Arneth behauptet zwar, dass die Untersuchungen Brougschs und Bourmoffs aus dem Grunde nicht massgebend sein könnten, weil sie grösstenteils nicht auf dem Höhepunkte der Krankheitsverschlimmerung, sondern während des Genesens angestellt wurden und weil die Mehrzahl der Fälle nur einmal untersucht wurde. Trotzdem fällt uns der Umstand auf, dass bei schweren Infektionskrankheiten (die Tuberkulose ausgenommen, wovon später die Rede sein wird) wie Erysipel, Scharlach, Dyphtherie, Rheumatismus, eine mässige Verschiebung des Bildes nach links zustande kommt, während die oben erwähnten Autoren bei einer chronischen Bronchitis eine bedeutende Verschiebung erhielten; wichtiger ist aber der Umstand, dass in Fällen von Lungenentzündung sowohl auf dem Höhepunkt des Fiebers als auch längere Zeit nach der Krise eine mässige Verschiebung des Bildes stattfindet. Von anderen Autoren, die mit Arneth nicht übereinstimmen, ist Paulicek zu erwähnen. In einer glänzenden Polemik schreibt Arneth: "Paulicek hat das Wesen meiner Lehre bestätigt" Mit Arneth haben wir das Recht, Pauliceks Beweise abzulehnen, nämlich, dass verschiedene Krankheiten gleiche und sich gleichbleibende verschiedene Blutbilder besitzen. Jedenfalls scheint uns Nr. 4, ein Fall ron Typhus (ein 15jähriges Dienstmädchen M. K.), ziemlich sonderbar zu sein; am 11. Tage der Krankheit finden wir in der $\mathrm{I}$. und II. Klasse $34 \%$ Neutrophilen bei der Allgemeinzahl von 8400 Leukozyten; das Bild ist also hier im Vergleich mit dem normalen nach rechts verschoben. Ebenfalls unverständlich und ungerechtfertigt ist das zwei Tage vor dem Tode normale Blutbild ( $42 \%$ in der I. und II. Klasse) bei einer chronischen, mit einer akuten Meningitis komplizierten Lungentuberkulose, von der noch später die Rede sein wird. Aus diesem Grunde sind die umsichtigen Folgerungen Pauliceks verständlich, der, den Grundsatz der Arnethschen Theorie annehmend, die folgende Verwahrung einlegt: "quoad Diagnose lässt sich die Arnethsche Methode nicht mit Sicherheit brauchen, auch quoad Prognose bietet sie keine zuverlässigen Resultate" (35).

Andererseits finden wir jedoch bei einer ganzen Reihe ron Forschern, welche das Arnethsche Blutbild nicht als "Kunstpro- 
dukt bei der Fixation", auch nicht als ein "Lähmungsphänom seitens der Leukozyten", sondern als einen Ausdruck wirklicher Blutveränderungen ansehen, nicht nur eine volle Übereinstimmung des Bildes mit der Infektionsschwere, sondern auch eine gänzliche Gleichmässigkeit desselben mit einem leichteren oder schwereren Krankheitsverlaufe. Aus diesem Grunde wird das neutrophile Blutbild als ein wichtiger Faktor bei der Diagnose und Prognose angesehen. Wenn wir uns mit den in dieser Richtung angestellten Untersuchungen beschäftigen, so würde uns der Umstand auffallen, dass sowohl in gynäkologischen als auch in physiologischen Vorgängen, wie Schwangerschaft und Geburt, als auch in Infektionsprozessen, welche mit oder nicht mit der Geburt in Verbindung stehen, die Veränderungen im neutrophilen Blutbilde entweder an und für sich, oder auch im Zusammenhange mit den bei den anderen Arten ron Leukozyten oder bei roten Blutkörperchen vorkommenden Veränderungen, massgebende klinische Indexe sind. Weiter fällt uns eine gewisse Eigentümlichkeit, was das Verhalten des Blutsystems bei den Kindern anbelangt, auf, wobei bei verschiedenen Untersuchern auch die Blutbilder verschieden sind. Unwillkürlich erinnert dies an das merkwürdige Verhalten des kindlichen Organismus angesichts des Tuberkulins, dessen Anwendung geradezu widersprechende Resultate bei verschiedenen Forschern ergab, worauf wir seinerzeit aufmerksam machten ${ }^{1}$. A rneth selbst lenkt in seinen Untersuchungen die Aufmerksamkeit auf den Einfluss der Schwangerschaft und der Geburt in einigen Stadien (mehrere Stunden vor oder nach der Entbindung), auf die Leukozytose sowie auf die grössere oder kleinere Verschiebung des neutralen Blutbildes nach links. Indem wir die verschiedenen Theorien, die zur Aufklärung dieser Erscheinungen gestellt wurden, beiseite lassen, bestätigen wir nur die Tatsache, dass der physiologische Akt, an welchem eine ganze Reihe von Faktoren, die die biologische Energie des Organismus bis zum Maximum steigern, teilnimmt, nach dem Muster des infizierenden Faktors, wie es Arneth bemerkt, Blutveränderungen hervorruft. Es ist möglich, dass die Grenze zwischen diesen beiden Zuständen unbedeutend ist, jedenfalls wurden die A rnethschen Untersuchungen betreffs des physiologischen Wochenbettes, das im Verhältnis zum Alter, Allgemeinzustand der Wöchnerin und zur Menge der bestandenen Geburten eine bedeutendere oder mindere Verschiebung des Bildes nach links nach sich zieht, von

1) K. DI uski, Über Tuberkulinanwendung in der Lungentuberkulose vom klinischen Standpunkte. Beiträge z. Klinik d. Tub. Bd. X. H. 1. p. 57, 58. 
B urkard bestätigt. Was die gynäkologischen Infektionen anbelangt, so wurde hier die Arnethsche Theorie neben Burkard ron einer ganzen Reihe von Untersuchern, wie Kownatzki, Bochenski, Wolff, Gräfenberg und anderen fast einstimmig bestätigt. Sie behaupten alle iibereinstimmend, dass, neben Veränderungen in quantitativen Beziehungen, grössere oder kleinere Veränderungen im Neutrophilensystem hervortreten, im entsprechenden Verhältnis zum Infektions- oder Intoxikationsgrade und einer grösseren oder kleineren Ausdehnung des Krankheitsprozesses auf die gynäkologischen Organe und das Bauchfell. Als die schwersten Krankheitszustände werden seitens dieser Autoren diejenigen angesehen, in denen eine bedeutende Verschiebung nach links von Leukopenie begleitet wird, wo wir also, mit einem Worte, mit einer hervorragenden Anisohypozytose zu tun haben. Leichte Infektionen bei lokalisierten oder "abgekapselten" Eiterungen oder auch Eiterherde, die auf dem Wege chirurgischer Eingriffe beseitigt wurden, werden umgekehrt von einer geringen Beschädigung des Blutbefundes begleitet. Deshalb ist auch die Arnethsche Methode ein höchst wichtiger Faktor für die Diagnose und Prognose und wird seitens oben erwähnter Autoren vollkommen anerkannt. „Eine sich nach links vergrössernde Verschiebung kennzeichnet den Sieg der Noxe, eine Verschiebung nach rechts bedeutet den Sieg des Organismus" (Kownatzki [28]).

Ebenso schreibt Bochenski. Auf eine ähnliche Weise in Bezug auf die Prognose drückt sich Wolff aus, indem er seine Folgerungen in die Formel seiner "Kernzahl" schliesst. Wolff führt das ganze Arnethsche Bild bis zu einer Zahl herab, er sieht nämlich einen länglichen Kern (Schlinge $=S$ ) als einen anderthalben runden Kern an, d. h. $S=1 \frac{1}{2} \mathrm{~K}$. Auf diese Weise wird das ganze Arnethsche Bild bis zu der Gesamtzahl aller Kerne, deren Durchschnittszahl in seinem Normalbilde 30̃0 beträgt, reduziert. „Je höher die Summe der Kerne, die wir in der Folge immer mit „Kernzahl“ bezeichnen werden, und welche die Summe sämtlicher $K$ und $S$ umfasst, desto besser die Prognose und umgekehrt." Weiter schreibt er folgendes: "Die Kernzahl ist in erster Linie ein prognostisches Hilfsmittel, das nie im Stiche lässt" (41). Einige ziehen gleichzeitig der Prognose wegen, neben Veränderungen im Neutrophilensystem, wie wir schon bemerkt haben, auch andere morphologische Blutbestandteile heran, wie das Erscheinen und Verschwinden der Eosinophilen, oder das Erscheinen von anormalen Formen der roten Blutkörperchen (Poikilozytose, kernhaltige Formen). Gräfenberg schreibt z. B. den kleinen Lymphozyten eine wichtige prognostische Rolle $\mathrm{zu}(2 \overline{\mathrm{b}})$. 
Alle diese Umstände setzen in ihren Augen den Wert der Arnethschen Methode nicht im mindesten herab. Im Gegenteil, Wolff verrollständigte sie, was um so mehr in der Absicht A rneths geschah, als er öfters gesagt hatte, dass er seine eigene Methode nicht als gänzlich vollendet ansehe, vielmehr solle man analog zu den Untersuchungen von neutrophilen Blutkörperchen auch solche auf andere Formen von weissen Blutkörperchen übertragen. Auf diese Weise ist die Arnethsche Methode ein offenes Feld für weitere Blutuntersuchungen in bezug auf ihre klinische Bedeutung.

In gänzlicher Übereinstimmung mit den Ergebnissen Arneths stehen, was die gynäkologischen Infektionen anbetrifft, die Blutuntersuchungen bei einer Wurmfortsatzentzündung, die Kothe an einem zahlreichen, 86 Fälle betreffenden Materiale, angestellt hatte. Aus rein technischen Gründen vereinfacht Kothe die Arnethsche Methode und nimmt als Kriterium des neutrophilen Blutzustandes nur die Quantität der einkernigen Neutrophilen in der I. Klasse an, deren Zahl nach ihm bei einem Gesunden durchschnittlich $6 \%$ beträgt. Während der Wurmfortsatzentzündung hebt sich die Zahl nach Kothe bis zu $65 \%$. Seine Untersuchungen erwiesen, dass wenn die Zahl dieser Körperchen in der I. Klasse 16 bis $20 \%$ im Durchschnitt beträgt, von der Operation Abstand genommen werden soll, wenngleich die Hyperleukozytose 20000 bis 22000 erreicht. Auf dieser Grundlage wurden wirklich 4 von ihm beschriebene Fälle ohne chirurgischen Eingriff geheilt. Umgekehrt bei einer Durchschnittszahl von $40 \%$ in der I. Klasse und mehr, soll man operieren, obgleich die allgemeine Leukozytenzahl unbedeutend und zur Krankheitsschwere unverhältnismässig wäre (z. B. in einem Falle 8000 Leukozyten bei $56 \%$ in der I. Klasse). Eine feste und sichere Regelmässigkeit zwischen dem Blutbilde, der Leukozytenzahl, dem Puls und der Temperatur vermerkt Kothe: „In den Fällen über $40 \%$ - sagt er - war stets eine hochgradige Infektion vorhanden, die sich meist auch in der Höhe der anderen Kurven und in der Schwere der allgemeinen und lokalen klinischen Erscheinungen zu erkennen gab. Wenn die Kernzahl $45 \%$ betrug, fand sich gewöhnlich eine intensive mehr oder weniger ausgebreitete Beteiligung von Seite des Peritoneums vor." Dass die Arnethsche Methode ein wichtiges diagnostisches und prognostisches Mittel ist, ergeht aus seinem Resumé, das er mit folgenden Worten schliesst:

„Die Arnethsche Methode erscheint berufen, wichtige Dienste für die Beurteilung und die Behandlung der akuten Appendizitis zu leisten, indem sie unsere Diagnose sichert und die Auswahl der Fälle für die operative und expektative Behandlung erleichtert" (30). 
Es ist bemerkenswert, dass die von Kothe beschriebenen Fälle von Appendizitis mehr mit den Grundsätzen Arneths übereinstimmen als jene, welche von dem letzteren angeführt wurden und die Arneth in seiner Monographie beschreibt (1). Dort enthalten nämlich die Fälle Nr. 61 und 62 trotz "eines übelriechendes Eiters", welches operativ abgeführt wurde und das in dem zweiten Falle "massenhaft" vorhanden war, in der I. und II. Klasse zusammen $44 \%$ Neutrophilen bei 18100 Leukozyten und $40 \%$ bei 19600 Leukozyten. Infolgedessen findet Arneth selbst einen hier vorhandenen Widerspruch, den er durch „Abkapselung“ zu erklären versucht; er setzt hinzu: „eine Erklärung für diesen normalen Befund hat ihre grossen Schwierigkeiten" (Seite 138). Es ist möglich, dass die Ursache dieses Befundes in der kleinen, nur acht Fälle betragenden Zahl liegt. Kothe führt 86 Fälle an, also eine Zahl, die hier massgebend sein kann. Ebenfalls auffallend ist das Verhalten des Arnethschen Bildes in der Leukämie, dieser sonderbaren Krankheit, die, wie bekannt, zwar unheilbar ist, sich jedoch auch für längere Zeiträume unter dem Einflusse der Röntgenstrahlen zur Verbesserung neigen kann. Soweit uns bekannt ist, werden diese Verbesserungen von denen des Blutsystems, das ist von der Verschiebung des Bildes nach rechts, begleitet und zwar parallel der Leukozytenzahl-Verminderung. Dies können wir in 2 ron Paulicek beschriebenen Fällen (Nr. 22 u. 23) sehen. Besonders gut lässt sich dies an dem ersten Falle betrachten, wo bei einer Verminderung der allgemeinen Leukozytenzahl innerhalb zwei Wochen von 311400 auf 198000 , dieselbe in der I. Klasse von 51 auf 34 herabfiel; was die Zahl der Myelozyten speziell anbetrifft, so verminderte sich diese von 22 bis auf 13 . Ebendasselbe gewahren wir in drei Fällen Frankes, wo während einer Röntgenotherapie parallel $z u$ Leukozytenverminderung auch die Quantität in der I. und II. Klasse von $84-90 \%$ bis auf $70 \%$ heruntersank (21). Sonderbar ist ebenfalls der von Funke beschriebene Fall, welcher unter dem Einflusse von Röntgenstrahlen eine so hervorragende Verbesserung der Arnethschen Bilder zeigte, dass die Therapie einstweilen eingestellt wurde. „Das Blutbild hatte sich quantitativ und qualitativ gebessert, subjektive Beschwerden waren fast verschwunden ${ }^{\text {a }}$ trotz einer 16 tägigen Unterbrechung.

Während eines so günstigen Zustandes trat, nach einer akuten durch Anurie (Hydronephrosis) hervorgerufenen Infektion, bei einer gleichzeitigen allgemeinen Verschlimmerung eine riesige Veränderung des Blutbildes ein, so dass die frühere Zahl von $9 \%$ in der I. Klasse bis auf $100 \%$ hinaufsprang, während in der II., III., IV., V. Klasse die Neutrophilen gar nicht vorhanden waren. Die Myelozytenzahl 
betrug $80 \%$. Das oben beschriebene Bild wurde von einer Leukopenie begleitet, es waren nämlich nur 4200 Leukozyten. Dieses Bild aber veränderte sich, dem Autor nach, schon nach 18 Tagen, und zwar in der Weise, dass wir in der I. Klasse nur 7\% Neutrophilen, in der II. $70 \%$, in der III. $22 \%$ und in der IV. $1 \%$, bei einer allgemeinen Zahl von 10600 Leukozyten zählten, wobei die Zahl der Myelozyten nur $5 \%$ anstatt $80 \%$ betrug. Was den positiven Einfluss der interkurrenten Infektion auf das Blutbild anbetrifft, verweisen wir Wissbegierige auf ausführliche Erklärungen in der Quelle (24). Unsererseits hatten wir nur die Absicht, einen starken Nachdruck auf die Übereinstimmung der Arnethschen.Bilder mit dem Verlaufe der Leukämie im Falle Funckes zu legen.

Was die neutrophilen Bilder bei den Kindern anbetrifft, so herrscht hier eine grosse Uneinigkeit, einerseits zwischen Flesch und Schossberger, andererseits zwischen verschiedenen anderen Autoren. Die ersteren geben ein Durchschnittsbild von Kindern über 4 Jahren (mit Ausnahme eines einmonatlichen), in dem sie in der I. und II. Klasse zusammen $81 \%$ ermitteln, wobei in der I. Klasse $10 \mathrm{~W}$ und $26 \mathrm{~T}$ vorhanden sind (22). Andere Autoren beschreiben ein Durchschnittsbild von Säuglingen, das bedeutend besser ist, weil es dem der Erwachsenen naht, ja sogar mehr nach rechts verschoben ist. Esse r (20) und O rland (36) behaupten z. B., dass „das neutrophile Blutbild der gesunden Brustkinder etwa von 3-4 Lebenswochen ab, gegenüber dem der Erwachsenen nach rechts verschoben ist". Zelenski schreibt z. B.: "Selbst das Blut der Säuglinge stellt im Grundsatze dasselbe Bild wie bei den Erwachsenen vor" (42).

Orland gibt uns ein Durchschnittsbild von 16 Untersuchungen bei Kindern von 3 Tagen bis 7 Monate, in welchem in der I. Klasse $7 \%$, in der II. $25 \%$, in der III. $40 \%$, in der IV. $24 \%$ und in der V. $4 \%$ Neutrophilen vorhanden sind. Im Vergleiche mit dem Durchschnittsbild, das er für die Erwachsenen aufgestellt hat, ist dasselbe ein wenig nach rechts verschoben. Der Widerspruch mit Flesch und Sch os s b e r ger ist hier um so grösser, da die von ihnen untersuchten Kinder mehr als 4 Jahre alt, dagegen die von Orland Untersuchten Säuglinge waren. Nicht unbedeutend ist ebenfalls der Unterschied zwischen den Bildern eines gesunden Kindes, die Arneth und Orland aufstellten. Arneth gab folgendes Bild eines Kindes an, $2^{1 / 2}$ Stunden nach der Geburt: I. $-60 \%$, II. $-26 \%$, III. $-12 \%$, IV. $-1 \% \%$, V. $-1 \%$; die Verschiebung nach links sucht Arneth durch verschiedene physiologische Gründe zu erklären, in die wir uns nicht einlassen wollen. Er be- 
hauptet, dass er in keinem Falle bei neugeborenen Kindern ein ganz normales Blutbild gefunden habe. Als das beste Blutbild führt A rneth das eines 8 tägigen Säuglinges an, nämlich: I. $-8 \%$, II.$47 \%$, III. $-28 \%$, IV. $-15 \%$, V. $-2 \%$. Orland gibt uns das Bild eines 7 tägigen gesunden Kindes etwas verschieden an, nämlich: I. $-7{ }^{\circ} \%$, II. $-29^{\circ} \%$, III $-42 \%$, IV. $-20 \%$, V. $-2 \%$. Der Unterschied fällt jedem in die Augen. Wir werden uns ebenfalls nicht mit den einzelnen Ergebnissen der einzelnen Krankbeiten Fleschs und Schossbergers beschäftigen, die in einer gewissen Kontroverse mit anderen Autoren stehen und welche sie zu dem Schlusse führen, dass der neutrophile Blutzustand in keinem $\mathrm{Zu}$ sammenhang mit den klinischen Krankheitserscheinungen steht; dass weiter derselbe „keinen Stützpunkt" für die Prognose bildet, für die Diagnose dagegen eine "untergeordnete Bedeutung “ besitzt. Wir müssen jedoch den Umstand hervorheben, dass ebendieselben Autoren die Bildverschiebung bei einem gesunden Kinde als einen wichtigen diagnostischen Faktor für die Masern betrachten und zwar schon vor dem Inkubationsstadium, ja selbst 8 Tage vor dem Erscheinen der Koplickschen Flecke, wie es aus den von ihnen angeführten Fällen ersichtlich ist. Auf dieser einzigen Grundlage empfehlen sie eine frühe Verordnung von prophylaktischen Mitteln. Auf eine sehr treffende Art beschrieb $\mathrm{Zelenski}$ zwei grundsätzliche Merkmale des neutrophilen Bildes bei Kindern, indem er in Erwägung zog, dass in diesem Alter der ganze Organismus und somit auch das Blutsystem auf jegliche äussere und innere Reize sehr empfindlich ist, und zwar die riesige Beweglichkeit dieses Bildes hinsichtlich der Verschiebung nach links, sowie die ausserordentliche Empfindlichkeit des Knochenmarks auf die leisesten Krankheitsreize. Infolgedessen ist bei den Säuglingen, sogar in leichteren Krankheitsfällen, wie z. B. bei leichter Hautverbrennung und Dermatitis, in der I. Klasse die Zahl der Neutrophilen eine so bedeutende, dass sie die grössten Mengen selbst in den schwersten Krankheitsfällen bei den Erwachsenen überschreitet. Es können zuweilen in der I. Klasse bei einer ziemlich grossen Anzahl von M und W ausschliesslich neutrophile Blutkörperchen vorhanden sein. Aus diesem Grunde ist die ohne offenbare Ursache entstandene Verschiebung nach links ein wichtiges diagnostisches Zeichen, welches eine irgendwo versteckte, sich aber äusserlich nicht verratende Infektion aufzusuchen befiehlt. Zelenski führt zwei in dieser Hinsicht bemerkenswerte Fälle an, in denen, wider Erwarten, ein anormaler Blutzustand bei einem augenscheinlichen Wohlbefinden gefunden wurde, der auf einen bestehenden Krankheitsprozess schliessen liess. Es wurde wirklich in dem einen Falle eine un- 
längst bestandene Mittelohrentzündung nachgewiesen, in dem zweiten Tuberkulose gefunden. Diesen Umstand bestätigen ihrerseits auch Orland und Esser.

Sie behaupten, dass nicht nur Krankheitsprozesse dieser Art, wie Rachitis und Kachexie zum Beispiel, oder leichte Verdauungsstörungen, Veränderungen im neutrophilen Bilde hervorrufen, sondern auch der Übergang von der mütterlichen Brust zur künstlichen Milchkost eine rasche und bedeutende Verschiebung der Bilder nach links bewerkstelligt. Esser gibt an, dass, als man einem viermonatlichen Kinde anstatt Muttermilch Kuhmilch darreichte, statt $22 \%$ in der I. und II. Klasse 59\% Neutrophilen erschienen. Orland führt Beispiele an, wo er einzig auf Grund des Blutbildes feste und ganz sichere Diagnosen stellte, ob das Kind durch Muttermilch oder durch Kuhmilch ernährt wurde. Er schreibt auch dem neutrophilen Blutbilde eine grosse diagnostische Bedeutung $\mathrm{zu}$, nicht nur in Infektionskrankheiten, auch "bei anderen Erkrankungen nicht bakterieller Art, wenn auch hier ein toxischer Einfluss durch Stoffwechselprodukte usw. nicht abzustreiten ist" (36). Eine nicht mindere Rolle schreibt er dieser Nethode bezüglich der Prognose zu, weil ,aus der Rückkehr des neutrophilen Blutbildes zur Norm die wirklich eingetretene Genesung mit Sicherheit sich konstatieren lässt" (Ibid.).

Wenn als Ausgangspunkt der Arnethschen Theorien der Umstand genommen wird, dass die allgemeine Leukozytenzahl ein unsicherer Faktor für das Bestimmen des Infektionsgrades sowie des Krankheitsverlaufes ist, so gewinnt dieser allgemeine Grundsatz im Verhältnis zur Tuberkulose desto mehr an Bedeutung und Bestätigung. Wir finden nämlich bei verschiedenen Autoren ein so grosses Schwanken in der Angabe der Leukorytenzahl in verschiedenen Krankheiten und Krankheitsphasen, dass es rein unmöglich ist, auf dieser Grundlage irgendwelchen allgemeinen Schluss zu ziehen. Diese Lücke soll nach A rneths Meinung das Untersuchen des neutrophilen Blutbildes füllen. Die Tuberkulose nimmt nach ihm in der langen Reihe anderer Infektionskrankheiten einen besonderen Platz ein und zwar deshalb, weil sie deutlichere Störungen im Blutsysteme verursacht als andere Krankheiten.

Wir wollen vorerst sehen, was in dieser Hinsicht andere Forscher angeben. Selbst solche Gegner der Arnethschen Methode, wie Brougsch und Bourmoff, fanden fast in allen 9 von ihnen untersuchten Fällen eine bedeutende Verschiebung 
der Bilder nach links; sie bermerken jedoch, dass dieselbe weder zum Verlaufe noch zur Krankheitsschwere parallel verlief. Ebenso verhält es sich mit den Untersuchungen Pauliceks. Mit AusAusnahme eines mit Caries vertehrae behafteten 14jährigen Mädchens, wo wir das ungünstigste Blutbild, $77 \%$ in der I. und II. Klasse, sehen, finden wir in 3 von 4 seiner Fälle Bilder, die der Krankheitsverschlimmerung nicht entsprechen. So begegnen wir z. B. 2 Fällen einer käsigen Pneumonie. Der eine von ihnen (Nr. 7) besitzt $64 \%$ Neutrophilen in den ersten zwei Klassen bei 10500 Leukozyten. Die Untersuchungen wurden 8 Tage nach der Entfieberung, aber mit Beibehalten aller physikalischen Erscheinungen - wie auf der Fieberhöhe - unternommen, mit den Diplokokken Fränkels und Tuberkelbazillen im Auswurf. Nach 2 monatlichem Aufenthalt verliess die Kranke nach eingetretener Besserung das Hospital. Im Zusammenhange mit dem Gesagten führen wir den zweiten Fall (Nr. 8) an, der ein Monat nach Krankheitsausbruch, nach einer mit hohem Fieber (bis zu $40^{\circ}$ und höher), einer Diazoreaktion usw. verlaufenen akuten Infektion mit dem Tode endigte. Die Sektion wies eine Miliartuberkulose nicht nur in den Lungen und in dem Brustfell, sondern auch in den Bronchial-, Hals- und Mesenterialdrüsen sowie in dem Darme, in der Leber und in den Nieren nach. Bei diesem Kranken finden wir 17 Tage vor dem Tode nur 55\% in der I. und II. Klasse, eine Woche vor dem Tode dagegen waren $63 \%$ Neutrophilen bei 9500 Leukozyten vorhanden. Solche Resultate hätte man nie erwartet. Gewiss, man kann die Mannigfaltigkeit dieser Bilder im allgemeinen dadurch erklären, dass die Blutbilder sich nach Arneths Behauptung den individuellen Eigenschaften entsprechend verändern. In diesem Falle war der Sieg über die Infektion seitens des Organismus eben die individuelle Eigenschaft des ersten geheilten Kranken; bei dem zweiten Kranken geschah es umgekehrt. In dem zweiten Falle sollte der Sieg der Infektion über den Organismus, der in der Gestalt einer in den einzelnen Organen weit disseminierten Tuberkulose zustande kam, in einem bedeutend nach links verschobenem Blutbilde zum Ausdruck gelangen, und eine der Krankheitsanstrengung entsprechende Blutbildung hervorrufen; man würde mit anderen Worten erwarten, dass der erwähnte Umstand, wie es bei der Miliartuberkulose geschieht, eine Anisohypozytose nach Arneth veranlassen würde. Es geschah geradezu das Umgekehrte.

Ebenso unklar ist das Blutbild eines 25 jährigen Mannes (Nr. 9), der seit Jahren an einer chronischen Lungentuberkulose leidet und welcher in dem oberen sowie dem unteren linken Lungenlappen eine 
grosse Kaverne besitzt. Derselbe starb, nach Pauliceks Angaben, innerhalb 12 Tagen infolge der Meningitis, wenṇ starke Kopfschmerzen als der eigentliche Krankheitsanfang angenommen werden. Das Blutbild dieses Kranken beträgt 8 Stunden vor dem Tode nur 51\% in den ersten zwei Klassen bei 30000 Leukozyten. Wahrscheinlich hat hier das normale Blutbild $\mathrm{P}$ auliceks (32 \% in der I. und II. Ḱlasse) auch seine Bedentung, weil es weniger als bei Arneth nach links verschoben ist. Aber diese Angelegenheit scheint uns nicht entscheidend zu sein. Arneth versucht das erwähnte Bild Pauliceks dadurch zu erklären, dass in dem gegebenen Falle zwei Krankheitsprozesse sich miteinander verwickelten, deren beiderseitige Gegenwirkung nicht erklärlich ist. „Denkbar ist übrigens, dass sich zwei Wirkungen nicht bloss addieren, sondern auch antagonistisch das Blutbild beeinflussen" (Arneth).

Arneth versucht diesen Fall za erklären; er schreibt nämlich: "Vielleicht waren die leukopoetischen Stätten durch die chronische Lungentuberkulose so geübt, dass sie eben bei Eintritt der Meningitis nur mit geringer Schädigung des Blutbildes geantwortet haben."

Was die zweite Voraussetzung anbetrifft, so finden wir dafür keine entsprechende Begriindung. Im Gegenteil, man kommt vielmehr zu einem ganz anderen Schluss, nämlich dass eine langdauernde Tuberkulose die blutbildenden Organe nicht allein nicht übt, sondern sie sogar beschädigt. Die erste Behauptung, dass die Meningitis antagonistisch auf die längst rorhandene Lungentuberkulose wirkt und dies eine unbedeutende Veränderung des Blutbildes rechtfertigt, scheint uns mit der Erfahrung der Klinik im Widerspruche zu sein, die uns belehrt, dass eine jede Komplikation der Lungentuberkulose mit der in einem anderen Organ vorhandenen Tuberkulose, den ganzen Organismus entschieden negativ beeinflusst; die Widerstandsfähigkeit desselben wird herabgesetzt und demgemäss sollte man erwarten, dass auch das Blutbild, als ein höchst empfindsames, beeintrïchtigt werde.

Es handelt sich doch hier nicht um mehrere Krankheitserscheinungen, sondern um die Dissemination derselben Krankheit von einem früheren Herde und einem ursprünglich ergriffenen Organ über andere bis jetzt noch nicht ergriffen gewesene. Es kann also wobl von keiner antagonistischen, sondern von einer kumulativen Toxin- und Infektionswirkung die Rede sein.

Ein solches Blutbild der Meningitis bleibt für uns unerklärlich. Ganz unerwartete Resultate finden wir bei den Untersuchungen Fleschs und Schossbergers und dies um so mehr, da das ihrige 
"normale" Blutbild von allen uns bekannten Autoren am meisten nach links verschoben ist ${ }^{1}$ ).

Von den 4 Fällen von Tuberkulose fanden diese Autoren in dreien, selbst nach Arneth, normale Blutbilder, nämlich $41 \%$ in der I. und II. Klasse bei einer im Initialstadium stehenden Lungentuberkulose, $43 \%$ bei einer tuberkulösen Meningitis, und $54 \%$ bei einer tuberkulösen Peritonitis; erst im vierten Falle, nämlich einer serösen tuberkulösen Pleuritis haben wir $65 \%$. Auf dieser Grundlage sich stützend, ziehen Flesch und Schossberger einen folgerichtigen Schluss, dass kein Zusammenhang zwischen dem Blutbilde einerseits und dem klinischen Verlaufe andererseits besteht sowie, dass das Blutbild einer Meningitis tuberculosa sich ron dem eines gesunden Menschen nicht im geringsten unterscheidet. Dieses Resultat erklärt Arneth dadurch, dass es sich hier um einen chronischen Fall handelte.

Die Erklärung ist durcbaus hypothetisch. Wir nehmen sie jedoch an, fragen aber unsererseits, weshalb Fälle von einer unbedeutenden chronischen Lungenspitzenaffektion, die ganz fieberlos verliefen, bei Arneth, wie wir das weiter sehen werden, um vieles schlechtere Bilder gaben? Eine Erklärung des Bildes durch den Krankheitscharakter im Falle einer chronischen Meningitis scheint uns unzureichend zu sein, um so mehr, da die langdauernde Meningitis bei den Kindern schwere funktionelle Störungen im ganzen Organismus verursacht, denselben herunterbringt und fast ausnahmslos zum Exitus letalis führt. - In den 19 von Lewinson untersucḥten Fällen der Lungentuberkulose scheint eine grössere Harmonie zwischen dem Blutbilde und dem klinischen Verlauf bestehen. - Den Initialsstadien entsprechen fast normale Blutbefunde. Bei vorgeschrittener Tuberkulose finden sich beinahe alle Leukozyten in zwei ersten Klassen. Andererseits aber, geht aus den Untersuchungen Le winsons hervor, dass man keinen näheren Zusammenhang zwischen der Intensität des Fiebers und der Verschiebung nach links konstatieren kann. Als

1)

\begin{tabular}{|c|c|c|c|c|c|c|c|c|c|c|c|c|c|c|c|}
\hline \multicolumn{3}{|c|}{ I } & \multicolumn{3}{|c|}{ II } & \multicolumn{4}{|c|}{ III } & \multicolumn{5}{|c|}{ IV } & \multirow[b]{2}{*}{$V$ und mehr } \\
\hline 艺 & $B$ & $E-$ & $\infty$ & $\begin{array}{l}\infty \\
\infty\end{array}$ & $\begin{array}{l}\text { D2 } \\
-1 \\
-1\end{array}$ & 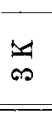 & $\begin{array}{l}\infty 2 \\
\infty\end{array}$ & $\begin{array}{l}\sqrt{2} \\
\mathbb{N} \\
N\end{array}$ & $\begin{array}{l}1 \\
\text { in } \\
\text { o }\end{array}$ & 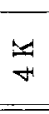 & $\stackrel{02}{+1}$ & $\begin{array}{l}02 \\
-1 \\
-10\end{array}$ & $\begin{array}{l}\frac{1}{2} \\
\frac{\pi}{2}\end{array}$ & $\begin{array}{l}\text { W } \\
0 \\
0 \\
\infty\end{array}$ & \\
\hline- & 10 & 26 & 2 & 25 & 18 & \multicolumn{4}{|c|}{ zusammen } & \multicolumn{5}{|c|}{ zusammen } & vereinzelt \\
\hline \multicolumn{3}{|c|}{$36 \%$} & \multicolumn{3}{|c|}{$45 \%$} & \multicolumn{4}{|c|}{$15 \%$} & \multicolumn{5}{|c|}{$3 \%$} & \\
\hline
\end{tabular}


Beispiel, $66 \%$ (I. u. II. Kl.) bei einer Temperatur von $39^{\circ}$ und $67 \%$ bei fieberlosem Zustand usw. (31). - Wir kehren zu dieser Frage bei der Besprechung der A rnethschen Lntersuchungen zurück. Jetzt gehen wir zu den Untersuchungen Arneths selbst über. An erster Stelle berücksichtigen wir verschiedene Formen der Tuberkulose, welche 29 von Arneth untersuchten Fälle umfasst, die jedoch nicht spezifisch behandelt wurden. 12 Fälle, bei denen Tuberkulin angewandt wurde, wollen wir, wie es A rneth getan, besonders besprechen. Wir kennen übrigens ausser den Kranken, die mit Alt-Tuberkulin oder Tuberkulinen behandelt wurden, auch bei anderen Autoren Fälle, wo das Marmoreksche Serum in Anwendung gebracht wurde. Wir wollen dies alles zusammen besprechen.

Jetzt werden wir uns mit der Frage beschäftigen, welche grundsächlichen Hauptmerkmale das neutrophile Bild in der Tuberkulose besitzt? Wir hatten dies schon vorher in allgemeinen Umrissen gezeichnet. Wir müssen vor dem Besprechen der Arneth schen Methode bemerken, dass wir in seinen Verallgemeinerungen und Synthetisierungen gewissen Widersprüche begegnen. Arneth schreibt, dass "die Tuberkulose eben deswegen, weil sie in ihrem Verlaufe zu so ausserordentlich schwerer Schädigung der neutrophilen Leukozyten führt, eine so schwer ausheilbare Krankheit darstellt" (7). Aus diesen Worten könnte man den Schluss ziehen, dass in der Reihe infektiöser Krankheiten die Tuberkulose eine spezielle Stelle, infolge der schweren Beschädigung des neutrophilen Blutbildes, einnimmit. Bei der Besprechung des Falles (Nr. 68) sagt Arneth indessen in seiner Monographie: „Keine Pneumonie, kein Typhus oder sonst irgend eine Erkrankung wird. bei gleich hohem und langdauerndem Fieberlauf, so wenig an dem Bestand des Körpers zehren und so wenig dessen Organe intoxizieren, als gerade diese hochfieberhaften Tuberkulosen." Bis dahin enthalten die Worte Arneths anderswo, aber nicht immer, viel Richtiges, besonders für den Kliniker, der mit einem reichlichen tuberkulösen Materiale zu tun hat. Es geschieht dies wirklich und man muss über die merkwürdige Widerstandsfähigkeit des Organismus in manchen Fällen staunen. Manchmal geht es geradezu umgekehrt, weil keine andere Krankheit den Körper in einer so kurzen Zeit dermassen auszehrt, wie eben die Tuberkulose und dies bisweilen bei einem anfänglich günstigen Verlaufe, wo ohne jede sichtbare Komplikation, die in einem solchen Falle als ein entscheidender Faktor angesehen werden könnte, eine unerwartete Verschlimmerung eintritt, die durch eine allgemeine Intoxikation des Organismus bald den Tod des Kranken verursacht. Arneth verallgemeinert jedoch diese Folgerung in bezug auf sein 
neutrophiles Bild. Was die Schädigungsschwere des neutrophilen Bildes anbelangt, so ist Arneth einer ganz entgegengesetzten Meinung zu der in oben angeführtem Satze ausgesprochenen Behauptung. "Bei keiner anderen Infektionskrankheit haben wir aber auch, wie wir nunmehr wissen, eine so geringe Veränderung an dem Bestande und der Form der Leukozyten zu verzeichnen; diese in die Augen springende Koinzidenz ist es, auf die wohl mit dem gebührenden Nachdruck hingewiesen werden darf" (Monographie, Seite 151-152).

Auf Grund der von ihm selbst untersuchten Formen der Tüberkulose führt.Arneth umfangreiche Abteilungen ein, in denen sich das Blutbild folgendermassen darstellt:

1. Miliartuberkulose - zeichnet sich durch Anisobypozytose aus.

2. Subakute Formen, - die sich auf dem Wege der Bronchienverzweigungen sowie der Lymphgefässe verbreiten und bei hohem Fieber nach einigen Monaten den Tod herbeiführen - Anisonormozytose, zuweilen Anisohyperzytose.

3. Chronische Formen - Fieberlosigkeit, ein guter Ernährungszustand (eine Lungenspitze ist affektioniert), das Blutbild dem Lungenzustand entsprechend wenig beschädigt, in leichten Fällen ist das Blutbild normal — gewöhnlich eine Anisonormozytose.

4. Chronische Formen - grosse Kavernen, reichliche Sekretionen, eine bedeutende Abmagerung, bei einer gemässigten oder starken Hyperleukozytose eine gleichzeitige Blutbild-Beschädigung Anisohyperzytose.

Wir wollen uns jetzt mit dem Besprechen der einzelnen Formen auf Grund der gegebenen Klassifikation befassen. Wir fangen mit der Miliartuberkulose an. Wir sehen, dass in den $4 \mathrm{Arneth-}$ schen Fällen dieselben mit seinen Behauptungen, was das neutrophile Blutbild anbelangt, übereinstimmen, da die Verschiebung nach links $92-96 \%$ in der I. und II. Klasse beträgt. Was die allgemeine Leukozytenzahl anbetrifft, so sehen wir bei 2 älteren Personen eine Leukopenie. Wir könnten ebenfalls als eine relative Leukopenie bei einem 9 monatlichen Kinde die 9200 Leukozyten bezeichnen, da die Kinder stets eine grössere Lenkozytenzahl als der Erwachsene besitzen. In dem 4. Falle, ein 21 jähriges Mädchen betreffend, sehen wir, dass die Lenkopenie von 4800 Lenkozyten 3 Tage vor dem Tode, wie es Arneth selbst bemerkt, in eine leichte Hyperzytose während der Agonie übergeht (6). Jedenfalls stimmt eine noch so leichte Hyperzytose mit den allgemeinen charakteristischen Eigenschaften der 
agonalen Leukozytose, wie sie Arneth beschreibt, nicht überein. $\mathrm{Er}$ behauptet nämlich, dass die agonale Leukozytose zu Unrecht als eine pathologische Leukozytose angesehen wird, weil „die grosse Mannigfaltigkeit des agonalen Blutfundes nur allein bedingt ist durch die Arten der zur Agonie führenden Erkrankungen, von denen jede den ihr eigentümlichen typischen Blutbefund aufweisst" (3).

Wenn wir die Hypozytose als Regel in der Miliartuberkulose annehmen, so halten wir das Verschwinden der älteren Neutrophilenformen für ganz berechtigt, auf Grund der Arnethschen Beweise, da wir infolge der Blutüberschwemmung durch die Bazillen, durch das massenhafte tödliche Einwirken der Toxine - welche nicht nur aus den initialen tuberkulösen Herden stammen, sondern auch von dem Massenzerfall herrühren, der durch die im ganzen Organismus disseminierten Bazillen hervorgerufen wird -, endlich dank der häufigen Komplikation der Miliartuberkulose mit Septikämie, die durch die sekundäre Infektion bewerkstelligt wird, mit einer Verminderung der allgemeinen Leukozytenzahl sowie mit einem besonders bescbädigten Bilde zu tun haben. Wir möchten hier rücksichtlich der seitens Arneth untersuchten Fälle von Miliartuberkulose noch einmal die Aufmerksamkeit auf den von $\mathrm{Paulicek}$ beschriebenen Fall ( $\mathrm{Nr}$. 8), der eine Miliartuberkulose betrifft, lenken. Dort hatte sich nach einer fast 2 monatlichen Krankheitsdauer die Leukozytenzabl dermassen vergrössert, dass wir eine Woche vor dem Tode 9000 Leukozyten, also eine Hyperzytose finden. Wir sollten aber, wenn wir in dieser Richtung weitergehen würden, mit Arneth übereinstimmend, bei einer akuten Sepsis stets Leukopenie finden.

Und Arneth behauptet dies, indem er eine Analogie zwischen dem massenhaften Eindringen der Eitererreger in das Blut bei Viliartuberkulose und einem solchen bei einer Sepsis durchführt. Als Beweis für seine Behauptung führt uns Arneth wiederum durch einen Vergleich mit der Miliartuberkulose Experimente an, die an Kaninchen unternommen wurden, bei denen auf dem Wege intravenöser Injektionen von tödlichen Dosen verschiedener Kulturen, parallel zu einer bedeutenden Beschädigung des neutrophilen Blutbildes, eine hochgradige Leukopenie erzielt wurde (4).

Wir finden einstweilen in 5 Fällen, die von Bochenski beschrieben wurden, und welche eine Sepsis puerperalis mit tödlichem Ausgang anbelangen (es wurden im Blute Streptokokken und Staphylokokken usw. gefunden, die darauf auf entsprechenden Nährboden gezüchtet wurden), bei einer bedeutenden Bildverschiebung nach links $(81-88 \%$ in der I. und II. Klasse) nur einen einzigen Fall ron Leukopenie (4000 Leukozyten); in einem Falle haben wir 
eine normale Menge (6700), in den drei übrigen Fällen eine Hyperzytose, nämlich: 11800, 19300 und 32000 Leukozyten (15).

Wir können uns deshalb nicht mit A rneth einigen, dass in Fällen bakterieller Invasion der Verbrauch stets grösser als die Produktion ist, sowie dass „Insuffizienz und Unterliegen des neutrophilen Schutzapparates gegenüber der Infektion beständig dauert" (6). Wir gehen der Reihe nach zu anderen von A rneth beschriebenen Formen der Lungentuberkulose über. Wenn wir Arneth richtig verstanden haben, sind bei dem Beschädigen des neutrophilen Bildes (die Miliartuberkulose ausgenommen) die sekundäre Infektion sowie die Resorption der tuberkulösen Toxine die Hauptfaktoren und zwar bei fiebernden Kranken, besonders bei langdauerndem, eine allgemeine Abschwächung des Organismus hervorbringendem Fieber. Bei Kranken, die fieberlos sind oder sich im Statu subfebrili befinden, spielt die reichliche Eitersekretion die Hauptrolle, in welchem Zustande Millionen von neutrophilen Zellen zugrunde gehen, während die Bedeutung der tuberkulösen und sekundären Toxine auf den zweiten Platz geschoben wird. Auch Arneth sucht eine Analogie in chronischen, fieberlosen Eiterungen zu finden, wo die Verschiebung nach links $83-92 \%$ beträgt 1).

Was die sekundäre Infektion und die tuberkulöse Toxinresorption bei fiebernden Kranken anbetrifft, so ist bei der Kombination dieser zwei Faktoren unbekannt, welcher von den beiden, wie es Arneth behauptet, wirksamer (Monographie, Seite 318) bei der schweren Blutinfektion ist, obgleich Arneth an anderer Stelle folgendes meint: „Und in bezug auf die Genese der Blutsveränderungen in den fieberhaften Fällen wird wohl anzunehmen sein, dass sich der Einfluss der giftigen Substanzen, die den Tuberkelbazillen und vor allem den Bakterien der Mischinfektion entstammen, gegenüber den oben erwähnten anderen Faktoren in Übergewicht befindet" (6). Die von ihm beschriebenen Fälle betrachtend, bemerkt Arneth, dass er ausnahmslos bei allen Kranken mit einer Körperwärme über $38^{\circ}$ eine schwere und sehr schwere Schädigung des Blutbildes fand (1). Wenn man aber die von Arneth zusammengestellten drei Tafeln mit einander vergleicht (I. Fieberlosigkeit oder Status subfebrilis, II. ein leichtes oder gemässigtes Fieber, III. ein bedeutendes Fieber) so zeigt es sich, dass die Blutbildbeschädigung in einem zweifelhaften Verbältnis zu der Fieberlosigkeit oder zur Intensität des Fiebers steht.

1) Fall 52 Osteomyelitis. Fall 53 eine reine Myelitis transversa mit decubitus, eine riesige jauchig eiterige Sekretion. Fall 54 Caries tbc. des Rückenmarks ungewöhnlich ausgebreitet mit Calcaneum tbc., in den letzten Tagen ein starkes Fieber (Monographie, S. 118-120). 
Wir wollen von der I. Tafel den Fall Nr. 10 erwähnen $\left(55^{0} \%\right.$ in der I. und Il. Klasse), der seitens A rneth als ganz normal angesehen wurde, sowie den Fall Nr. 13 (61\% in denselben Klassen).

Von der Tafel II führen wir 2 Fälle $(22,23)$ mit unbedeutenden Veränderungen in den Lungen an, deren Bilder in der I. und II. Klasse 63 und $69 \%$ erwiesen und welche sich nach Arneth ebenfalls den normalen Bildern nähern; wir erhalten bei den restierenden 7 fieberlosen Fällen (Tafel I) das Blutbild zwischen $72 \%$ und $80 \%$; bei den übrig gebliebenen 8 mässig febrilen Krankheitsfällen (Tafel II) zwischen 83-97\%; endlich bei allen 5 Fällen mit einem bedeutenden Fieber (Tafel III) von 75-95\% (7). Aus diesen Zahlen geht es hervor, dass zwischen den fieberlosen oder subfebrilen Fällen einerseits und den mässig febrilen andererseits in der Bildverschiebung nach links ein Unterschied von $10 \%$ besteht, was im gewissen Grade die oben erwähnte Behauptung Arneths bestätigen würde. Dieser Voraussetzung widersprechen dagegen Blutbilder, die bei Kranken mit einem hohen Fieber ein wenig besser als bei Kranken mit einem mässigen Fieber sind. Wir kommen auf Grund dieser Angaben zu dem Schluss, dass, wenngleich das Fieber ein Ausdruck der durch Tuberkulose und sekundäre Infektion kombinierter Intoxikation ist, sie sich dennoch nicht in Einklang mit der Beschädigung des neutrophilen Bildes befindet oder demselben nicht gleichlaufend ist.

Wenn wir zum Analysieren der einzelnen Fälle übergehen, so werden wir uns bald nicht recht im Klaren befinden. Bei dem Besprechen des Falles Nr. 5 (Monographie, Seite 68) macht Arneth selbst auf das sonderbare Verbalten des neutrophilen Blutbildes aufmerksam. Dieser Fall ist wirklich in bezug auf das neutrophile Blutbild merkwürdig; wenn wir auf die Krankengeschichte dieses Falles, der mit schweren Symptomen anfing und mit einem stets hohen Fieber $\left(39-40^{\circ}\right)$ verlief, zurückblicken, gelangt man zum Schluss, dass der Kern dieser Krankbeit die käsige tuberkulöse Pneumonie war, was, wie bekannt, eine der schwersten Formen der Lungentuberkulose ist, wenn wir uns auf Autoritäten wie Fränkel und Grancher berufen dürfen. Diese Krankheit sollte also nach Arneth dank der Fieberhöhe und an und für sich eine bedeutende Schädigung des Blutbildes hervorrufen. Einstweilen geschieht es umgekehrt. 
A rneth versucht diesen Widerspruch auf zweierlei Art zu erklären. Einmal (in seiner Monographie [1]) dadurch, dass der Organismus der an Tuberkulose Kranken in jeder Hinsicht weit besser ein hohes und langwieriges Fieber erträgt, als wie der an allen anderen Krankheiten Leidende, was wir schon erwähnt haben. Ein zweites Mal (Zeitschr. f. Tuberkul. [7]) vermutet er, dass das fast normale Bild in der ersten Krankheitshälfte im Zusammenhange mit der reinen tuberkulösen Intoxikation war, während in der zweiten Hälfte die sichtbare Verschlimmerung in Verbindung mit einer Mischinfektion stehen konnte. Welche von diesen Anschauungen die richtige ist, wollen wir nicht entscheiden. Wir werden uns dagegen noch mit einer Besonderheit der Krankengeschichte dieses besprochenen Falles befassen, nämlich damit, dass während des Krankheitsverlaufes, am 22. XII., eine Komplikation in Gestalt einer linksseitigen Pleuritis erfolgte. Am nächsten Tage, das ist am 23. XII., besitzt der Kranke $52 \%$ in der I. und II. Klasse, mit anderen Worten: dieses Bild ist das beste von den angegebenen Blutbildern vom Anfange der Krankheit bis zu dem Tode $(97 \%)$.

Gleichfalls unverständlich in einer anderen Bedeutung ist der Fall Nr. 69 (Monographie, Seite 153), wo bei einer beiderseitigen Lungenspitzenaffektion eine Komplikation in der Gestalt von Typhus sowie einer frischen Lues vorhanden ist. Die an der Höhe des Fiebers unternommenen Blutuntersuchungen erwiesen $97 \%$ in der I. und II. Klasse (wobei $1 \mathrm{M}$ und $1 \mathrm{~W}$ ) sowie eine Leukopenie von 3400 Leukozyten; dennoch kehrte, so vieler Komplikationen ungeachtet, der Kranke zur Gesundheit zurück. A rn eth selbst sieht bedeutende Schwierigkeit bei dem Erklären dieses Vorganges. Er glaubt, dass die Erklärung dieses Falles bei „den ausserhalb des neutrophilen Blutbildes gelegenen Faktoren zu suchen" ist. In Erwägung dessen, dass dieses Bild eine hervorragende Anisohypozytose darstellt, welche gewöhnlich die ungünstigste Prognose leitet, bemerkt Arneth: „Es dürfte kein weiterer Beweis mehr notwendig sein für die Behauptung, dass die Leukopenie eine ebenso salutäre oder kaum schädliche Reaktion des Organismus ist, wie die Leukozytose. Natürlich zunächst immer nur mit Beziehung auf die Neutrophilen." Ebenso unklar ist der Fall Nr. 73 (1) "vorgeschrittene Tuberkulose mit grossen Kavernen und mit einem nicht hohem Fieber", der 4 Tage vor dem Ableben $73 \%$ in der I. und II. Klasse (ohne M and W) bei 14600 Leukozyten zeigte; ein solches Bild finden wir bei nicht allzu schwer Erkrankten. Man könnte diesen Befund durch das rerhältnismässig niedrige Fieber erklären; andererseits aber bat der Kranke seit 3 Monaten eine reichliche eitrige Sekretion 
ausgespieen, was nach Arneth, wie schon erwähnt, eine schwere Schädigung des Blutbildes herbeiführt. - Wir machen jetzt dem Besprechen ron nicht spezifisch behandelten Fällen ein Ende.

$\mathrm{Zu}$ dem neutrophilen Blutbilde bei Anwendung von bakteriologischen Präparaten in der Tuberkulose übergehend, müssen wir bemerken, dass wir eine ganze Reihe belehrender experimentaler Cntersuchungen besitzen, die Arneth an Kaninchen unternahm, deren pseudo-eosinophiles Blutbild dem neutrophilen Bilde des Menschen nahe steht. Die durchschnittliche Leukozytenzahl des Kaninchens beträgt 7700. Wir besitzen im Znsammenhange mit dieser Angelegenheit interessante Untersuchungen, die Burkard mit dem Streptokokkenserum und D ünge $\mathbf{r}$ mit dem Kollargol anstellten. Es ist aus den Arnethschen Untersuchungen ersichtlich, dass z. B. eine intravenöse Peptoninjektion schon nach 10 Minuten nicht nur Störungen in der Form einer Verschiebung nach links seitens des pseudo-eosinophilen Bildes, sondern auch gleichzeitig eine riesige, wenn auch kurzdauernde Leukopenie (von 10000 auf 2400 Leukozyten) verursacht. Die gewaltigen Störungen im Blute, eo ipso auch im Organismus, die dank der Peptoninjektionen zustande kommen, legen den Gedanken nahe, dass die Reaktion, welche durch die Peptoneinführung in den tierischen und menschlichen Organismus hervorgebracht wird, hinsichtlich seiner Erscheinungen der Tuberkulinreaktion sehr ähnlich ist, was übrigens in zahlreichen Versuchen bewiesen wurde ${ }^{1}$ ).

Arneth erhielt bei Bazillenkulturinjektionen ähnliche Resultate. Der Art der Kultur (Bac. coli., Staphyloc. pyogen. flavus, Streptococ.) und der Widerstandsfähigkeit des Kaninchens entsprechend, bemerkte A rneth eine kleinere oder grössere, länger oder kürzer dauernde Schädigung des eosinophilen Bildes und der Leukozytenzahl. Hierbei fällt die grosse Widerstandsfähigkeit des Kaninchens gegen die Tuberkelbazillen auf, da bei intravenösen Reinkulturen- oder Tuberkulininjektionen nach augenblicklichen, bedeutenden Blutbildstörungen schon innerhalb 24-48 Stunden das Blutbild auf gleiche Weise zur Norm zurückkehrt. Ebenfalls interessant sind die Ergebnisse Burkards und Dungers. Der erstere experimentierte mit dem Streptokokkenserum (Paltaufs polyvalentes Serum) in puerperalen Infektionen, der zweite mit intrarenösen Kollargolinjektionen in Infektionskrankheiten (Rheumatismus, Pneumonie, Sepsis usw.).

1) Krehl u. Mathes, Wie entsteht die Temperatursteigerung des fiebernden Organismus, Arch. f. exper. Pathol. Bd. 30. 1897.

Frey muth, Peptoninjektionen. Autoreferat. Zeitschr. f. Tub. Bd. II. H. IV.

Schröder, „Über die Wirkung des Alttuberkulins". Beitr. z. Klinik d. Tub. Bd. VI. H. IV. 
Burkard fand 2-3 Stunden nach der Seruminjektion eine vorübergehende Hyperzytose, welche $30-40 \%$ Vergrösserung unterlag, sowie eine Bildverschiebung nach links, die durchschnittlich 24 Stunden dauerte und welche nach Burkard für "lebhaft gesteigerten Verbrauch und Zerfall der Neutrophilen" spricht (16). D unger bemerkte unmittelbar oder auch in 1-2 Stunden nach der Kollargolinjektion eine durchschnittliche 1-2 Stunden dauernde Leukopenie, bis $20-59 \%$, nach welcher eine Hyperleukozytose folgte. Dieselbe gelangte durchschnittlich bis zu 130-150\% der anfänglichen Leukozytenzahl und ging fast ausschliesslich dank der Neutrophilenzahlvergrösserung sowie der Bildverschiebung nach links mit einer deutlichen, verhältnismässigen Vermehrung der M- und W-Zellen von statten (19).

Auf Grund dieser Versuche und rücksichtlich der grossen Empfindlichkeit des menschlichen Organismus auf Tuberkulosetoxine, können wir a priori voraussetzen, dass wir bei Injektionen verschiedener tuberkulöser Präparate Veränderungen der neutrophilen Bilder finden.

$\mathrm{Zu}$ interessanten Folgerungen führten die Arnethschen Untersuchungen, die er mit dem Kochschen Alttuberkulin an 12 Kranken unternahm, bei denen ohne Ausnahme Bazillen im Sputum nachgewiesen wurden und deren grösserer Teil schwer krank war, da bei einigen neben dem Hauptkrankheitsprozesse in den Lungen eine Komplikation seitens des Kehlkopfes vorhanden war. Wir werden weder von der theoretischen Seite dieses Vorganges sprechen, noch uns mit dem Toxineinfluss auf das Leben der Zellen, mit der Empfindlichkeit und Überreizbarkeit des Organismus auf tuberkulöse Toxine, oder endlich mit Immunisation oder Immunisierung beschäftigen. Es handelt sich in erster Linie um die Klinik. Wir wissen bereits, dass nach verhältnismässig grossen Dosen von Tuberkulin, laut der von der Kochschen Schule angewandten Methode, eine grössere oder kleinere Reaktion des Organismus erfolgt. Dieselbe drüickt sich nach aussen durch subjektive Trübungen im Allgemeinzustand der Kranken (Essunlust, Schmerzen, Erbrechen, allgemeines Übelbefinden) sowie durch subjektive Veränderungen in den Lungen (überwiegend in den Herden) bei grösseren oder kleineren Temperaturerhöhungen, anders durch die sogenannte "negative Phase" aus.

Wir wissen ebenfalls aus der klinischen Erfahrung, dass bei Injektionen von minimalen Dosen des Kochschen oder B eraneckschen Tuberkulins nach der Methode Goetsch-Sahli sich die Reaktion von Seite des Organismus auf ein Minimum reduziert oder auch gar nicht, bei minimalen Symptomen, zum Vorschein kommt. 
Seine Untersuchungen führten Arneth zu dem Schluss, dass zwischen der Reaktion nach der Tuberkulininjektion und der Blutbildschädigung eine gewisse Gleichläufigkeit und Harmonie vorhanden ist, infolge der Störungen im biologischen Leben der Zellen überhaupt und im gegebenen Falle speziell der weissen Blutkörperchen, „Der Reaktionsintensität entsprechend, entstehen gleich schwere Störungen im neutrophilen Blutbilde" (Arneth [7]). Die schwachen Reaktionen werden von unbedentenden Störungen begleitet. Aber auch bei kleinen Dosen trifft man zuweilen nach A rneth starke Reaktionen des Organismus, die gewöhnlich die Folge von starken Dosen sind. Dies geschieht bei Kranken, welche für Tuberkulin speziell empfindlich sind, was übrigens von einer ganzen Reihe von Forschern bestätigt wurde, die das Tuberkulin in der Tuberkulose in Anwendung brachten.

Die klinischen Resultate Axneths stimmen mit der Voraussetzung seiner Theorien selbst überein, nämlich, dass in dem Kampfe des Organismus mit Infektion oder Intoxikation grössere oder kleinere Mengen in erster Linie der reifsten Zellen, als am meisten mit "Antikörpern" versorgt, zugrunde gehen. Hieraus folgt es, dass bei der einmaligen Einführung einer gewissen Toxinquantität in Form der Tuberkulinsubstanz im Organismus eine entsprechende Störung des Blutbildes entstehen sollte. Die Tuberkulintherapie bei seinen 12 Kranken verfolgend, gelangt A rneth zu höchst interessanten Schlüssen. Leichtkranke, die die Tuberkulininjektion ohne grössere Reaktion vertrugen, erwiesen während der Kur in der negativen Phase eine unbedeutende Schädigung des Blutbildes. Die Behandlung ging glatt von statten und sie genossen eine Verbesserung des allgemeinen Befindens und des Lungenzustandes. Aber auch bei schweren Kranken, wo anfänglich bedeutende Blutbildstörungen Hand in Hand mit bedeutenden Reak. tionen gingen, zeigte sich später während der Kur, dass nach einem gewissen Grade der Immunisierung gegen das Tuberkulin das Blutbild sich bei verminderten Reaktionen allmählich verbesserte. Dieser Befund wurde von einer Verbesserung des allgemeinen und Lungenzustandes begleitet. Selbst bei zwei Kranken, von denen bei einem der Zustand ein sehr schwerer, bei dem anderen ein hoffnungsloser zu nennen war, der auch zum Exitus letalis führte, bemerkte Arneth eine der augenblicklichen Verbesserung des neutrophilen Bildes parallele Verbesserung des Allgemeinzustandes sowie eine Gewichtszunahme (Nr. 39 u. 40) (7). Aus diesen Tatsachen zieht Arneth, was das Tuberkulin, das er ein antituberkulöses Mittel par excellence nennt, anbelangt, den Scbluss, dass, wenn man positive - wenn auch nur augenblickliche - Resultate bei Schwerkranken erzielen 
will, die Anwendung besonders in Initialstadien angezeigt ist, wo sie die grössten Aussichten auf Erfolg hat. Dasselbe betrifft Prophylaktiker und für die Tuberkulose Prädisponierte und dies schon aus theoretischen Gründen, „da sie in jedem Falle mit einer künstlichen Schulung der Leukozyten einhergeht" (7). Was das neutrophile Blutbild bei diesen Vorgängen anbetrifft, so reichen Arneths Folgerungen sehr weit hinaus. Er erachtet dasselbe als einen ausserordentlich empfindlichen Index für die Orientierung im Verlaufe der Tuberkulintherapie. Es kommt nämlich vor, dass bei Kranken, bei denen die Tuberkulinbehandlung, oberflächlich betrachtet, günstig vor sich geht und der Allgemein- und Lungenzustand sich verbessert, das Blutbild scblecht oder unbedeutend gebessert bleibt. Nur auf Grund des neutrophilen Blutbildes ist es möglich, die in näberen oder entfernteren Zeiträumen zu erwartende Verschlimmerungen vorauszusehen.

Die Praxis lehrt uns nämlich, dass man die Patienten mit einem schlechten Blutbilde "trotz brillanten Ernährungszuständen, trotz bedeutender Besserung des Lungenbefundes vom rein morphologischhämotologischen Standpunkte nur als gefährliche Explosionsherde zu betrachten". genötigt ist. Mit seinen Resultaten übereinstimmend, behauptet Arneth, dass seine Blutuntersuchungsmethode zu jeder Zeit in dem Kampfeszustande des Organismus sich zu orientieren erlaubt und viel sicherer ist "als alle anderen Momente, die die Besserung unter Umständen vortäuschen". Das neutrophile Blutbild ist nicht nur eine sichere Bestätigung während der Therapie, ungeachtet anderer augenscheinlicher Erscheinungen, sondern es greift weiter in den Bereich der Prognose und trägt zur Feststellung eines sicheren Kriteriums für die Genesung bei Tuberkulinanwendung nicht wenig bei.

Die Praxis lehrt uns, dass die durch das Tuberkulin erhaltene Immunität selbst beim Darreichen von 1,0 (des Alttuberkulins) noch nicht ein Kriterium der Heilung ist. Dies stimmt mit dem wirklichen Tatbestande überein. Die umfangreiche, das Tuberkulin betreffende Literatur, unterrichtet uns, dass das Immunisieren selbst gegen grosse Tuberkulindosen, keineswegs ein Immunisieren gegen die Tuberkulose ist. Wenn wir uns den klinischen Versuchen zuwenden, können wir uns überzeugen, dass nur die Zeit die einzige Gewähr für die Heilung leistet und sie allein über das wirkliche Ausheilen eigentlich entscheidet. A rneth sieht wiederum das in jeder Hinsicht normale neutrophile Blutbild als das Kriterium der tatsächlichen Heilung an. Deswegen ist auch nach dem Immunisieren gegen grosse Tuberkulindosen das positive neutrophile Blutbild ein entscheidender Faktor.' Selbst nach solchen, im Laufe der Zeit erhaltenen Ergebnissen, erteilt Arneth den Rat, das neutrophile Blutbild zu 
fragen, um nötigenfalls die Tuberkulintherapie nach der bekannten „Etappenkur"-Vethode Petruschkys zu wiederholen. Auf diese Weise ist das neutrophile Blutbild nach Arneth einerseits ein fester Prüfstein für den komplizierten Kurverlauf der Tuberkulose, andererseits ein sicheres Kriterium der Heilung; endlich bildet es das wachsame "Memento" für die Zukunft, zu dem man von Zeit zu Zeit zurïckkehren muss, einmal um die Gewissheit der Heilungsdauer zu haben, ein andermal um im Falle einer unvermuteten Verschiebung des neutrophilen "Seismographanzeigers" nach links entsprechende Schutzmassregeln anzuordnen. Arneth dehnt die Folgerungen, welche aus jener allseitigen Rolle, die dem neutrophilen Blutbilde bei der Tuberkulinkur zufällt, gezogen wurden, noch weiter aus und er zieht in ihren Umfang alle anderen therapeutischen Mittel und Methoden zur Heilung der Tuberkulose hinein: „Man wird vielleicht einen ähnlichen Massstab für alle zur Behandlung und Heilung der Tuberkilose empfohlenen Mittel anwenden und ebenso den Blutbefund allein schon als Indikation für den Wert dieser oder jener Behandlung und als wichtig für die Prognose des Einzelfalles betrachten können" (7). - Wir hätten, falls sich dieses Arnethsche Kriterium an einem reichen Materiale bestätigen würde, eine wirklich wertvolle Methode im Besitz, die uns auf gleiche Weise in dem Kurverlaufe der Tuberkulose wie in der Beständigkeit der erhaltenen Heilerfolge sich zurechtzufinden gestatten würde.

Soviel uns aus der uns zugänglichen Literatur bekannt ist, stellte $\mathrm{Uhl}$ in dieser Richtung Untersuchungen (24 Fälle), nicht nur mit dem Alttuberkulin Kochs, sondern auch mit BazillenEmulsion (BE), mit dem Bouillon filtré Denys' (BF) und endlich mit dem Landererschen Hetol an Kranken in verschiedenen Krankheitsphasen an. Die von ihm gewonnenen Ergebnisse stimmen mit den Beobachtungen und Resultaten Arneths überein. Wir bemerken nämlich bedeutende Veränderungen des neutrophilen Blutbildes, die der Reaktionsintensität entsprechen, sowie eine volle Harmonie zwischen der Verschlimmerung oder Verbesserung des Krankheitzustandes während der Behandlung und den analogen Veränderungen im Blutbilde. Wir sehen endlich, dass gegen Ende der Kur parallel den erreichten positiven Resultaten eine Verbesserung des neutrophilen Blutbildes bei der BE (BazillenEmulsion), BF (Boullion filtré) und Alttuberkulinbehandlung zustande kommt. Uhl macht ausserdem noch eine Bemerkung, nämlich, dass die Veränderungen des Blutbildes eine bedeutend feinere Reaktionserscheinung nach Tuberkulininjektionen darstellen als die Temperaturerhöhungen. Diese letztere kann nämlich kaum die 
normalen Grenzen überschreiten $\left(37,3^{\circ}\right.$ Maximum), während die Störungen im Blutbilde sehr bedeutend sind, denn sie gelangen manchmal bis zu $95 \%$ in den ersten zwei Klassen. Die Veränderungen im neutrophilen Blutbilde sind aus diesem Grunde in solchen Fällen ein höchst wertvoller Index für das Zurechtfinden in der spezifischen Behandlung.

Uhl schreibt auch: „In dem neutrophilen Blutbefunde besitzen wir ein viel feineres Reagens des Organismus als in der Temperatur selbst" (39). - Anders verhält es sich mit der Behandlung der Tuberkulose mit dem Marmor ek schen Serum, dessen Anwendung noch einen Streitpunkt bildet, weil sie, wie bekannt, ebenso warme Anhänger wie sehr eifrige Gegner besitzt. Soviel aus der Literatur bekannt ist, stellten $\mathrm{Kaufmann}$ und $\mathrm{Röver}$ Untersuchungen an dem neutrophilen Blutbilde bei Marm or ekscher Serumtherapie an. Röver, ein warmer Anhänger dieser Behandlungsart, ordnete häufige Untersuchungen bei 16 Kranken an (4 Fälle von Tuberkulose der Lymphdrüsen, 9 der Lungen-, 2 der Knochen-, 1 Fall von Miliartuberkulose) und in allen Untersuchungen, die der Miliartuberkulose ausgenommen, bestätigt er alle Schlüsse Arneths, gleichwohl jene den Kurverlauf betreffende wie auch dessen Ergebnisse. "Aus unseren Untersuchungen — sagt Röver - ergibt sich in den meisten Fällen eine völlige Übereinstimmung im Verlaufe der Vorgänge unter den neutrophilen Leukozyten und dem klinischen Krankheitsbilde. Es ist bei den günstig verlaufenden Fällen mit den Resultaten der Blutuntersuchung eine weitere Stütze zur Annahme einer Besserung gegeben" (39). - Es ist merkwürdig, dass nur in der einen rasch mit dem Tode geendeten Miliartuberkulose eine bedeutende Abweichung bei diesem Autor vorkommt, die auch der Autor selbst bemerkt. Während wir 4 Wochen vor dem Tode hier $89 \%$ in der I. und II. Klasse finden, verändert sich das Blutbild deutlich positiv und zwar geschieht dies 5 Tage vor dem Tode. Röver versucht diesen Widerspruch durch ein gewisses Neutralisieren der Toxine seitens des Serums zu erklären. Es scheint uns eine solche Erklärung unzureichend begründet zu sein. $\mathrm{Zu}$ ganz anderen Resultaten gelangt Kaufmann. Er sieht Röver gegenüber das Marmoreksche Serum als nachteilig in der Tuberkulose wirkend an, da vielfache in 14 Fällen nach Arneth angestellte Untersuchungen im Widerspruche mit dem Krankheitsverlaufe bei 11 Fällen stehen (eine Übereinstimmung zeigt sich in 2 Fällen: einer Verschlimmerung des Zustandes bei einer Bildverschiebung nach links, in einem Falle einer Zustandsverbesserung bei einer Verschiebung nach rechts), weil die Verschlimmerung des Krankenzustandes von einer Verbesserung des 
nentrophilen Blutbefundes begleitet wird. Deshalb folgert $\mathrm{K}$ a $\mathrm{uf}$ mann: "Wir machten dabei aber durchaus nicht die Erfahrung, dass sich der Blutbefund nach Arneth immer mit den sonstigen Symptomen für eine Besserung oder Verschlechterung der lokalen Prozesse und des Allgemeinbefundes deckt" (29).

Indem wir jetzt zu unseren eigenen Untersuchungen übergehen, wollen wir ein paar Worte ihrer technischen Seite widmen. Alle Untersuchungen wurden mit Ausnahme von einigen, mit den Forderungen Arneths übereinstimmend, in nüchternem Zustande unternommen. Auf diese Weise vermeiden wir besonders bei dem Berechnen der allgemeinen Leukozytenzahl Irrtümer, denen die sogenannte Verdauungsleukozytose zu grunde liegt. Die allgemeine Leukozytenzahl hatten wir mittels des Thoma-Zeissschen Apparates bestimmt, wobei wir in jedem einzelnen Falle die Leukozytenzahl nur in diesen Präparaten berechneten, die nach dem Aufsetzen des Deckgläschens eine deutliche Interferenz in der Gestalt der Ne w to n schen Ringe sehen liessen. Nur in einem solchen Falle können die Berechnungen, nach Anzeigen vieler Autoren, genau sein. Um die allgemeine Lenkozytenzahl zu bestimmen, berechneten wir sechsmal das Netz des Thoma-Zeiss schen Gläschens und erst auf Grund dieser sechs Berechnungen bestimmten wir die Durchschnittszahl. Auf diese Weise wurde eine grössere Garantie der Genauigkeit geschaffen. Was die Klassifikation der Leukozyten anbelangt, so wurden die Präparate in den ersten zwei Serien unserer Untersuchungen nach dem $\mathrm{Ehrlich}$ schen Trockensystem fixiert, d. h. in einem Thẹrmostat eine Stunde lang bis zu $120^{\circ}$ erwärmt. Später jedoch bedienten wir uns zwecks Erzielung grösserer Einfachheit sowie besserer Resultate einer anderen am häufigsten gebrauchten Methode, nämlich der Mischung gleicher Teile von absolutem Alkohol und Äther. Was die Färbungsmethode anbelangt, so folgten wir anfänglich den Vorschriften A rneths. Wir wandten bei allen Präparaten von Kranken der ersten zwei Serien (55 Fälle) das Ehrlichsche Triazid an. Wir sahen in ihm gewisse Vorzüge, die A rneth empfahl, und denen wir in der ersten von uns veröffentlichen Untersuchungsserie bereits Erwähnung getan haben $\left.{ }^{1}\right)$.

Im Laufe der Zeit aber überzeugten wir uns, vornehmlich durch Vergleichen mit anderen Methoden, dass das Triazid neben den besagten Vorzügen einen besonderen Mangel besitzt, es gibt nämlich

1) „Die Blutuntersuchungen nach A rnethscher Methode bei Tuberkulösen vom klinischen Standpunkte." Gazeta lekarska 1908. Nr. 1-9. 
die Umrisse der Kerne nicht dentlich genug wieder, sondern bietet ein breites Feld für Mutmassungen und subjektive Anschauungen. Es macht bald das Auge müde, was um so mehr die Berechnungsresultate negativ beeinflusst.

Aus diesem Grunde schien uns die Abwechselung der Färbungsmethode als angezeigt; zu diesem $Z$ wecke verglichen wir Präparate, die nach May-Grünwald, Romanowski-Ziemann, Giemsa sowie mit Ehrlichs Triazid und Hämatoxylin und Eosingefärbt waren. $\mathrm{Da}$ wir an von einem und demselben Kranken stammenden, nach diesen Methoden gefärbten Präparaten sehr naheliegende Ergebnisse erbielten (der Unterschied beruhte auf dem Fehlen von einigen Prozenten in den einzelnen Klassen, was nicht auf die Farbstoffe zurückgeführt werden kann), sahen wir sie als gleichbedeutend an. Wir wählten Hämatoxylin und Eosin, da diese am leichtesten angewandt werden können und weil diese Färbungsart die Cmrisse der Kerne am deutlichsten hervortreten lässt. Diese Methode lässt, wie bekannt, selbst die feinsten Chromatinfädchen erblicken. Aus diesem Grunde haben die Kerne den Anschein, als ob sie vermittelst dieser Fädchen miteinander verbunden wären, sie bilden einen sogenannten Nuklearapparat. Diese bei der Triazidanwendung unsichtbaren Fädchen hatten wir, wie es andere Forscher getan, nach Arneths Weisungen nicht berïcksichtigt. Wir waren genötigt, auch bei HämatoxylinEosin-Färbung sie ausser acht zu lassen, um unsere Berechnungen in analogen Umständen zu vollführen, die Arneth durch die Anwendung des die Fäden nicht sichtbar machenden Triazid in seiner Methode geschaffen hat. Aus diesem Grunde sahen wir nur diejenigen von den Neutrophilen als einkernige an, die nach Weidenreich "kompakt kernig" genannt werden konnten. Andere neutrophile Formen, die sichtbar getrennt und miteinander durch jene feine fast Spinnenfäden verbunden waren, zählten wir, von der deutlich hervortretenden Kernsegmentzahl abhängig, zu der II., III., IV. oder V. Klasse. Wir fanden nämlich nirgends, dass Arneth in Abrede stellen würde, dass man bei gewissen Färbungsmethoden nicht imstande wäre nachzuweisen, dass die Kerne der Leukozyten eigentlich vermittelst jener Chromatinfädchen das Ganze des Nuklearapparates bilden. Wie wir A rneth verstanden haben, handelt es sich tatsächlich um etwas ganz Anderes. Wenn wir als Grundlage annehmen, dass eine grössere Kerndifferenzierung, sei es Vielkernigkeit oder Polymorphkernigkeit, eine grössere Reife eines gegebenen Leukozyten beweist, so müssen wir uns bemühen, diese Polymorphkernigkeit in gewisse Grenzen zu schliessen und sie einer gewissen Analyse zu unterwerfen. Diese Analyse sollte man dahin auf- 
fiassen, dass es sich hier eigentlich nicht darum handelt, dass der Leukozyt A eine doppelt grössere Kernemenge wie der Leukozyt B besitzt, sondern dass der erstere reifer und bedeutend mehr differenziert als der zweite ist; weiter, dass der erstere, mit Arneths Grundhypothese übereinstimmend, bei seinem Zerfall eine grössere Zahl von Antikörpern produziert.

Es handelt sich deshalb bei allen nach der Arnethschen Methode angestellten Untersuchungen darum, ob die Zahl dieser Individuen zunimmt oder auch abnimmt. Wir wollen also die Bezeichnung "Vielkernigkeit" vermeiden, da es sich hier um etwas ganz Anderes handelt. Das Zusammenfassen von Leukozyten in Klassen gibt und braucht auch nicht unserer Meinung nach den wirklichen polynukleären Leukozytenzustand wiederzugeben; es bildet nur eine Beobachtungsform, um eine leichtere Orientierung in den die Leukozyten betreffenden Verhältnissen zu gestatten. Wenn man also den Arnethschen Theorien Einwürfe machen kann, so darf man nach unserem Erachten dieselben nur auf folgende Weise, hinsichtlich des oben Erwähnten, formulieren: Bildet die Polymorphkernigkeit wirklich einen Beweis für die Reife eines gegebenen Leukozyten, sowie für dessen Kampffähigkeit oder ist sie ein Kernzeichen des Altwerdens sowie des Schwindens jener Eigenschaften und gehen tatsächlich im Kampfe des Organismus mit der Infektion oder Intoxikation vor allem die am meisten differenzierten Individuen zugrunde? Dies kann aber nur auf dem Wege der Betrachtung des Verhaltens dieser Formen in pathologischen Zuständen des Organismus bewiesen werden.

Wir hatten nur zu dem Zirecke unsere Untersuchungen unternommen, um auf diese Fragen zu antworten. Sobald nämlich die Klinik bestimmen wird, dass wirklich ein gegebener Krankeitszustand rom gewissen und festen Schwund dieser polymorphen Formen aus dem Blutkreislaufe begleitet wird, so wird das Ziel der Arneth schen Methode vollständig erreicht und ihre Bedeutung bewiesen. Da bei der Anwendung selbst der am besten den Kern färbenden Farbstoffe bisweilen Ungewissheiten vorkommen, in welche Klasse wir eine gegebene Zelle bringen sollen, nahmen wir uns vor, solche zweifelhafte Fälle beiseite zu lassen und dieselben gar nicht in Betracht zu ziehen. Auf diese Weise begehen wir einen kleineren Fehler, als wenn wir sie zu einer der Klassen zählen würden. Um sich ein Urteil zu verschaffen, bis zu welchem Grade die Blutuntersuchungen nach der Arnethschen Methode von dem subjektiven Sehen abhängig sind, unternahm Dluski, da nur einer von uns (Rozpedzihowski) die Präparate verfertigte, in 10 Fällen Kontroll- 
untersuchungen. Es zeigte sich dabei, dass, obgleich der individuelle Faktor in der Beurteilung, welcher Klasse ein gegebener Leukozyt angehört, auch der Arnethschen Methode nicht fremd bleibt, er dennoch keine allzugrosse Rolle spielt, da die Differenz, die zwischen uns rorkam, durchschnittlich $4 \%$ betrug ${ }^{1}$ ).

Van muss noch bemerken, dass wir stets 100 neutrophile Leukozyten berechneten, wobei die Berechnung auf zwei am meisten gelungenen Präparaten bewerkstelligt wurde. Unser Mikroskop stammte von der Firma Stiassnie (vormals Verick) mit einer Ölimmersion und Okular Nr. 6 ausgestattet. Zum Versehieben der Präparate benutzten wir ein verschiebbares Objekttischchen.

Wir wollen, zum Besprechen unserer Untersuchungen übergehend, bemerken, dass wir zwecks Bewährung des normalen Blutbildes A rneths Untersuchungen bei 10 Gesunden ( 5 Frauen und 5 Männer) im Alter von 18-44 Jahren angeordnet hatten, die folgendes Resultat ergaben.

Wir erhielten auf diese Weise ein normales Blutbild, das ganz unbedeutend von dem A rneth schen abweicht ${ }^{2}$ ). Wir werden also als Ausgangspunkt für das Vergleichen der Bilder in pathologischen Zuständen, wie wir es bisher getan haben, das normale Arnethsche Blutbild benïtzen.

Arneth nimmt, wie schon erwähnt, die Verschiebung des Blutbildes in den ersten zwei Klassen selbst um $15 \%$ als eine normale Erscheinung an; andererseits gibt er keine genaue Terminologie für die Bezeichnung des Schädigungsgrades des neutrophilen Blutbildes. Wir fanden es also für nötig, unsere eigene 'Terminologie einzuführen. Wir sehen nämlich das Blutbild, das in den ersten zwei Klassen $55 \%$ nicht überschreitet, als normal an. Die Verschiebung von 55-70\% nach links in denselben Klassen halten wir für einen Übergangszustand vom normalen zum schlechten Befund, von $70 \%$ bis zu $85 \%$ für einen schlechten und oberhalb $85 \%$ (in denselben Klassen) für einen sehr schlechten Zustand. Überdies nennen wir „geringe Verschlechterung oder geringe Besserung" die Verschiebung nach links bezw. nach rechts um $5 \%$ bis $15 \%$. Eine Verschiebung von mehr als $15 \%$ nach rechts oder nach links sehen wir als eine bedeutende Besserung bezw. eine bedeutende Verschlechterung an. Eine solche auf künstlichen Grundlagen stehende Terminologie ist zwar willkürlich, sie hat aber ihre Unterlage, weil sie einen bestimmten Charakter besitzt, während die Bezeichnungen Arneths an Genauigkeit mangeln. Er sieht zum Beispiel das Blut-

1) Siehe Tafel A.

2) Siehe Tafel B. 
bild mit $81 \%$ in der I. und II. Klasse als "schweres Bild" an (Monographie, Seite 116), während er ein zweites mit $90 \%$ in denselben Klassen nur "bedeutende Veränderung" nennt (Monogr. Seite 92). An einer anderen Stelle benützt er für das Bild mit $76 \%$ in der I. und II. Klasse (Monographie, Seite 15̆1) die Bezeichnung „mässige Verschiebung" und in einem anderen Falle (Münch. med. Wochenschr. Seite 1102, Nr. 25, 1904) für $71 \%$ in denselben Klassen "schwer geschädigt."

Wir gehen jetzt zu eingehenden Betrachtungen unserer Untersuchungen über. Wir teilten unsere Kranken in drei Gruppen.

Die I. Gruppe (die Untersuchungen wurden einmal vorgenommen) umfasst:

20 Kranke im I. Stadium
10 / zusammen 46 Unter-
16 .

Die II. Gruppe (die Untersuchungen wurden zweimal angestellt): o Kranke im

$17 " \quad " \quad$ III. $\quad "$ zusammen 70 Untersuchungen.

Die III. Gruppe (die Untersuchungen wurden dreimal und öfters unternommen):

$$
\begin{aligned}
& 3 \text { Kranke im. I. Stadium } \\
& 7 \text {, III. " } \\
& 11 " \text { "III. " } \quad \text { suchungen. } \\
& 205 \text { Untersuchungen. }
\end{aligned}
$$

Bei 19 von 20 Kranken im I. Stadium, die einmal untersucht wurden, wie aus der Tafel I ersichtlich ist, schwankt das neutrophile Blutbild zwischen $41-78 \%$ in den ersten zwei Klassen ${ }^{1}$ ). In den diese Krankengruppe betreffenden Bildern sehen wir bei 11 Kranken einen normalen, bei 7 Kranken einen Übergangs-, bei einem Kranken einen schlechten und bei einem nach jener Terminologie, die wir oben angegeben hatten, einen sehr schlechten Zustand.

Was die normalen Blutbilder anbelangt, so standen sie im Einklang mit dem klinischen Zustande der Kranken, welche bei unbedeutenden Veränderungen in den Lungenspitzen, vorwiegend in einer Spitze, sich eines guten oder sehr guten Ernährungszustandes erfreuten; wobei bei 9 Kranken während ihres Aufenthaltes in der Anstalt der Zustand fieberlos war, 2 Kranke erwiesen einen kurzdauernden subfebrilen Zustand ohne Tuberkelbazillen in dem spärlich oder gar nicht abgesondertem Sputum.

1) Einen Fall (Nr. 26) mit $100 \%$ in zwei ersten Klassen werden wir besonders besprechen. 
Angesichts der in allen diesen 9 Fällen herrschenden Harmonie halten wir es nicht für nötig, uns hier länger aufzubalten. Wir möchten dagegen den 2 übrigen Fällen Nr. 15 und Nr. 22 mehr Aufmerksamkeit schenken. Was den ersteren Patienten (15) anbelangt, so ist dieser seit längerer Zeit krank, er hat Blutspucken gehabt, litt an trockener Pleuritis, - Tuberkelbazillen wurden im Sputum nicht gefunden. Wir hatten ihn in der Anstalt jedes Jahr von 1906 angefangen durch einige Monate in Observation und konnten stets eine fortschreitende Besserung in den Lungen wie in dem Allgemeinzustande, der ganz befriedigend war, feststellen. In dieser Richtung unternommene Blutuntersuchung bestätigte vollends diesen Zustand. Bei dem zweiten Kranken (22) ist das Blutbild rücksichtlich des ganzen Verlaufes noch viel merkwürdiger. Der Kranke kam im Jahre 1903 in einem sehr schweren Zustande in die Anstalt, und nach einer zweijährigen, mehrmals unterbrochenen Kur erreichte er eine vorzügliche Besserung. Es blieb nur bei ihm eine Condensatio der linken Lungenspitze, die sich bei einem fieberlosen und allgemeinen guten Ernährungszustande bis zu der Zeit der ersten Blutuntersuchung erhielt, obgleich sich bisweilen Tuberkelbazillen im Sputum vorfanden. Seit dem Verlassen des Sanatoriums wohnt der Patient beständig in Zakopane. Er hesuchte die Anstalt dreimal in der Woche, wo ihm das Beranecksche $\mathrm{TB}_{\mathrm{K}}$ injiziert wurde; er erreichte nach dem Schema Sahlis die Dosis von ${ }^{2} / 10 \mathrm{~g}$. Wie die Blutuntersucliung in der beigefügten Tafel zeigt, wurde ein normales Blutbild nachgewiesen, was ähnlich dem vorherigen Falle, auf das Resultat einer langjährigen Behandlung sowie auf den mehrjährigen Stillstand des tuberkulösen Prozesses hinweist. Bei 7 folgenden Kranken fanden wir trotz unbedeutender Veränderungen in den Lungen, was uns die Möglichkeit gab, sie zu dem ersten Stadium zu zählen, unserer Terminologie nach, einen Übergangszustand, der von 55 bis zu $70 \%$ schwankte. Wir sehen diese Bilder trotz unbedeutender Veränderungen in den Lungen als mit dem Allgemeinzustande der Kranken übereinstimmend an, weil wir bei Allen Komplikationen fanden, die bis zu gewissem Grade einen solchen Blutbefund berechtigten. Ebenso ist es in dem Falle Nr. 30, bei dem auf Grund des Gutachtens von Spezialisten (Laryngologen) eine Kehlkopftuberkulose verdächtigt wurde. Desgleichen der Fall Nr. 11, der, obgleich er keine Komplikationen erwies, sich dennoch durch einen hervorragend schlechten allgemeinen Ernährungszustand, sowie durch eine längere Zeit vorhandene Kraftlosigkeit auszeichnete.

Bei dem Kranken Nr. 1 sind vereiterte Halsdrüsen, sowie ein ständiger, bisweilen $38^{\circ}$ und mehr erreichender subfebriler Zustand 
die erklärenden Momente für den Übergangszustand des Blutbildes. Bei der Kranken Nr. 23 kann wiederum das Blutbild durch einen dauernden subfebrilen Zustand, sowie durch einige Tage lang währende, hartnäckige Diarrhöe erklärt werden, die, wie uns bekannt ist, einige Monate nach dem Verlassen der Anstalt sich verschlimmert hat und bis auf den heutigen Tag noch andauert. Unlängst wurde dieser Vorgang seitens eines bekannten Spezialisten als eine enterogene Darm-Intoxikation bestimmt, ohne jedoch die Möglichkeit eines Tuberkuloseprozesses im Darmkanal auszuschliessen. Wir sehen einen solchen chronisch verlaufenden Intoxikationszustand unabhängig von der Lungenerkrankung, in Eintracht mit den Indikationen Arneths als einen negativ das Blutbild beeinflussenden Faktor an.

Die Fälle Nr. 38 und 34 wollen wir zusammen besprechen, da sie sich durch die Ähnlichkeit der klinischen Bilder auszeichnen. In beiden Fällen ist die Lungenaffektion eine minimale und beschränkt sich auf unbedeutende Respirations- und Perkussionsabweichungen ohne Rasselgeräusche. Eine sechsmonatliche Beobachtung lässt uns Komplikationen in verschiedenen Organen, wie in dem Darmkanale, Nieren, Knochen, Peritoneum usw. sowie alle anderen krankhaften Prozesse ausschliessen; sie empfiehlt uns, an Tuberkeloseherden in den Drüsen festzuhalten, um so mehr, da bei einer solchen Ausschliessung von Komplikationen durch die ganze Kurzeit ein leichter, selten unterbrochener subfebriler Zustand vorhanden war. Diese Voraus. setzung ist vom klinischen Standpunkte vollends begründet, da wir eine ganze Reihe analoger Fälle besassen, die nur durch eine Drüsenaffektion zu erklären waren. Unsere Annahmen werden um so wahrscheinlicher, wenn wir uns an die Versuche Rabinowitschs erinnern, welche nachgewiesen haben, dass die Injektion von teilweise verkalkten und verhärteten Stoffen der Mesenterialund Peribronchialdrüsen, welche von Menschen stammen, von denen einer unbedeutende Veränderungen, die anderen gar keine tuberkulösen Symptome bei Lebzeiten zeigten, keine mindere Virulenz erweist wie die aus dem Sputum gezüchteten Bazillen, relche die Tuberkulose beim Meerschweinchen und Kaninchen hervorrufen ${ }^{1}$ ).

In einem solchen Falle hätten wir bier mit aktiven tuberkulösen Herden zu tun und das Vorhandensein solcher Herde würde die Schädigung des Blutbildes rechtfertigen.

Was den Kranken dieser Gruppe (Nr. 13) anbelangt, so müssen wir bemerken, dass dieses Blutbild ein näheres Besprechen fordert. Die Untersuchung betrifft einen 24 jährigen Mann, der

1) L. Rabinowitsch: „Zur Frage latenter Tuberkulose", Ber]. K. Woch. 1907, Nr. 2. 
schon vor 16 Jahren sich den Rat eines von uns beiden erholte; es wurde damals eine unbedeutende Affektion der rechten Lungenspitze festgestellt. Durch diese ganze Zeit wurde er niemals untersucht und für gesund gehalten. Ein athletischer Körperbau und Fieberlosigkeit liessen auf keine Krankheitserscheinungen schliessen. Eine zufällige Untersuchung hatte konstatiert, dass in der rechten Lungenspitze die Affektion sich an derselben Stelle befindet und dass die Perkussions- und Auskultationserscheinungen beim Fehlen der Tuberkelbazillen im Sputum aber bei geringen Rasselgeräuschen deutlicher wie vor 16 Jahren hervortreten. Wir wollen nicht entscheiden, $\mathrm{ob}$ es in dem gegebenen Falle sich um eine exogene oder endogene Reinfektion oder um die Kontinuität eines und desselben Prozesses handelt. Jedenfalls haben wir es hier mit der Tuberkulose zu tun, die sich als ein infektiöser Vorgang unseres Blutbildes kennzeichnet. Ein noch viel schlechteres Blutbild, wie die oben erwähnten, besitzt der vorletzte Kranke (Nr. 31), der dem I. Stadium angehört. Wir sehen, dass sein Blutbild nach unserer Terminologie in der Kategorie des schlechten Blutbildes gezählt werden muss, da es $78 \%$ in der I. und II. Klasse beträgt. Ein solches Bild würde im grellen Widerspruch mit den unbedeutenden Veränderungen in den Lungenspitzen stehen, wenn sich nicht bei diesem Kranken eine Komplikation in der Gestalt einer Fistel mit reichlicher eitrig-störkoralen Sekretion auf Grund einer früber operierten Appendizitis erwiesen hätte. Dieser Eiterungsprozess erklärt genügend, mit der Behauptung Arneths übereinstimmend, dass jede länger dauernde Eiterung Millionen von älteren Zellen vernichtet, eo ipso die Zahlverminderung der Leukozyten in den höheren Klassen und die Steigerung von jüngeren Formen herbeiführt.

Wir wollen uns jetzt mit dem letzten Patienten Nr. 26 beschäftigen. Wir müssen hierbei bemerken, dass dieser wohlgenährte, fieberlose, sehr gut gebaute, nicht hustende und sich wohlfühlende Patient aus eigener Initiative einzig zu dem Zwecke die Anstalt besuchte, um alle seine Zweifel betreffs seines Lungenzustandes zu beseitigen. Die erste physikalische Untersuchung ergab eine leichte Verschärfung des Atems vorne in der linken Spitze selbst; von der Rückenseite der Atem leicht rauh, eine leichte Schallverkürzung über dem Schulterblatte und dem rechten Schlüsselbeine, eine verlängerte Respiration daselbst, einige leise Krepitationen in dem I. Spatium intercostale nach dem Husten. Nicht hereditär belastet. Im Jahre 1904 machte er eine Influenza durch und ron dieser Zeit an ist er um seinen Lungenzustand besorgt. Die zweite Untersuchung, 9 Tage nach der ersten, der Kontrolle wegen rorgenommen, ergab 
dasselbe. Wir hielten, da wir ihn als einen klinisch ganz Gesunden und Arbeitsfähigen betrachteten, nicht für angezeigt ihn länger in der Anstalt aufzuhalten. In der Meinung, dass auch das Arnethsche Blutbild den klinischen Befund gänzlich bestätigen werde, nahmen wir bei ihm eine Blutuntersuchung vor, die, wie aus der Tafel ersichtlich ist, ganz unerwartet ein wirklich paradoxes Resultat ergab. Wir sehen nämlich bei diesem Patienten, dass sich das Blutbild lediglich auf die ersten zwei Klassen beschränkt, es ist buchstäblich von Zellen der III., IV. und V. Klasse entblösst. In der I. Klasse haben wir $57 \%$ in der II. $43 \%$ bei 6000 Leukozyten.

Man könnte voraussetzen, dass ein dermassen äusserst nach links verschobenes Blutbild Ankündigung einer Verschlimmerung in nächster Zukunft wäre. Tatsachen aber sprechen dagegen. Auf unser Verlangen wurde der Patient 51/2 Monate nach dem Verlassen des Sanatoriums seitens eines unserer besten Spezialisten der Kontrolle wegen untersucht, welcher einen gleichen und vielleicht einen besseren Lungenzustand als im Sanatorium feststellte. Es fehlte nämlich jegliches Rasseln in der rechten Lungenspitze. Ausserdem hatte unser Patient während dieser ganzen Zeit eine normale Körperwärme, die $37^{\circ}$ niemals überschritt und freute sich in jeder Beziehung eines sehr guten Allgemeinzustandes. Er ist von Beruf Schriftsteller und arbeitet fortwährend schwer.

Wir gehen jetzt zu dem zweiten Stadium über. (Zusammen 10 Kranke.) Bei 3 Kranken fanden wir normale Blutbilder. Dieser Umstand wird dadurch gerechtfertigt, dass die Blutuntersuchungen zur Zeit, wo die Kranken nach einem mehrmonatlichen Aufenthalte im Sanatorium einer bedeutenden Besserung des Lungen- und des Allgemeinzustandes genossen sowie das Fieber verloren, angestellt wurden.

Bei $\check{o}$ Kranken gewahren wir, dass das Blutbild in einer mehr oder weniger bestimmten Übereinstimmung mit dem klinischen Befunde bleibt, ihre Bilder sind schlechter als die der ersten 3 Kranken. Sie unterliegen der Rubrik der Übergangszustände; dies würde sich dadurch erklären lassen, dass wir es hier mit Kranken, die sich im subfebrilen Zustande befinden oder auch zum Blutspucken neigen, sowie einen schlechten Ernährungszustand nachweisen, zu tun haben. Die restierenden 2 Fälle besprechen wir besonders, da ihre Blutbilder sich als schlechte erweisen.

In dem einen Falle, Nr. 41, sehen wir, wie es ans der beigefügten Tafel ersichtlich ist, $74 \%$ in der I. und II. Klasse. Dieses Bild betrifft eine Patientin, die, obgleich zum II. Stadium gezählt, in dem Lungenzustande doch keine Besserung aufwies, sondern eine 
langsame Verschlimmerung zeigte. Die Körperwärme war stets gehoben und der Allgemeinzustand war ebenfalls nicht zufriedenstellend. Die Patientin verliess alsbald die Anstalt und unsererseits wurde eine ungünstige Prognose auf Grund eines ganzen Komplexes klinischer Symptome gestellt.

Bei dem zweiten Kranken, Nr.40, stimmte das schlechte Blutbild ganz deutlich mit den klinischen Erscheinungen und dem Krankheitsverlaufe vor den Blutuntersuchungen überein. Der Kranke kam 6 Tage vor der Blutuntersuchung in die Anstalt in einem verhältnismässig guten Allgemeinzustande; er befand sich in einem unbedeutenden subfebrilen Zustande und hatte einen auf $4-5 \mathrm{~cm}$ begrenzten Herd, der den Charakter eines bronchopneumonischen besass. Wie die tagtäglichen Untersuchungen erwiesen, verbreitete sich der bei Ankunft im Sanatorium oberhalb der linken Brustwarze lokalisierte Herd über die Armhöhle nach hinten, indem er ungefähr den Raum von der Schulterblattgräte bis zum Angulus scapulae eịnnahm. Dieser Umstand wurde von einem allmählichen Kraftverfall, Temperatursteigerung, die bis $39^{\circ}$ und mehr gelangte, und einer deutlichen Tendenz zum Zerfall begleitet.

In dem III. Stadium haben wir 16 Kranke, bei denen wir nur einmal das Blut untersuchten. Bei 11 Fällen besteht eine Harmonie zwischen dem Blutbilde und dem klinischen Befund. Sieben (Nr. 4, 5, $6,21,33,35,45)$ unter ihnen besitzen ein schlechtes Blutbild, da bei allen diesen Kranken kleinere oder grössere Infiltrationen in den Lungen vorhanden gewesen waren. Im Verhältnis zu ihrem Allgemeinzustande aber, zu der Fieberintensität, sogar zu der Eiterauswurfquantität, befand sich das Bild in den Grenzen von $14 \%$, im Schwanken von $70-84^{\circ}, 0$ in der I. und II. Klasse. Wir können tatsächlich die besten Bilder, $70-\mathbf{7 1} \%$, bei den Kranken beobachten, bei denen seit einer gewissen Zeit ein Stillstand des Krankheitsprozesses, eine Besserung des Allgemeinzustandes und eine nur ron Zeit zu Zeit eintretende Temperaturerhöhung sich vorfand. Dagegen kehrte die Kranke Nr. 6, - die schon einmal 5̃ Monate lang sich in der Anstalt aufhielt und am Anfange des Jahres 1907 unbedeutende Veränderungen erwies, - im April 1908 mit einer Verhärtung der linken Lungenspitze und einer grossen Infiltration in der rechten Lunge, die eine grosse Tendenz zum Zerfalle zeigte, mit einem hohen Fieber bis zu $39^{\circ}$ und höher, in einem äusserst schlechten Allgemeinzustande, einer grossen Menge von Bazillen, sowie mit einer bedeutenden Anzahl ron elastischen Fasern im Sputum zurück. Die nach über 10 Tagen nach der Ankunft vollführten Untersuchungen wiesen $84 \%$ in der I. und II. Klasse nach, d. h. ein 
Bild, das an der Grenze eines sehr schlechten Zustandes steht. Bei den weiteren 4 Kranken $(2,10,42,44)$ finden wir neben riesig grossen Kavernen in den Lungen, ein hohes Fieber, bei einer gänzlichen Abzehrung des Organismus, sehr schlechte Blutbilder, die jedoch in einer Harmonie mit ihrem Lungen- und Allgemeinzustand verbleiben. Wie aus der Tafel ersichtlich ist, schwanken die diese Kranken betreffenden Bilder in den Grenzen von $87-92 \%$ in der I. und II. Klasse. Zwei von diesen Kranken starben kurz darauf $(10,44)$. Wir müssen hinzufügen, dass wir das schlechteste Bild $92 \%$ (Nr. 42) bei einer Kranken gewahren, die neben oben erwähnten Veränderungen in den Lungen eine klinisch und bakteriologisch nachgewiesene Darmtuberkulose besass. - Bei 3 Kranken dieses Stadiums (Nr. 8, 9, 20) fanden wir ein vorübergehendes Blutbild, das gänzlich mit dem Lungen- und Allgemeinzustande dieser Kranken übereinstimmte, da es nach einer wesentlichen Besserung untersucht wurde. Wir konnten dagegen bei den 2 restierenden Kranken eine solche Eintracht nicht feststellen. Der erste von ihnen, Nr. 43, schritt, bei riesigen Verwüstungen in den Lungen sowie bei einem schlechten Allgemeinzustande und einem hohen Fieber, fortwährend in der Verschlimmerung weiter, er starb $2^{1 / 2}$ Monate nach der Blutuntersuchung. Diese erwies, wie aus der Tafel ersichtlich, ein fast rorübergehendes Bild, da es $65 \%$ in der I. und II. Klasse bei 7000 Leukozyten betrug, was einen grellen Kontrast mit den erwiesenen Todesfällen und den oben angeführten Beispielen bildet. Viel merkwürdiger ist das Blutbild eines Kranken (Nr. 37), der in einem sehr schweren Zustande nach Zakopane kam, alle möglichen klinischen Erscheinungen einer in den Lungen disseminierten Miliartuberkulose zeigte (die Sektion wurde nicht vorgenommen) und bei dem wir 10 Tage vor dem Tode bei 11400 Leukozyten nur $69 \%$ in der I. und II. Klasse fanden.

Unsere einmaligen Untersuchungen in kurzen Worten noch einmal zusammenfassend, konstatieren wir, dass wir auf 46 Fälle in 43 einen relativen Zusammenhang zwischen dem klinischen Befund und dem neutrophilen Blutbilde festgestellt haben. In den drei letzteren Fällen fehlte diese Harmonie, im Gegenteil, wir bemerkten hier einen bedeutenden Widerspruch, besonders im Falle Nr. 26 und in der Miliartuberkulose Fall Nr. 37, wo eine hervorragende Anisohypozytose zu erwarten war.

Die zweimaligen Untersuchungen betreffen 35 Kranke, von denen sich $5 \mathrm{im}$ I. Stadium, $13 \mathrm{im}$ II. Stadium und $17 \mathrm{im}$ III. Stadium befanden. Sie wurden aus dem Grunde unternommen, um sich zu überzeugen, ob die Veränderungen in Blutbilde dem klinischen Ver- 
laufe entsprechen und sind in Zeiträumen von 2 bis 6 Monaten angestellt. Bei 4 von 5 Fällen im I. Stadium bestätigen wir, wie dies aus der Tafel ersichtlich ist, eine vollkommene Übereinstimmung mit dem klinischen Verlaufe in der Bedeutung, dass bei einem Kranken (Nr. 55) die Besserung des Blutbildes Hand in Hand mit der Besserung des Allgemein- und Lungenzustandes ging, bei 2 Kranken (Nr. 62, 76) sich das Blutbild in den normalen Grenzen oder im Übergangszustande hielt, bei einem endlich (Nr. 68) die Krankheitsverschlimmerung der unbedeutenden Verschlechterung des Blutbildes, bei einer Temperaturerhöhung nach einer vorherigen langen, fieberlosen Zeit, entsprach. Bei der letzten Kranken konnten wir diese Harmonie nicht bestätigen. Diese Kranke, Nr. 65, erwies bei unbedeutenden Veränderungen in der linken Lungenspitze (ohne Sputum und Bazillen) am Anfange der Behandlung; sowie bei einer ausgezeichneten Besserung, der sie nach einem mehrmonatlichen Verweilen in der Anstalt genoss, in den Blutbildern, die in einer Zwischenzeit von $3 \frac{1}{2}$ Monaten gefunden wurden, fast gar keine Veränderungen. Wir sehen nämlich, dass sich das Blutbild kaum um 5\% nach rechts in der I. und II. Klasse verschoben hatte. Wenn wir die Einzelheiten, die den Allgemein- und Lungenzustand betreffen, in Betracht ziehen, so werden wir zur Überzeugung kommen, dass diese Kranke im allgemeinen ein viel besseres Blutbild besitzen sollte, da sie kaum ein um 2 bis $7 \%$ besseres Blutbild besass als der Kranke mit Miliartuberkulose 3 Tage vor dem Tode.

Bei Kranken des II. Stadiums, bei denen die Untersuchungen zweimal vollführt wurden und welche 13 Kranke umfassten, fanden wir in 10 Fällen die Übereinstimmung des Blutbildes mit dem klinischen Verlaufe. Dieser Vorgang stellt sich beim speziellen Besprechen dermassen dar, dass in einem Falle, Nr. 73, die Verschlechterung des Blutbildes der Verschlimmerung des Krankenzustandes, sowie dem Krankheitsverlaufe parallel war. Bei den 6 folgenden Kranken haben wir dieselbe Gleichmässigkeit bezüglich der Besserung beobachtet, die, wie aus der Tafel $(52,53,57,64,67,81)$ ersichtlich, sich durch die Verschiebung des Bildes nach rechts in den Grenzen von 5 bis $19 \%$ in I. und II. Klasse ausdrïckte. Bei den 3 nächsten Kranken überschritten die Veränderungen im Blutbilde in keinem Falle die Schwankungen von $5 \%$ in der I. und II. Klasse $(50,54,63)$.

Deshalb nehmen wir an, dass sich in der zweiten Untersuchung ihr Blutbild im statu quo bezüglich der ersten Untersuchung befindet. Klinisch stellten sich die Kranken folgendermassen dar, dass der erste von ihnen (Nr. 50) wirklich keine leränderung in dem 
Gesundheitszustande erlitt, der zweite, Nr.63, eine Verschlimmerung und der dritte, Nr. 54, eine Besserung zeigte. Das Eine wie das Andere ging nicht allzusehr deutlich von statten und es konnte, unserer Meinung nach, sich fast gar nicht in dem Blutbilde der Krianken ausprägen.

Wir können dagegen keine Übereinstimmung bei den letzten 3 Kranken gewabr werden, deshalb wollen wir diese Fälle einzeln besprechen.

Bei der Kranken Nr. 69, die nach mehrmonatlicher Kur eine bedeutende Besserung genoss, wiesen wir eine Verschiebung des Bildes nach links in der I. und II. Klasse nur um $2 \%$ nach. Hier würden wir also vergebens eine Übereinstimmung suchen. Wir können diesen Umstand durch die Infektion der Gallengänge erklären, da die Kranke schon jahrelang an Chotelithiasisanfällen litt; überdies sei noch bemerkt, dass trotz einer bedeutenden Besserung des Allgemeinzustandes, sowie der Gewichtszunahme, der subfebrile Zustand sich fortwährand erhielt, bisweilen $37,6 \%$ und von Zeit zu Zeit noch mehr erreichend.

Auf diese Weise könnten wir diesen Fall mit den Faktoren, von denen wir eben gesprochen haben, erklären. In den zwei folgenden Fällen finden wir keine solche Faktoren, somit sehen wir die bezüglichen Bilder als im grellen Widerspruche mit dem klinischen Verlaufe stehend an. Bei dem Kranken Nr. 49 gewahren wir im ganzen rechten Lungenlappen deutliche Veränderungen mit einem Herde unterhalb der rechten Schulterblattgräte mit krepitierenden Rasseln. In der linken Lunge haben wir unbedeutende Atemveränderungen an der Spitze. Der allgemeine Ernährungszustand ist schlecht, das Fieber hebt sich bis $38^{\circ}$, später jedoch schwindet es fast gänzlich. Unterdessen erwies die zum erstenmale nach der Ankunft angestellte Intersuchung, wie aus der Tafel ersichtlich ist, $57 \%$ in der I. und II. Klasse, während die zweite Untersuchung bei einer bedeutenden Besserung des Allgemein- und Lungenzustandes sowie einer Gewichtszunahme ron $11 \mathrm{~kg}$ eine Bildrerschiebung um $15 \%$ nach links zeigt. Was hier aber ins Gewicht fällt, ist, dass diese hervorragende Besserung Merkmale einer dauernden trug, da sie, wie uns bekannt ist, längere Zeit (ein Jahr) währte. Die weiteren Schicksale dieses Kranken sind uns fremd geblieben.

Das Blutbild kann also selbst auf die Art, wie es Arneth will, dass es zuweilen ein Vorbote einer später folgenden Verschlechterung des Gesundheitszustandes eines gegebenen Kranken ist, nicht erklärt werden. Ebenso ist das, die Kranke Nr. 78 betreffende Bild für uns unverständlich. Die Iiranke kam am 1. VIII. 08 in 
das Sanatorium mit unbedeutenden Veränderungen in der rechten Spitze und grösseren in dem oberen linken Lappen, bei einem subfebrilen Zustande; der Ernährungszustand war nicht sehr schlecht, in dem Sputum wurden zahreiche Bazillen und elastische Fasern gefunden. Nach einmonatlichem Aufenthalte zeigte sich eine deutliche Verschlechterung des Allgemein- und Lungenzustandes, die Temperatur überschritt $39^{\circ}$, in dem Harne wurde Eiweiss gefunden. Im Oktober ist der Zustand ein noch viel schlechterer, die Temperatur erreicht ohne Remissionen $40^{\circ}$, wobei die Harnuntersuchung neben zahlreichen Leukozyten granulierte Harnzylinder und tuberkulöse Bazillen nachweist, was deutlich eine Komplikation seitens der Harnwege bezeugt. Die Kranke verlässt in einem vollends hoffnungslosen Zustande die Anstalt im Oktober. Die erste in der Mitte September, sowie die zweite in der Mitte Oktober angestellte Blutuntersuchung, also dann, als schon die Tuberkulose der Harnorgane festgestellt war, stimmte in der Zusammenstellung mit den Bildern anderer unserer Kranken ebenfalls mit dem klinischen Befund nicht überein, sie erwiesen nämlich kaum 70 und $73 \%$ in der I. und II. Klasse.

In dem III. Stadium besitzen wir 17 Kranke, bei denen wir die Untersuchungen zweimal, in Zwischenräumen von 1-3 Monaten angestellt hatten. Bei 11 Kranken finden wir die Harmonie, bei 6 dagegen nicht. Bei 2 von diesen 11 Kranken (Nr. 74, 75), wie dies aus der Tafel ersichtlich ist, treffen wir vorübergehende Blutbilder, von denen Nr. 7丂 im Verlaufe der Krankheit kleiner Veränderung unterlag (Verschiebung um $6 \%$ nach links); bei dem zweiten Kranken erfolgte eine mässige Verschlimmerung, die sich durch eine Verschiebung des Bildes um 12\% nach links in der I. und II. Klasse kennzeichnete, was in jener Zeit ganz dem Befinden des Patienten entsprach.

Bei 9 weiteren Kranken hatten wir mit schlechten oder sehr schlechten BIntbildern, die bei zweien $(60,79)$ das status quo behielten, was mit dem klinischen Befunde und dem Verlauf übereinstimmte; bei vieren $(58,66,71,72)$ mit mässiger Besserung zu tun, die einem solchen Kurergebnis entsprechen; dies bezieht sich besonders auf die Kranken Nr. 66, 71 (s. Tafel), welche trotz grosser Veränderungen in den Lungen (ein grosses Infiltrat in beiden Lungen in dem einen, eine grosse "vertrocknende" Kaverne in dem zweiten Falle) das Fieber verloren, an Gewicht zunahmen und einer deutlichen Besserung des Allgemeinzustandes sich erfreuten.

Bei 3 weiteren Kranken entspricht die Verschlechterung in den Lungen einer geringen oder mässigen Verschlechterung des Blutbildes; wir halten es nicht für nötig, uns länger dabei aufzuhalten (s. Nr. 56, 59, 70). 
Die 6 übrigen Kranken dieses Stadiums werden wir, da sie eine grössere oder kleinere Uneinigkeit zwischen dem Blutbilde und dem Krankheitsverlaufe sehen lassen, einzeln mit einigen Worten besprechen.

Wir finden z. B. bei der Kranken $\mathrm{Nr}$. 51, die, wie dies aus der Tafel ersichtlich, einen vorübergehenden Blutzustand besitzt, trotz einer bedeutenden Besserung in dem Allgemein- und Lungenzustande nach einer 3 monatlichen Kur, keine deutlichen Veränderungen im Blutbildzustande. Dasselbe kann in Vollständigkeit von 2 Kranken (Nr. 77 und 47) gesagt werden, bei denen das Blutbild keine Veränderungen erlitt, trotz einer hervorragenden Besserung des Allgemeinund Lungenzustandes, zumal andererseits ein gänzlicher Fieberverlust erfolgte. Um so mehr fällt noch diese Unstimmigkeit bei dem Kranken (Nr. 48) auf, wo das Blutbild nicht nur nicht sein status quo behielt, wie in den vorigen Fällen, sondern es sich deutlich verschlechterte; auf diese Weise stand es im Gegensatz zu den klinischen Erscheinungen, die zu einer sichtbaren Besserung führten. Wir müssen hinzufügen, dass wir uns auf Grund brieflicher Information seitens dieses Kranken überzeugten, dass die Besserung angehalten hatte. Einen grossen Widerspruch können wir im umgekehrten Sinne bei dem Kranken Nr. 80 betrachten, bei welchem sich der Lungen- und Allgemeinzustand zugleich bedeutend verschlechterte bei einer allmählichen Ausbreitung eines Zerfallprozesses in beiden Lungen, bei dauerndem Vorhandensein von Tuberkelbazillen, elastischer Fasern, sowie der Diazoreaktion, endlich bei einem hohem Fieber, sowie einer vorschreitenden Abzehrung des Organismus. Dagegen zeigt die zweite einen Monat nach der ersten angestellte Blutuntersuchung nicht nur keine Verschlechterung, sondern eine sogar $14 \%$ in der I. und II. Klasse betragende Besserung. Ebenfalls unberechtigt ist der letzte Fall dieser Kategorie, die Kranke Nr. 61 betreffend; jene Kranke verschied nach einer drejmonatlichen Kur in der Anstalt allem Anscheine nach an einer Miliartuberkulose der Lungen, sowie an der Tuberkulose der Nieren, was den Verdacht zulässt, dass die Tuberkulose auch in anderen Organen disseminiert war. Wir bemerken noch, dass bei diesen Kranken ein Lupus der Zunge bestand, der im Jahre 1907 in dem Finsenschen Institute in Kopenhagen mit einem günstigen Erfolge behandelt wurde, aber bei uns dem Lungenzustande parallel sich ebenfalls verschlechterte. Die einige Tage nach der Ankunft, sowie einen Monat später unternommenen Blutuntersuchungen wiesen nach, dass im Augenblicke, wo die Verschlechterung auf der ganzen Linie sichtbar war, das anfänglich vorübergehende Blutbild $(64 \%$ in der 1 . und

I'eiträge zur Klinik der Tuberkulose. Bd. XIV. H, 3. 
II. Klasse) keiner Veränderung unterlag und fast ebenso wie bei der ersten Untersuchung ( $68 \%$ in der I. und II. Klasse) sich darstellte.

Mehrmalige Untersuchungen vollführten wir an 21 Kranken, von denen wir zu dem I. Krankheitsstadium 3 Kranke, zum II. Stadium 11 Kranke, zum III. Stadium endlich 7 Kranke zählen.

In dem I. Stadium stellten wir bei der Kranken Nr. 85 dreimal Untersuchungen an, die ein vorübergehendes Bild erwiesen, was aus der beigefügten Tafel ersichtlich ist.

Wenn wir bei dieser Kranken unbedeutende Veränderungen in den Spitzen sowie den guten Allgemeinzustand in Betracht ziehen, so könnten wir ein normales Bild erwarten. Dennoch berechtigen die öfteren subfebrilen Zustände, sowie die sich wiederholende trockene Pleuritis unterhalb des rechten Schulterblattes mit klassischen subjektiven und objektiven Erscheinungen in einem gewissen Grade diesen vorübergehenden Zustand, welcher zwischen 58-65\% in der I. und II. Klasse schwankt. Die Kranke genoss nach der durchgeführten Kur eine Besserung; das Blutbild veränderte sich jedoch nur unbedeutend. Bei dem Kranken Nr. 92 hatten wir ebenfalls eine dreimalige Blutuntersuchung ausgeführt. Dieser Kranke war am Ende des Jahres 19064 Monate lang in nnserer Behandlung. Er machte weiter eine Kur in Reichenhall und Meran während beinahe 8 Monaten des Jahres 1907 durch, hierauf verweilte er vom Ende August 1907 bis Ende April 1908 in unserem Sanatorium. Zwischen der ersten Untersuchung im Jahre 1906 und der folgenden im April 1908 im Augenblicke, wo gleichfalls Blutuntersuchungen vorgenommen wurden, war ein auffallender Unterschied hinsichtlich der Gesundheitsbesserung vorhanden. So zeigt auch das erste Blutbild vom 14. IV. 1908 normale Verhältnisse. Der Kranke verliess am Tage der Blutuntersuchung die Anstalt und verweilte während $5^{1 / 2}$ Monaten fast ausschliesslich in Warschau, so dass wir nach seiner Rückkehr in die Anstalt eine unbedeutende Verschlechterung in den Lungen, aber eine deutliche Verschlechterung des Allgemeinzustandes und einen Gewichtsverlust von $3 \mathrm{~kg}$ feststellten. Die einige Tage nach der Ankunft angesteliten Untersuchungen erwiesen $62 \%$ in der I. und II. Klasse, das heisst eine Bildverschiebung um $11 \%$ nach inks, was aber in Einklang mit den klinischen Erscheinungen stehen würde. Die nach dreimonatlicher Behandlung wiederum angeordnete Blutuntersuchung erwies eine deutliche Besserung des Bildes - das Bild verschob sich um $13 \%$ nach rechts -, was dem ganzen klinischen Verlauf entspricht, welcher sich durch eine Besserung in den Lungen, sowie durch eine deutliche Besserung im Allgemeinzustande mit einer Gewichtszunahme von $4 \mathrm{~kg}$ auszeichnete. 
An dem Kranken Nr. 100 unternahmen wir 5 mal die Blutuntersuchungen. Wir werden nur die erste sowie die letzte, die das Resultat der Behandlung ausdrücken, besprechen. Der drei mittleren werden wir an einer anderen Stelle, beim Besprechen des Tuberkulins, Erwähnung tun. Wir bestätigen die Gleichläufigkeit, welche bei diesem Kranken zwischen den Resultaten der Klinik und der Blutbildbesserung bestand, und die sich durch die Verschiebung des Bildes um $17 \%$ in der I. und II. Klasse nach rechts ausdrückte, ungeachtet, dass das Bild anfänglich schon normal war.

In dem II. Stadium besitzen wir 11 Kranke, bei denen die Blutuntersuchungen mehrmals unternommen wurden.

Der Kranke Nr. 84. - Wir müssen bemerken, dass bei diesem Kranken während seines sechsmonatlichen Aufenthaltes im Sanatorium periodisch eine Besserung bestand, abwechselnd eine Verschlechterung der Lungen wie auch des Allgemeinzustandes vorkam, schliesslich aber das Resultat auf keinen Fall einer Besserung entsprach. Die 3 während $3^{1 / 2}$ Monaten unternommenen Untersuchungen veranschaulichen diese Veränderungen, obgleich sie unbedeutende Schwankungen darstellen. Schlechte Blutbilder entsprechen schliesslich einem ernsten Zustande des Kranken.

Der Kranke Nr. 94. - Wir können von ihm fast dasselbe sagen, wie von ersterem, jedoch mit dem Unterschiede, dass sein Lungenzustand ein leichterer und das Blutbild besser war. Wie aus der Tafel ersichtlich ist, wurde dem Blutbilde eine kleine Besserung zuteil, was mit der Temperaturherabsetzung des Kranken in dieser Zeit, mit der Gewichtszunahme und mit Besserung des Lungenbefundes übereinstimmen würde. Gleichzeitig erfuhr auch eine vor 4 Monaten operierte Fistula ani einer Besserung, die von Zeit zu Zeit ein eitriges Sekret aussonderte.

Der Kranke Nr. 90, 9 Jahre alt. - Wir sehen bei diesem Kranken, dass das Blutbild sich im Augenblicke seines besten Lungen- und Allgemeinzustandes besserte, die nach einer 4monatlichen Kur die Hoffnung einer Heilung gaben. Einige Tage darauf erschien plötzlich eine bedeutende Verschlimmerung mit einer Verbreitung des tuberkulösen Prozesses, sowie mit Komplikationen seitens des Peritoneums, des Perikardiums sowie der Pleura. Mit einem Worte, wir hatten es mit einer Miliartuberkulose zu tun. Das Blutbild zeigte zu jener Zeit eine bedeutende Verschlechterung mit einer Verschiebung um $24 \%$ in der I. und II. Klasse nach links.

Dasselbe lässt sich von dem Kranken Nr. 98 sagen, bei dem die 4 mal unternommenen Untersuchungen eine fortwährend vorschreitende 
Blutbildverschlechterung erwiesen. Da der klinische Verlauf während der ersten zwei Monate gut war und der Kranke eine Besserung genoss, so erklären wir das dennoch verschlechterte, um $10^{\circ} \%$ in der I. und II. Klasse verschobene Blutbild (dritte Untersuchung) durch eine Komplikation (Pleuritis). Die vierte mit einem noch mehr beschädigten Bilde (eine im Verhältnis zu der dritten um $7 \%$ grössere Verschiebung nach links) vollführte Untersuchung lief der seit der zweiten Untersuchung vorschreitenden Verschlimmerung gleich. Wie wir erfahren haben, starb der Kranke einige Tage nach dem Verlassen der Anstalt.

Der Kranke Nr. 102. -- Wir können von ihm folgendes sagen. Wir zählten ihn zwar zu dem II. Stadium auf Grund physikalischer Veränderungen nach der Klassifikation Turbans, obgleich wir es mit einem Kranken zu tun hatten, der äusserst guten Ernährungszustand besass, mit einem bis zu $90 \mathrm{~kg}$ reichenden Gewicht, sowie einem fieberlosen Zustande; wir sollten also ein besseres Bild, als es hier der Fall ist, erhalten. Wir erklären die Abweichung dadurch, dass wir bei ihm stets, während des 10 monatlichen Verweilens im Sanatorium, zahlreiche Bazillen im Sputum neben reichlichen elastischen Fasern fanden, was auf einen ständigen infektiösen Herd im Organismus weist.

Der Kranke Nr. 97. - Wie aus der Tafel ersichtlich ist, genoss cler Kranke eine grosse Besserung, die um so grösser ist, wenn wir das Bild IV mit dem I. vergleichen. Wir gewahren hier eine Verschiebung des Bildes um 35\% in der I. und II. Klasse nach rechts. Wie wir sehen, stimmt dieses Blutbild mit dem Krankheitsverlauf gänzlich überein.

Die erste Untersuchung wurde kurz nach dem Auftreten einer exsudativen Pleuritis (bei so drohenden Symptomen, wie wir sie nur beim schweren Typhus sehen), mit einem bis $z u \quad 40^{\circ}$ und höheren Fieber, sowie bei einer augenblicklichen Bewusstlosigkeit unternommen, so dass er während 2 bis 3 Wochen zwischen Leben und Tod hing. Nach der Krise folgte eine langsame Rückkehr zur Gesundheit, was auch auf das Blutbild nicht ohne Einfluss geblieben war. Wir sehen nämlich in dieser Zeit eine Verschiebung des Bildes um $15 \%$ nach rechts. Nach einer längeren Behandlung erfolgte eine ausgezeichnete Besserung des Lungen- und Allgemeinzustandes, die sich in der bedeutenden Besserung des Blutbildes - $50 \%$ in der I. und II. Klasse anstatt $85 \%$ - wiederspiegelt.

Die zwei folgenden Kranken (Nr. 87 und 89) wollen wir zusammen besprechen, weil ibre Blutbilder in ungefähr gleichem Yer- 
hältnis zu dem Krankheitsverlauf stehen. Wir sehen, dass die Blutbilder sich einmal bessern und einmal verschlechtern, obgleich sich der Allgemeinzustand rerbessert. Dagegen sehen wir in den Lungen, unabhängig von der augenblicklichen Besserung, hartnäckige Herde, die von Zeit zu Zeit mehr aktiv werden, da wir durch nichts berechtigte Temperaturerhöhungen bemerken, unabhängig noch von der von Zeit zu Zeit entstehenden Pleuritis sicca. Mit einem Worte, befindet sich die Veränderlichkeit des Blutbildes in relativer Harmonie mit dem schwankenden Krankheitsverlanfe.

Der Fall Nr. 86, wie aus der Tafel ersichtlich, hat viel schlechtere Blutbilder als die zwei vorigen, die von uns, unserer Terminologie nach, zu den schlechten gezählt wurden. Die erste Untersuchung wurde 10 Tage nach der Ankunft der Kranken vollführt, als nach mehrmaligen Fäzesuntersuchungen eine Darmtuberkulose festgestellt wurde, neben Veränderungen II. Grades in den Lungen. Das aus dieser Zeit herrührende Blutbild stellt $83 \%$ in der I. und II. Klasse dar. Es fängt eine rasche Besserung in den Lungen und im Darmkanal an. Das Blutbild verbesserte sich innerhalb eines Monats um $11 \%$. Von nun an schreitet die Besserung rasch vor, so dass nach 3 Wonaten die Kranke $10 \mathrm{~kg}$ an Gewicht zunahm. Während dieser 3 monatlichen Frist wurden in Fäzes die Koch schen Tuberkelbazillen nicht vorgefunden. Die Erscheinungen seitens des Darmes schwinden gänzlich, in den Lungen eine deutliche Besserung. Die Blutuntersuchungen im Januar geben uns unerwartete Resultate, wiederum $83 \%$ in der I. und II. Klasse. Ein solches Blutbild schien uns zuerst paradox zu sein, bisweilen verschlechterte sich plötzlich nach mehreren Wochen das Befinden der Patientin, die Temperatur, die bisher fast normal war, fing an, sich zu erhöhen und erreichte einen febrilen oder subfebrilen Status. Die Erscheinungen seitens der Därme verschärfen sich. Die Fäzesuntersuchungen erweisen Tuberkelbazillen. Ein solcher Verschlimmerungszustand erhält sich weiter. Womit man diese Wendung in dem Gesundheitszustande der Kranken begründen soll, wissen wir nicht.

Es handelt sich für uns nur darum, dass in diesem Falle das Blutbild wirklich jene Warnung darstellte, die die Arnethsche Behauptung bestätigte, dass nämlich das Blutbild ein Index, bei augenscheinlich guten klinischen Symptomen, für eine in nächster Zukunft folgende Verschlimmerung sein kann.

Bisher sehen wir eine gänzliche Übereinstimmung zwischen dem klinischen Verlaufe und den die Kranken dieser Gruppe betreffenden Bildern. Bei zwei übrigen Kranken fehlt diese Einigkeit. Wir werden dieselben einzeln besprechen. 
Der Kranke Nr. 83 genoss nach mehrmonatlichem Aufenthalte im Sanatorium eine deutliche und, wie uns aus brieflicher Nachricht bekannt ist, eine dauernde Besserung des Lungen- und Allgemeinzustandes, während das schlechte Blutbild, wie aus der Tafel ersichtlich ist, bis zum Ende seines Verweilens im Sanatorium sich erhielt. Der zweite Kranke Nr. 96 kam zu uns mit einem hohen Fieber $\left(39,4^{\circ}\right)$ und in einem solchem Allgemeinzustande, der, bei deutlichen Veränderungen in den Lungen, das ein Monat nach der Ankunft gefundene Blutbild, welches $85 \%$ in der I. und II. Klasse betrug, rechtfertigen würde. Um so mehr, als der dreimonatliche Krankheitsverlauf nicht regelmässig war, bei Rezidiven eines ziemlich hohen Fiebers. Ausserdem hatte der Kranke 10 Tage nach der ersten Blutuntersuchung ungefähr ein Wasserglas Hämoptöe. Vermittelst dieser Faktoren kann man noch das schlechtere II. Blutbild erklären, zumal der Kranke eine akute Mageninfektion durchmachte. - Bis jetzt lässt sich das Verhalten des Blutbildes erklären. Hierauf fängt allmählich sich der Lungen- und Allgemeinzustand des Kranken an zu bessern (die Gewichtszunahme beträgt bis zu der dritten Untersuchung $5,5 \mathrm{~kg}$ ), es folgt ein vollständiger Fieberverlust, aber das Blutbild zeigt immer noch $80 \%$ in der I. und II. Klasse. Wir könnten vielleicht, den Fall Nr. 86 vergleichend, dieses Blutbild als ein Vorzeichen naher Verschlimmerung ansehen. Indessen erweisen eingehende ärztliche Untersuchungen, dass dieser Kranke (Nr. 83) in der zweimonatlichen Pause seit der letzten Untersuchung nicht nur an seiner Gesundheit keine Verschlimmerung erlitt, sondern umgekehrt seine Besserung andauernd und fortwäbrend fortschreitend war.

Im III. Stadium besitzen wir 7 Kranke, bei denen wir mehrmalige Untersuchungen vollführten. Der Kranke Nr. 99 besitzt, wie aus der Tafel ersichtlich ist, schlechte oder sehr schlechte Blutbilder, was dem Lungenzustand (in beiden Lungen Kavernen), dem hohen Fieber, einer allgemeinen Abschwächung des ganzen Organismus, Diazoreaktion usw. entsprach. Wir haben hier aber nichts Besonderes, was eine nähere Betrachtung fordern würde.

Die Kranke Nr. 93. - Diese Kranke zeigte, obgleich sie, wie der vorherige Fall, zum III. Stadium gezählt wurde, einen bedeutend besseren Lungen- und Allgemeinzustand. Während der Kur fiel das Fieber zur normalen Temperatur oder subfebrillem Zustande herab; sie erhielt nach einer mehrmonatlichen Behandlung eine relative Besserung in dem Lungen- und Allgemeinzustande, diesem entspricht die Blutbildbesserung während der I. und III. Untersuchung, in fast vier- 
monatlichem Zeitraume, welche sich in einer Verschiebung des Bildes um $12^{\circ}, 0$ in der I. und II. Klasse nach rechts ausdrückt.

Der Kranke Nr. 82. - Dieser Fall ist aus dem Grunde interessant, da der Kranke sich bei uns im Jahre 1906 durch den ganzen Sommer aufhielt, nicht bedeutende Veränderungen in der linken Lungenspitze hatte und dabei weite Bronchiektasien erwies; in der reichlichen Sekretion wurden niemals Tuberkelbazillen gefunden, der Allgemeinzustand ist gut und fieberlos. Im April 1907 wurde nach der nochmaligen Ankunft des Kranken eine grosse Kaverne in dem ganzen oberen linken Lungenlappen von vorne festgestellt, bei einem sehr schlechten Ernährungszustande, einem hohen Fieber, deren Exazerbationen stets von einem Schüttelfrost begleitet waren. In dem massenhaft und fortwährend ausgeschiedenem eitrigen Sputum wurden Mengen von Kochschen Tuberkelbazillen und elastischen Fasern gefunden. Der Allgemein- und Lungenzustand verschlechterte sich fortwährend, diesem entsprach wieder die Verschlechterung des Blutbildes, da die in zweimonatlichen $Z$ wischenräumen angestellten Untersuchungen eine Bilderverschiebung nach links um $27 \%$ in der I. und II. Klasse zwischen der, I. und III. Lntersuchung erwiesen.

Der Kranke Nr. 88. Dieser Fall betrifft einen Kranken, der sich im Sanatorium 8-9 Monate aufhielt. Er $\mathrm{kam}$ mit bedeutenden Veränderungen in beiden Lungenspitzen, hohem Fieber, schlechtem Ernährungszustand usw. an. Während 3 Monate genoss er eine vorzügliche Besserung des Lungen- und Allgemeinzustandes, er verlor das Fieber und nahm an Gewicht $10 \mathrm{~kg}$ zu. Dieser $\mathrm{Zu}-$ stand dauerte während weiterer $2^{1 / 2}$ Monate an, als ohne sichtliche Veranlassung plötzlich eine unverhoffte Verschlimmerung eintrat; ein hohes Fieber, Essunlust usw. Diese Wendung führte, innerhalb 2 Monate sich steigernd, zum Exitus letalis, bei einer ständigen Lungenverschlimmerung. Die Blutuntersuchung entsprach vollständig diesem Verlaufe.

Die erste Untersuchung, die nach der plötzlichen Wendung in der Krankheit des Patienten angestellt wurde, erwies schon ein schlechtes Blutbild; 9 Tage vor dem Tode ein sehr schlechtes und 2 Tage vor dem Tode hatte sich das Blutbild noch etwas rerschlechtert, indem es $91 \%$ in der I. und II. Klasse betrug.

Von dem nächsten Kranken Nr. 101 müssen wir bemerken, dass dieser Fall zum Exitus letalis mit Symptomen der tuberkulösen Meningitis führte. Dieser Vorgang drückte sich gleich in dem vom Anfang an schlechten Blutbilde aus und zwar in einem allzu bedeutenden Grade, da wir hier eine Blutverschiebung nach links bei der letzten Untersuchung im Vergleich mit der ersten um kaum $10 \%$ sehen, 
indessen die sichtbaren Verschlimmerungserscheinungen in dem Lungenund Allgemeinzustande, Temperatur usw. schon seit mehr als drei Monaten vor dem Tode datierten. Ausserdem finden wir in den Blutbildern ein Schwanken einmal in der Richtung der Besserung, ein anderes Mal in der Richtung des Verschlechterns, was in dem sich ständig verschlimmernden Zustand des Kranken keine Berechtigung fand. Da die letzte Blutuntersuchung aus von uns unabhängigen Gründen nicht, so wie in dem vorigen Falle, kurz vor dem Tode angeordnet werden konnte, sind wir ausserstande zu begutachten, ob dieser Fall nicht noch bedeutendere Blutbildveränderungen unmittelbar vor dem Ableben des Kranken erfuhr und infolgedessen mit dem klinischen Befunde in Eintracht oder Zwietracht stand.

Die Kranke Nr. 95. - Drei diese Kranke betreffende Untersuchungen erwiesen, dass das anfänglich vorübergehende Blntbild $(68 \%$ in der I. und II. Klasse) bei der zweiten Lntersuchung eine Besserung zeigte, die sich durch das Bildverschieben um $11 \%$ nach rechts ausdrückte. Diese Besserung fiel tatsächlich auf den Zeitpunkt, wo die Kranke, nach einem 5 monatlichen Aufenthalte in der Anstalt, einer vorzüglichen Besserung in dem Lungen- und Allgemeinzustand sich erfreute (Gewichtszunahme $10 \mathrm{~kg}$ ). Von diesem Augenblick fing die Iranke an, zuerst ohne jeden sichtbaren Grund, sich schlechter zu fühlen, auch der Allgemeinzustand fiel ab. Es zeigte sich eine mässige Diarrhöe (2-3 Stuhlgänge täglich). Die mehrmals T'uberkelbazillen im Fäzes nachweisenden Untersuchungen setzten dies auseinander. Der Zustand der Kranken verschlimmerte sich, was in dem damals untersuchten Blutbilde sich getreu abspiegelte. Die Blutbildverschiebung nach links betrug nämlich in diesem Falle $25 \%$ (I. und II. Klasse) im Verhältnis zu der zweiten Untersuchung.

Der Kranke Nr. 91. - Wir werden ihn eingehender besprechen, da im Gegensatze zu den oben erwähnten Fällen dieser Gruppe, die im grossen und ganzen mit den Blutbildern übereinstimmen, bei diesem Patienten eine solche Übereinstimmung nicht festgestellt werden konnte. Der Kranke kam in das Sanatorium in der Mitte des Nonats Juli 1908 mit grossen Infiltraten in den beiden oberen Lungenlappen, vorwiegend in dem linken, mit einem hohen Fieber, in schlechtem Ernährungszustande und mit zahlreichen Tuberkelbazillen im eitrigen Sputum, sowie elastischen Fasern.' Während 3 Monate waren Schwankungen in dem Gesundheitszustande des Kranken vorhanden und zwar einmal in der Richtung der Besserung, ein anderes Mal in der Richtung der Verschlechterung und auf gleiche Weise im Lungen- wie im Allgemeinzustande und der Körperwärme. Im Grunde genommen aber fand keine Besserung in diesem Zeitraume 
statt. Unterdessen erfolgte plötzlich ein linksseitiger Pneumothorax bei drohenden 2 Tage lang dauernden Symptomen: Die 10 Tage nach der Ankunft des Kranken angestellte Blutuntersuchung erwies eine Verschiebung nach links (73\% in der I. und II. Klasse). Die niederum 10 Tage nach dem Pneumothorax unternommene Blutuntersuchung erwies eine Verschlechterung des Bildes hinsichtlich des ersten um $6^{\circ} \%$ (79\% in der I. und II. Klasse).

Bisher befindet sich das Blutbild einigermassen in Einklang mit dem klinischen Verlaufe. Nach der ersten stürmischen Krankheitsphase erfolgte ein Stillstand, daraufhin 5-6 Wochen nach dem Pneumothorax eine Wendung zum Besseren. Diese Besserung des Lungen- und Allgemeinzustandes hält bis zum gegenwärtigen Augenblicke, das heisst $4 \frac{1}{2}$ Monate lang an. Ein sodch glückliches Resultat von Komplikationen mit dem Pneumothorax, der früher als tödlich angesehen wurde, ist heute, dank der Untersuchungen Forlaninis, Brauers, L. Spenglers und Mosheims, Shingus, Graetz und anderer ein bekannter Vorgang. Es kann uns dies also nicht wundern. Aber die dritte Blutuntersuchung, die $2^{1 / 2}$ Monate nach der erfolgten Verbesserung vollführt wurde, erweist nicht nur keine Blutbildbesserung, sondern umgekehrt eine Verschiebung des Bildes um $8 \%$ nach links im Vergleich mit der zweiten Untersuchung und um $14 \%$ im Vergleich mit der ersten. Einen solchen Mangel an Parallelismus könnten wir zwar als das Zeichen einer möglichen, zukünftigen Verschlimmerung ansehen, im Augenblicke aber, wo wir dieses schreiben, erfreut sich der Kranke fast seit 5 Monaten, wenn nicht eines besseren, so auf jeden Fall eines gleichen Gesundheitszustandes, wie im Augenblick der letzten Intersuchung. Vorläufig sind wir ausserstande, in dem gegebenen Falle etwas Sicheres zu behaupten. Wir kennen nämlich selbst bei Arneth lieine analogen Fälle, wo das Blutbild über die Prognose auf eine gleich lange Zeitdauer, wie in unserem Falle, entscheiden konnte ${ }^{1}$ ).

Wir möchten gegenwärtig in einigen Worten die Tuberkulinanwendung besprechen. Wir hatten schon erwähnt, wie sich das Verhalten des neutrophilen Bildes in den Untersuchungen Arneths und Uhls an Kranken, die mit dem Tuberkulin behandelt wurden, darstellt und was für Folgerungen diese beiden Autoren hieraus ziehen. Arneth sieht, wie wir es schon bemerkt haben, mit der Kochschen Schule übereinstimmend, das Tuberkulin als ein in der Tuberkulose par excellence spezifisch wirkendes Mittel an.

1) Siehe analoge Fälle Nr. 24 u. 17 in Zeitschr. für Tubk. Bd. VII. H. 4, Seite 318-325. Tafel auf Seite 317 . 
Zwar wenden auch wir seit mehr als 2 Jahren das Beranecksche $\mathrm{TB}_{\mathrm{K}}$ nach der Methode Sahlis an; wir besitzen schon 60 Kranke die mit dem $T B_{K}$ behandelt wurden, aber unsere Untersuchungen sind noch nicht abgeschlossen. Wir enthalten uns deshalb, allgemeine Schlüsse in dieser Richtung zu ziehen. Wir möchten dagegen kurz bemerken, in welchem Verhältnis die Tuberkulininjektionen in unseren Fällen mit den neutrophilen Bildern standen. Von 102 Kranken, bei denen wir Blutuntersuchungen vollführten, wandten. wir bei 19 Kranken das Tuberkulin an. Drei von dieser Zahl schliessen wir aus, da sie eine zu kleine Injektionenzahl erhielten. Das Resultat der Behandlung der 16 übrigen Kranken stellt sich auf diese Weise dar, dass in 8 Fällen das ganze Behandlungsresultat ohne Veränderung war, bei 3 eine Verschlimmerung und bei 5 eine Verbesserung erfolgte.

Wir können uns von den häufigen Untersuchungen dieser Kranken während der Injektionen keine bestimmte Anschauung bilden, ob wirklich die Tuberkulininjektionen einen negativen Einfluss anf das Blutbild bei Verschlimmerungen ausübten, da wir im Falle einer Übereinstimmung des Bildes in dem Faktum der Verschlimmerung des Krankheitszustandes selbst, den die Verschlimmerung des Bildes hervorrufenden Faktor sehen. Andererseits wieder wissen wir bei der Verbesserung des Lungen- und Allgemeinzustandes mit ebendenselben positiven Veränderungen im neutrophilen Blutbilde nicht, ob wir diese Besserung ausschliesslich auf die spezifische Behandlung oder auf die allgemeine klimatische oder endlich auf alle beiden Behandlungsarten zurückführen sollen.

Wir wollen also nur von dem Zusammenhange, der zwischen den $\mathrm{TB}_{\mathrm{K}}$-Injektionen und dem Verhalten des neutrophilen Blutbildes durch 24 Stunden nach der Injektion besteht, sprechen. Zwecks Aufklärung dieses speziellen Vorganges unternahmen wir bei 2 Kranken mehrmalige nachträgliche Blutuntersuchungen und zwar im Laufe von 24 Stunden nach der Injektion. Die Injektionen nach der Methode Sahlis dürfen, wie uns die klinische Erfahrung lehrt, nicht gleichgültig für die normale Tätigkeit der Zellen bleiben. Die Einführung selbst so kleiner Toxindosen in der Gestalt von $\mathrm{TB}_{\mathrm{K}}$ übt ihren Einfluss auf das biologische Zellenleben aus und zwar während der sogenannten "negativen Phase" oder der Phase der Resorption und Assimilation der Toxine durch den Organismus.

Unsere Untersuchungen bei diesen 2 Kranken zeigen tatsächlich, dass die grössten Veränderungen des neutrophilen Blutbefundes sich 6-8 Stunden nach Injelstion abspielen, wonach das ganze Blutbild allmählich innerhalb 24 Stunden zur Norm zurückkehrt. 
Wir wollen zum Schlusse die Resultate unserer Untersuchungen in kurze Worte zusammenfassen.

In unseren Untersuchungen handelt es sich hauptsächlich, wie wir es am Anfange erwähnten, darum, festzustellen, ob wir neben den unzureichenden Untersuchungsmethoden bei der Tuberkulose zur Orientierung in ihrem Verlaufe und für ibre Prognose bei schweren wie leichteren Formen in den Arnethschen Blutuntersuchungen nicht ein neues Mittel an der Hand haben, das uns eine grössere Gewähr bezüglich der Sicherheit in dieser Richtung leisten würde. Andererseits wollten wir uns überzeugen, ob in einer so par excellence spezifischen Krankheit, wie die Tuberkulose, wirklich Veränderungen in der Polymorphie der Kerne nach der Ansicht Arneths vorkommen, die sich durch das Hinabführen einer differenzierten Kernfigur, unter dem Einflusse von pathogenen Erregern, zu einer mehr einfachen ausdrücken, infolge des massenhaften Verschwindens der ersten reiferen Formen und des Erscheinens anderer jüngerer Formen. Indem wir uns auf die Beobachtung von 102 Kranken stützen, können wir die Arnethsche Behauptung bestätigen, nämlich, dass Krankheitsvorgänge und in dem gegebenen Falle die Tuberkulose, in einem normalen Blutbilde solche Veränderungen herbeiführen, die wir nicht ein einziges Mal bei 10 klinisch als gesund angesehenen Menschen vorfanden. Auf diese Weise würde sich also eine gewisse Regelmässigkeit der Kernformen in gewissen physiologischen oder pathologischen Bedingungen bestätigen. Wenn wir sie aber einzeln betrachten werden, so müssen wir hinzufügen, dass von 102 beobachteten Fällen bei 3 Kranken das Blutbild nicht ganz mit dem klinischen Befund der Kranken übereinstimmte; bei 13 Kranken sahen wir dem Krankheitsverlaufe gegenüber äusserst widersprechende Untersuchungsresultate des neutrophilen Blutbildes. Wir haben diese Fälle an einer anderen Stelle besonders besprochen, aus diesem Grunde wiederholen wir sie nicht. Wir vermerken nur die allgemeinen Resultate. In Rücksicht einer unbedeutenden Anzahl von bewiesenen Unstimmigkeiten müssen wir bestätigen, dass der Arnethschen Methode wahre Tatsachen zugrunde liegen müssen. Wir können nämlich 86 übereinstimmende Fälle nicht auf eine zufällige Gelegenheitszusammenkunft zurückführen. Andererseits berechtigen nnsere Untersuchungen uns nicht solche weitgehende Schlüsse zu ziehen, wie sie Arneth aufstellt, der in dem Blutbilde nicht nur ein bestimmtes Kriterium für den gegenwärtigen Zustand eines gegebenen Kranken, sondern auch ein massgebendes prognostisches Index in den Infektionskrankheiten überhaupt und speziell in der Tuberkulose sieht. 
Die Rechtfertigung einer solchen Behauptung, in einer so genauen und bestimmten Form, haben wir in unseren Fällen nicht gesehen. Es ist leicht möglich, dass öfters und zahlreich an einem und demselben Kranken unternommene Untersuchungen, und an einem reicheren Material von Kranken, auch uns ähnliche Beispiele liefern würden. Die mit der A rneth schen Methode verbundenen technischen Schwierigkeiten, die einen grossen Zeitanfwand erfordern, liessen dies bei uns nicht zu. Wir können also unsere eigenen Schlüsse, welche die prognostische Bedeutung betreffen, nicht endgültig und bestimmt aussprechen. Dagegen führt uns unsere, auf ziemlich zahlreiches Material sich stützende Überzeugung zur Folgerung, dass in den Krankheitszuständen wirklich ein kausaler Zusammenhang zwischen den pathogenen Faktoren einerseits und dem neutrophilen Blutbilde andererseits besteht. Dieser Zusammenhang scheint uns nicht genügend bestimmt zu sein. Es kann sein, dass noch gewisse vermittelnde Glieder in dieser Kette von Ursachen und Folgen fehlen. Aus den Untersuchungen verschiedener von uns angefübrter Autoren sehen wir, dass Infektionskrankbeiten das neutrophile Blutbild und zugleich auch andere Gattungen von weissen Blutkörperchen, wie auch rote Blutkörperchen beeinflussen. Sie berïhren mit einem Worte das $\mathrm{g}$ a $\mathrm{nz}$ e Blutbild in seinen verschiedenartigen Bestandteilen; also nicht die Neutrophilen allein. Diesen Gedanken spricht übrigens Arneth selbst mehrmals ans, besonders bei seinen Untersuchungén über den Krebs und den Experimenten an Tieren. Hieraus folgt, dass nicht die Neutrophilen allein in den Kampf des Organismus mit der Infektion und Intoxikation gezogen werden. Dann noch ein weiterer Schluss, nämlich, dass die Observation ron anderen Gestalten der weissen Körperchen sowie anch der roten Blutkörperchen, die Arnethsche Methode vervollkommnen und ergänzen könnte. Eigene Erfahrung haben wir in dieser Richtung leider nicht. In der riesigen Mehrheit von Fällen (86 auf 102), wie wir es schon besprochen haben, sahen wir das übereinstimmende Verhalten des Arnethschen Bildes mit dem Krankheitsverlaufe, der sich entweder durch eine Besserung oder durcb eine Verschlechterung eines gegebenen Patienten ausdrückt. Wir müssen jedoch bemerken, dass im grossen und ganzen die bezüglichen Besserungen und Verschlechterungen des Blutbildes gewissermassen hinter ebensolchen Veränderungen in den Krankenzuständen zurïckblieben, d. h. sie gingen etwas langsamer und in einem kleineren Umfange vonstatten, was man schon, auf die klinischen Erscheinungen gestützt, voraussehen konnte. Wir können endlich nicht umhin, die Aufmerksamkeit auf die Tatsache zu lenken, dass wir die am meisten charakteristischen 
und bedeutendsten Störungen im Blutbilde bei Lungenkranken mit Komplikationen seitens der Darmtuberkulose sahen.

Dagegen waren die Bilder bei den Kranken mit einer Miliartuberkulose und Meningitis tub. wider Erwarten nicht bedeutend rerschoben. Wir können in gleicher Weise auf Grund unserer Fälle wie auch der Fälle anderer Autoren, die ebenfalls keine Übereinstimmung des Blutbildes in der Miliartuberkulose und Meningitis fanden, roraussetzen, dass speziell in diesen Formen abweichende spezifische Prozesse vorkommen, die unzureichend sich in dem Leben der neutrophilen Zellen abspiegeln. Trotz gewisser Mängel, die die A rnethsche Methode besitzt, sehen wir sie als fähig an zum Erweisen ernster Dienste in der Reihe komplizierter Probleme, die mit der Klinik der Tuberkulose verbunden sind. Obgleich in zweifelhaften Fällen die klinischen Erscheinungen wie bisher entscheidend sind, so geben die Blutuntersuchungen, nach der Methode Arneths, den klinischen Erscheinungen das Gepräge einer grösseren Gewissheit und dienen für diese gewissermassen als Ergänzung.

Wie wir sehen, ist es ein nicht geringes Verdienst Arneths, dass er dank seinem Weitblick als erster die Augen aller von der bisher üblichen Prozentberechnungsmethode jeder Gattung weisser Blutkörperchen, die in der klinischen Anwendung eine ganz untergeordnete Bedeutung hatte, abwandte. Es ist möglich, dass FachHämatologen den Grundsätzen der A rnethschen Methode viel zu entgegnen haben, die, wie der Autor selbst zugibt, sich auf hypothetische Grundlagen stützt. Es ist auch möglich, dass mit der Zeit diese Methode unter dem Einfluss neuer Untersuchungen und einer neuen Beleuchtung der bis jetzt bekannten Tatsachen zahlreichen Cmänderungen unterliegen wird. Dies wird aber auf keinen Fall die Verdienste eines um ihren Fortschritt verdienten Gelehrten schmälern, - der Methode selbst aber zu noch grösserer Bedeutung verhelfen.

\section{Literatur.}

1. J. Arneth, Die neutrophilen weissen Blutkörperchen bei Infektionskrankheiten. (Monographie.) Jena 1904.

2. Derselbe, Zum Verhalten der neutrophilen Leukozyten bei Infektionskrankheiten. Münch. med. Wochenschr. 1904. Nr. 25.

3. Derselbe, Die agonale Leukozytose. Münch. med. Wochenschr. 1904 Nr. 27. 
4. J. Arneth, Experimentelle Untersuchungen zum Verhalten der weissen (und roten) Blutkörperchen bei Infektions- und Intoxikationsversuchen, sowie nach Einverleibung von Eiweisskörpern und Heilseris. Zeitschr. f. klin. Med. 1905. Bd. 57 und Münch. med. Wochenschr. 1904. Nr. 45.

5. Derselbe, Die ,kachektische“ Leukozytose; Verhalten der neutrophilen Leukozyten bei Karzinom. Zeitschr. f. klin. Med. 1904. Bd. 54.

6. Derselbe, Blutuntersuchungen bei der Tuberkulose der Lungen und bei der Tuberkulinkur. Münch. med. Wochenschr. 1905. Nr. 12.

7. Derselbe, Die Lungenschwindsucht auf Grundlage klinischer und experimenteller hämatologischer Untersuchungen. Zeitschr. f. Tub. Bd. VII. H. 4 und 5 .

8. Derselbe, Erwiderung zu Hillers Beiträge zur Morphologie der neutrophilen Leukozyten und ihrer klinischen Bedeutung. Folia Haematol. 1905. Nr. 3.

9. Derselbe, $\mathrm{Zu}$ meinen Blutuntersuchungen (Nachprüfungen, einige weitere Beiträge). Erwiderung zu Flesch und Schossberger. Deut. Arch. f. klin. Med. 1906. Bd. 87.

10a. Derselbe, H. Pollitzers Anschauungen über die Kernbeschaffenheit der neutr. Leukozyten unter normalen und pathologischen Verhältnissen. Wien. med. Wochenschr. 1907. Nr. 9 und 10.

10b. Derselbe, Entgegnung zuH. Pollitzer: zu Arneths Verschiebung etc. etc. Deut. Arch. f. klin. Med. Bd. 94.

10c. Derselbe, Zu H. Pollitzer: Beiträge zur Morphologie und Biologie etc. Folia Haemat. 1908 Bd. VI.

11. Derselbe, Zu Paulićek: zur qualitativen Blutuntersuchung nach der von Arneth angegebenen Methode. Folia Haemat. Supplement. 1907. Nr. 2.

12a. Derselbe, Entgegnung zu Bourmoff und Brugs ch: Das nentr. Blutbild bei Infektionskrankheiten Zeitschr. f. klin. Med. Bd. 64 .

12b. Ders el be, Das neutr. Blutbild bei Infektionskrankheiten. Gegenerwiderung zur Antwort von Th. Brug s ch etc. Zeitschr. f. klin. Med. Bd. 66. Heft 1 u. 2.

13. Derselbe, Diagnose und Therapie der Anämien. 1907. Würzburg. Stuber.

14. Derselbe, Die Leukozytose in der Schwangerschaft etc. und die Leukozytose der Neugeborenen. Arch. f. Gynäkol. 1907. Bd. 74. Heft 1.

15. K. Bochenski, Zuaczenie badania krwi w przypadkach zakaźenia guilnego z uwzgleddieniem neutrofilowego obrazu i bakteryologiernego badania krw. Typ. Lek. 1908. Nr. 45-48 (inkl.).

15a. Derselbe, Die Bedeutung der Blutuntersuchungen in den Fällen der septischen Infektion mit Berücksichtigung des neutr. Blutbildes u. der bakteriologischen Blutuntersuchungen (aus der Lemberger Gynäkol. Klinik). Lemberg. med. Wochenschr. 1908. Nr. 45-48 (inkl.).

16. O. Burkard, Das neutrophile Blutbild im physiologischen und pathologisehen Wochenbette und seine Veränderungen unter der Streptokokkenserumwirkung. Arch. f. Gynäkol. 1907. Bd. 80. Heft 3.

17. Th. B ourmoff und 'I'h. Brugs ch, Das neutrophile Blutbild bei Infektionskrankheiten. Zeitschr. f. klin. Med. 1907 Bd. 63, Heft 5 u. 6.

18. Th. Brugsch, Das neutr. Blutbild bei Infektionskrankheiten, eine Antwort auf Arneth s Entgegnung etc. etc. Zeitschr. f. klin. Med. Bd. 64.

19. R. Du nger, Das Verhalten der Leukozyten bei intravenösen Kollargolinjektionen und seine klinische Bedeutung. Deutsch. Arch. f. klin. Med. 1907. Bd. 91.

20. Esser, Das neutrophile Blutbild beim natürlich und künstlich ernährten Säugling. Münch. med. Wochenschr. 1906. Nr. 34. 
21. M. Franke, Über den Einfluss der Röntgenstrahlen auf den Verlauf der Leukämie (mit besonderer Berücksichtigung der Blutbefunde). Wien. klin. Wochenschr. 1905. Nr, 33.

22. Flesch und A. Schossberger, Die Veränderungen des neutrophilen Blutbildes bei Infektionskrankheiten. Jahrb. f. Kinderheilkunde 1905. Bd. 62 . Heft 3. N. H.

23. Dieselben, Die Veränderungen des neutr. Blutbildes im Inkubationsstadium von Masern. Ibidem 1906. Bd. 64. Heft 3. N. F.

24. C. Funck, Zum Verständ̉nis der Besserung der Leukämie durch interkurrente Infektion. Berl. klin. Wochenschr. 1906. Nr. 40.

25. E. Gräfenberg, Die prognostische Bedeutung der morphologischen Blutelemente bei puerperalen Erkrankungen. Arch. f. Gynäkol. 1908. Bd. 85. Heft 2.

26. E. Grawitz, Klinische Pathologie des Blutes. 1908.

27. F. Hiller, Beiträge zur Morphologie der neutrophilen Leukozyten und ibrer klinischen Bedeutung. Folia Haematol. 1905. Nr. 2.

27a. Pappenheim, Einige Bemerkungen zu vorstehenden Artikel. Ibidem.

28. Kownatzki, Blutuntersuchungen bei Puerperalfieber. Beiträge zur Geburtshilfe und Gynäkol. 1906. Bd. 10. Heft 2.

29. K a ufma nn, Unsere Erfahrungen mit Serum Marmorek. Beiträge zur Klin. der Tub. Bd. XI.

30. Kothe, Das neutrophile Blutbild im Frühstadium der akuten Appendizitis. Berl. klin. Wochenschr. 1908. Nr. 36.

31. St. Lewinson, Spostrezenia nad neutrofilowymi lenkocytami aw niektórych sprawach chorobowych. Pamietnik Tow Lek. Warsr. 1908. T. 104.

31a. Derselbe, Beobachtungen über neutrophile Leukozyten in einigen Krankheiten. In Memoiren der Warschauer Med. Gesell. 1908. Bd. 104.

32. H. Pollitzer, Über Arneths Verschiebung des neutr. Blutbildes. Wien. Med. Wochenschr. 1906. Nr. 18 u. 19.

33. Derselbe, Zu Arneths Verschiebung des neutr. Blutbildes. Deut. Arch. f. klin. Med. 1907. Bd. 92. Heft 1 und 2.

34. Derselbe, Beiträge zur Morphologie und Biologie der neutrophilen Leukozyten. Zeitschr. f. Heilkunde 1907.

35. E. Pa uliček, Zur qualitativen Blutuntersuchung nach der von A rneth angegebenen Methode. Folio Haemat. 1907. Nr. 6.

36. F. O rland, Beiträge zur Untersuchung des neutrophilen Blutbildes beim gesunden und kranken Säugling. Inaug.-Disser. Bonn 1907/8.

37. Röver, Über 25 mit Marmoreks Serum behandelte Fälle von Tuberkulose. Beitr. z. Klin. der Tub. Bd. V.

38. N. Schneider, Über das Verhalten des Blutes im Verlaufe einer kruppösen Pneumonie bei einem Kranken mit Polycythaemia myelopatica bei welchem die Milz früher exstirpiert wurde. Wien. klin. Wochenschr. 1907. Nr. 27.

39. Uhl, Über die neutrophilen Leukozyten bei der spezifischen Therapie der Lungentuberkulose. Beitr. z. Klin. der Tub. 1906. p. 249.

40. Fr. Weidenreich, Beiträge zur Kenntnis der granulierten Leukozyten. Arch. f. mikr. Anat. 1908. Bd. 72.

41. W. W olf, Die Kernzahl der Neutrophilen, ein diagnostisches Hilfsmittel bei Eiterungen des weiblichen Geschlechtsapparates. Heidelberg 1906.

42. T. Zel enski, Über das Verbalten des neutrophilen Blutbildes bei gesunden und kranken Säuglingen. Wien. klin. Wochenschr. 1906. Nr. 40. 


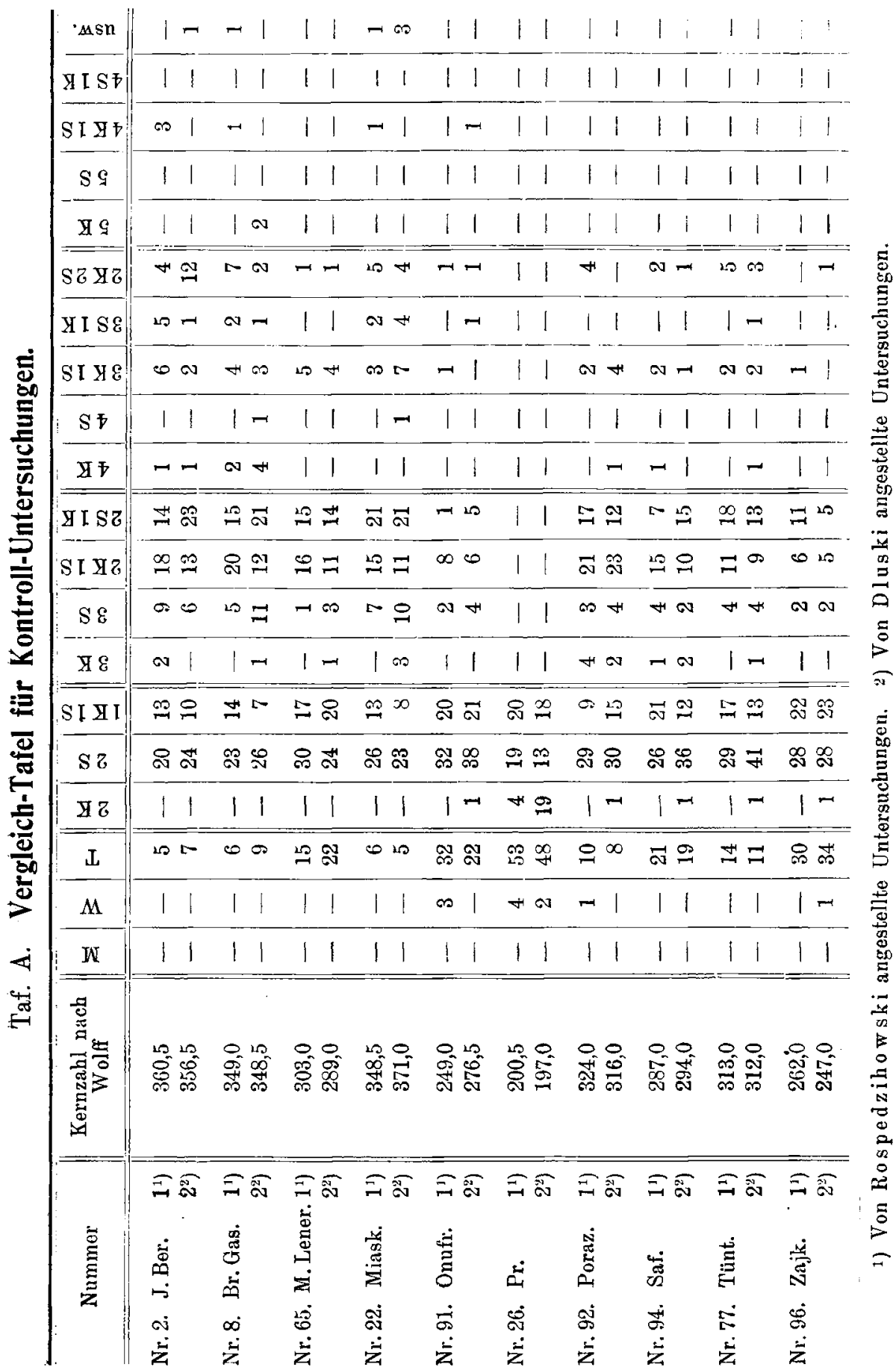




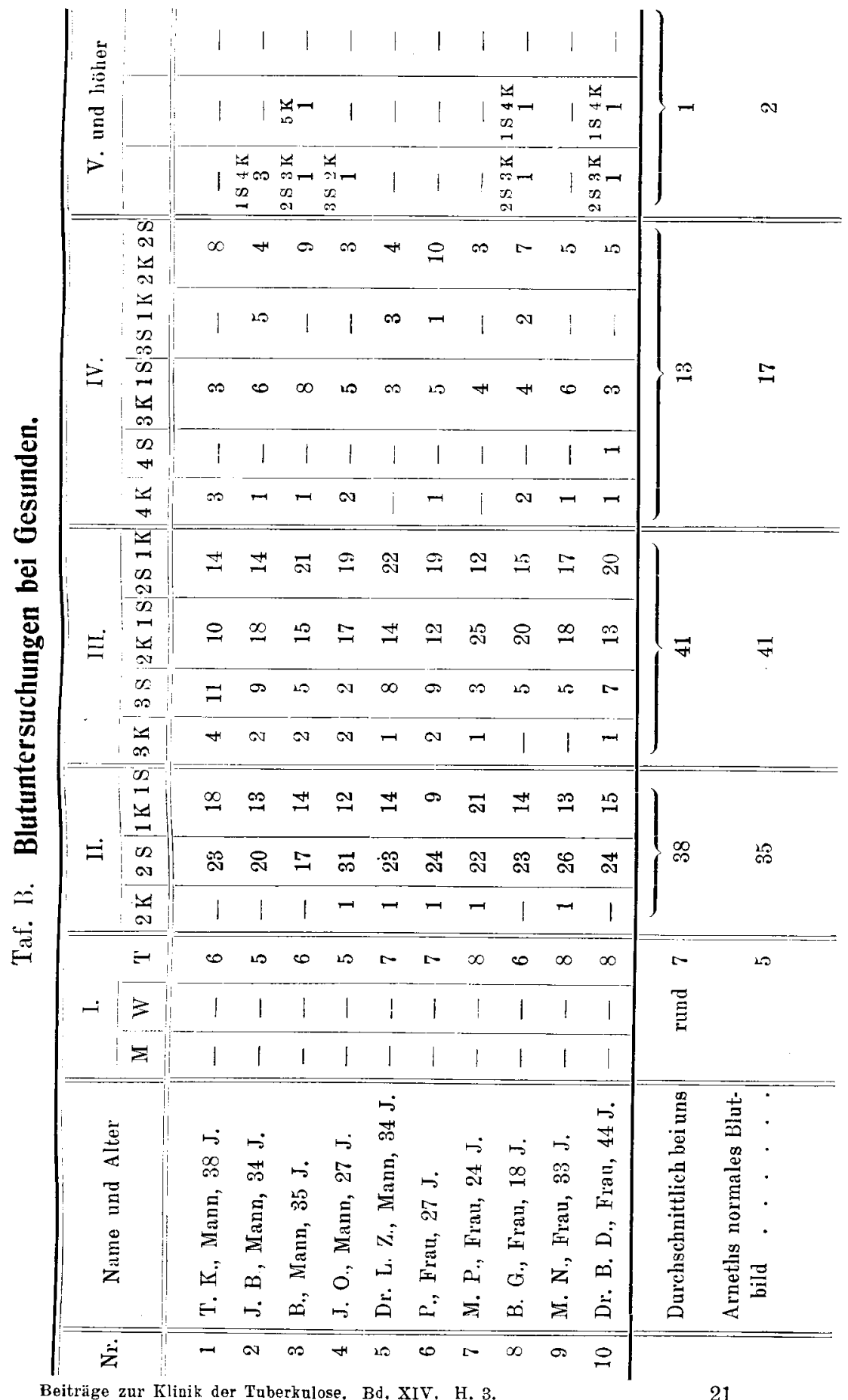

Beiträge zur Klinik der Tuberkulose, Bd, XIV, H. 3. 


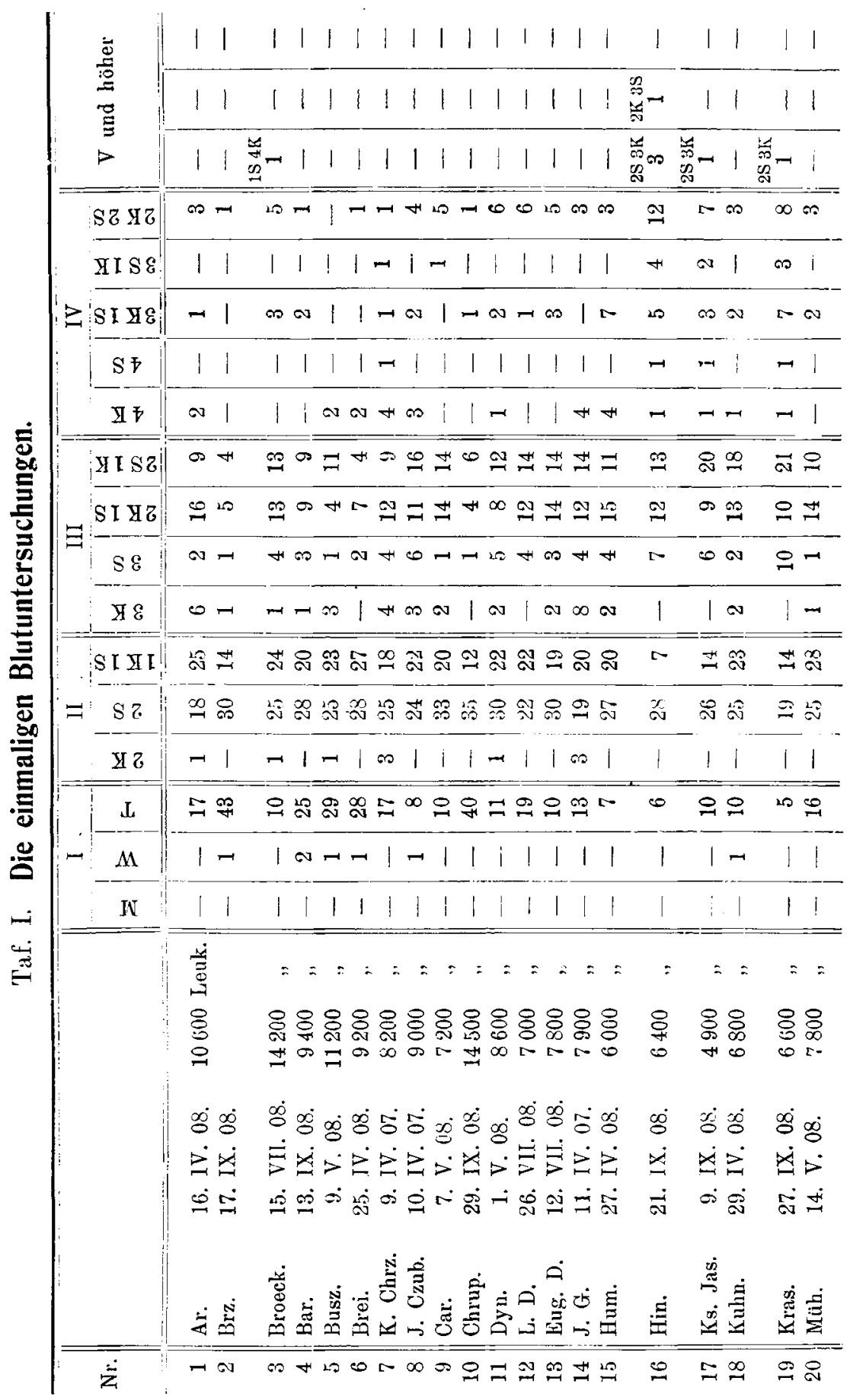




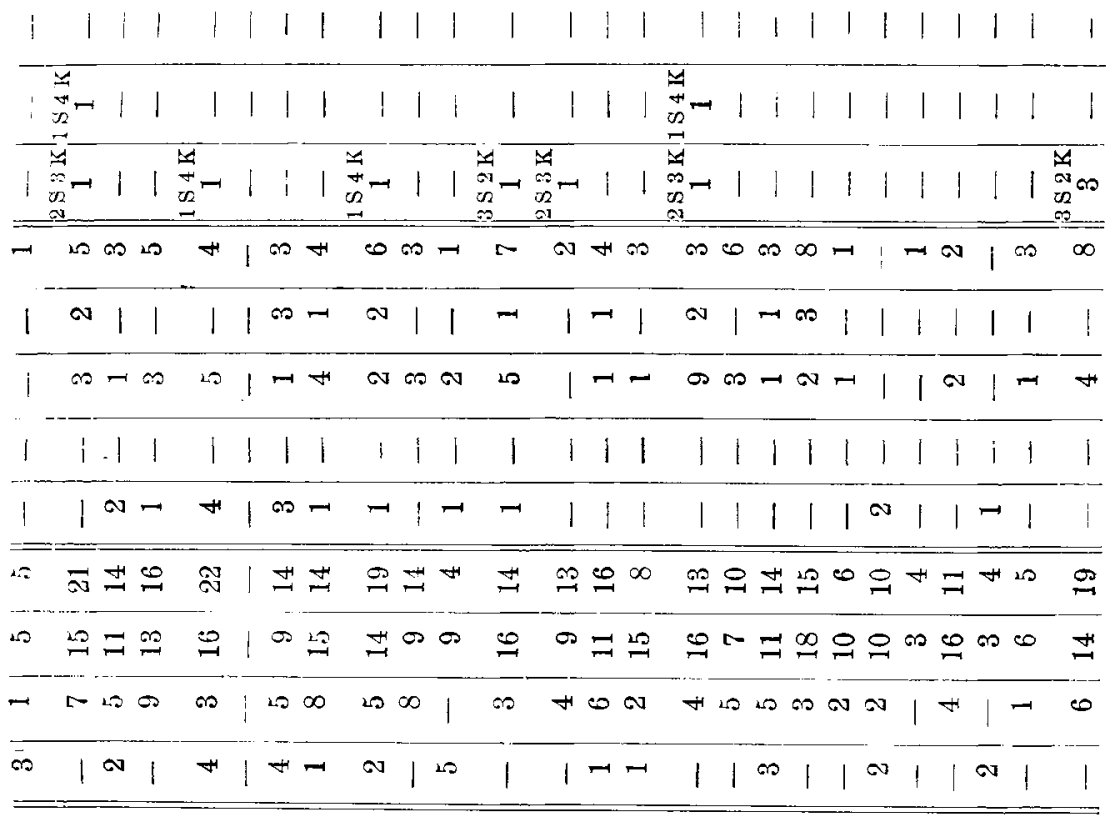

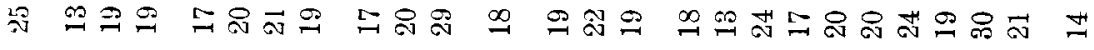

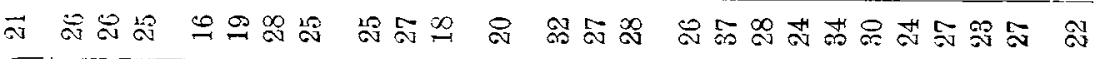

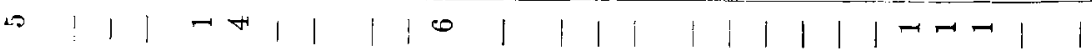

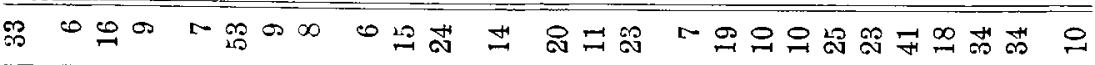
$-1-11$ 1 1 1 111111111111111111111111

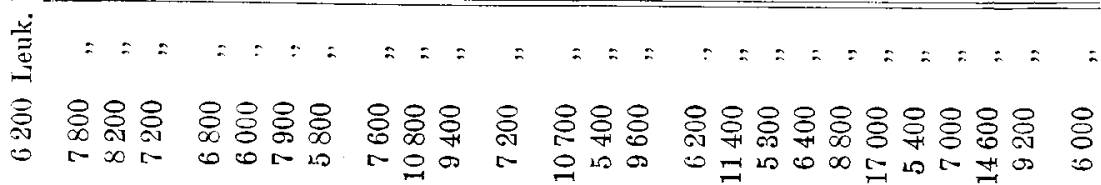

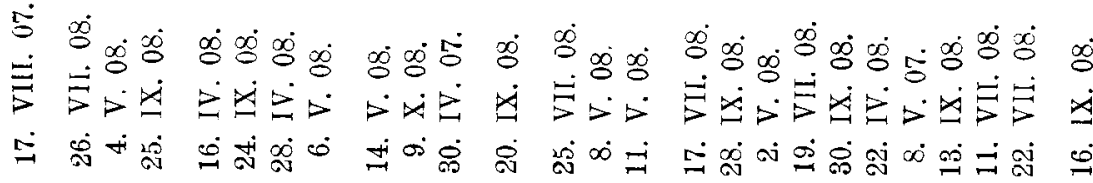

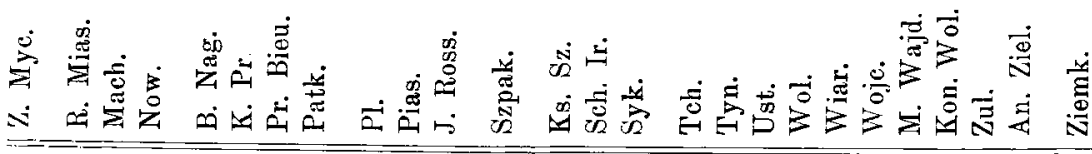

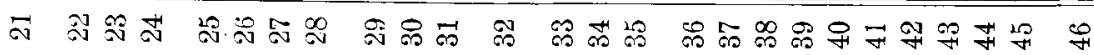




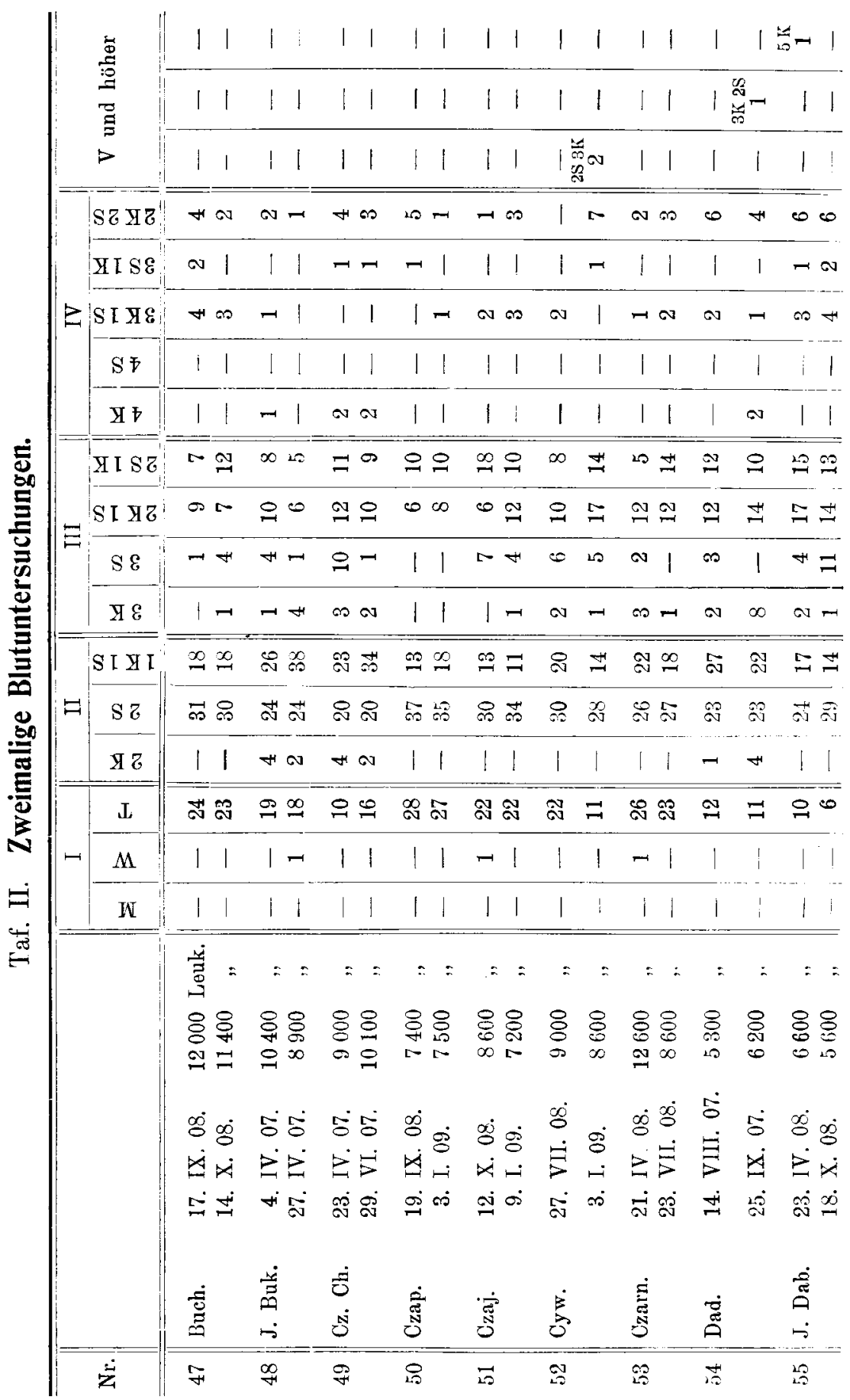




\begin{tabular}{|c|c|c|c|c|c|c|c|c|c|c|c|}
\hline 1 & 1 & 1 & 11 & 11 & 11 & 11 & 11 & 11 & 11 & 11 & 1 \\
\hline 11 & $\begin{array}{l}x-1 \\
\infty \\
\text { on } \\
0\end{array}$ & $\begin{array}{l}3 \\
b \\
o n \\
a \\
a\end{array}$ & 11 & 11 & 11 & 11 & $\begin{array}{ll}\infty & \\
0 & \\
0 & -1 \\
01 & 1\end{array}$ & 1 & 11 & $\begin{array}{lll}4 \\
0\end{array}-1$ & 1 \\
\hline$\infty 1$ & - & 20 & $\rightarrow \infty$ & $\infty 1$ & $\forall \infty$ & m & +20 & $\rightarrow 1$ & $\infty$ & -1 & $1-1$ \\
\hline 11 & 1 & $\infty$ & 11 & 11 & -1 & 11 & $\infty 1$ & 11 & 11 & -1 & 11 \\
\hline i 1 & $\infty$ & 20 & 11 & -1 & 11 & $\infty \infty$ & هם & -1 & $1-$ & ס & 10 \\
\hline 11 & 1 & 1 & 11 & 11 & 11 & 11 & 11 & 11 & 11 & 11 & 11 \\
\hline+ & 1 & - & -1 & 11 & 11 & $\rightarrow \rightarrow$ & 11 & 11 & 11 & 11 & 11 \\
\hline$\exists \infty$ & $\infty$ & $\stackrel{\infty}{\longrightarrow}$ & $\forall r$ & $\cos$ & $\circ 0$ & {$[-9$} & $\mathscr{P}$ & $\infty$ m & $\infty \infty$ & $\stackrel{\infty}{\rightarrow} \underset{\sim}{\infty}$ & $\infty \infty$ \\
\hline$\angle 0 \infty$ & 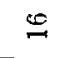 & $r$ & 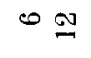 & $\Gamma \infty$ & $\infty \infty$ & $\simeq 20$ & $\stackrel{\oplus}{=}$ & $\infty \bullet$ & $10 \infty$ & $\omega \stackrel{\varphi}{\oplus}$ & $N \cong$ \\
\hline$\therefore 1$ & $H$ & $\infty$ & $\infty \infty$ & $\infty !$ & $\infty \infty$ & $\infty 1$ & 2010 & $-\not$ & $\rightarrow-$ & מ & $\pi-$ \\
\hline 10 & 1 & - & $\infty 1$ & $\infty \infty$ & 11 & $* 1$ & $\rightarrow 1$ & $\rightarrow+$ & $a$ & 11 & $\rightarrow 1$ \\
\hline 60 & న & $\Xi$ & $\vec{\sigma}$ & ח & S $=$ & $\stackrel{\infty}{=}$ & $8 \underset{\infty}{\infty}$ & 98 & ণ & $\oplus \simeq$ & 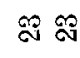 \\
\hline 象 & 50 & $\infty$ & 范 & $\stackrel{\infty}{\Im}$ & 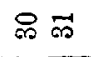 & $\bar{\infty} \approx$ & ア゚ & 品留 & 出 & 10 & 오 \\
\hline$N$ & 1 & 1 & - & I 10 & i 1 & 11 & 11 & $\sigma+$ & $+\infty$ & 11 & $\infty$ \\
\hline
\end{tabular}

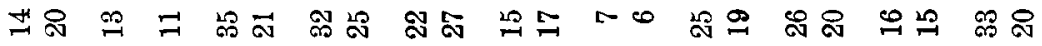

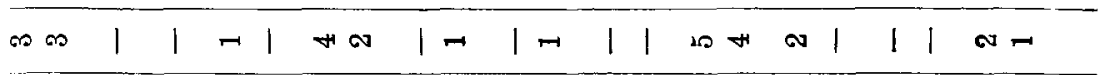

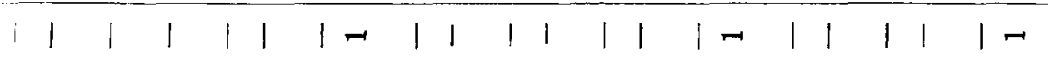

\begin{tabular}{|c|c|c|c|c|c|c|c|c|c|c|c|}
\hline$\vec{\Xi}=$ & $=$ & $=$ & $==$ & $==$ & $=:$ & $==$ & $=$ & $==$ & $=2$ & $==$ & $==$ \\
\hline 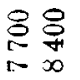 & $\begin{array}{l}8 \\
8 \\
\circ\end{array}$ & 용 & 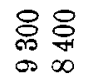 & 88 & $\begin{array}{l}8 \\
8 \\
\infty\end{array}$ & 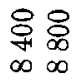 & 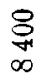 & 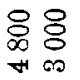 & 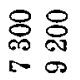 & 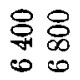 & $\begin{array}{l}8 \\
\varnothing \\
\infty \\
\circ\end{array}$ \\
\hline
\end{tabular}

ப் த் و

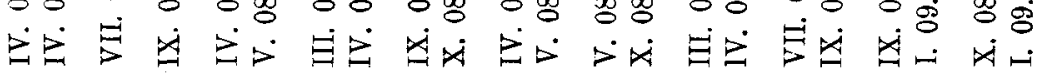

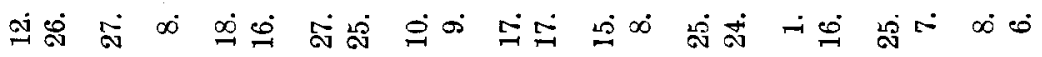

\begin{tabular}{|c|c|c|c|c|c|c|c|c|c|c|}
\hline $\begin{array}{l}\frac{\vec{\sigma}}{\vec{b}} \\
\dot{\vec{v}}\end{array}$ & $\stackrel{3}{3}$ & $\underset{j}{\dot{E}}$ & 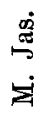 & $\stackrel{\Xi}{\Xi}$ & $\stackrel{\Xi}{\Xi}$ & 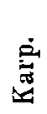 & $\begin{array}{l}\dot{\vec{u}} \\
\dot{0}\end{array}$ & $\begin{array}{l}\text { : } \\
\dot{\pi} \\
\dot{4}\end{array}$ & $\dot{\sim}$ & 胥 \\
\hline 0 & is & $\infty$ & 周 & 8 & $\overline{6}$ & $\mathscr{0}$ & $\mathscr{B}$ & ठే & 18 & $\dddot{8}$ \\
\hline
\end{tabular}




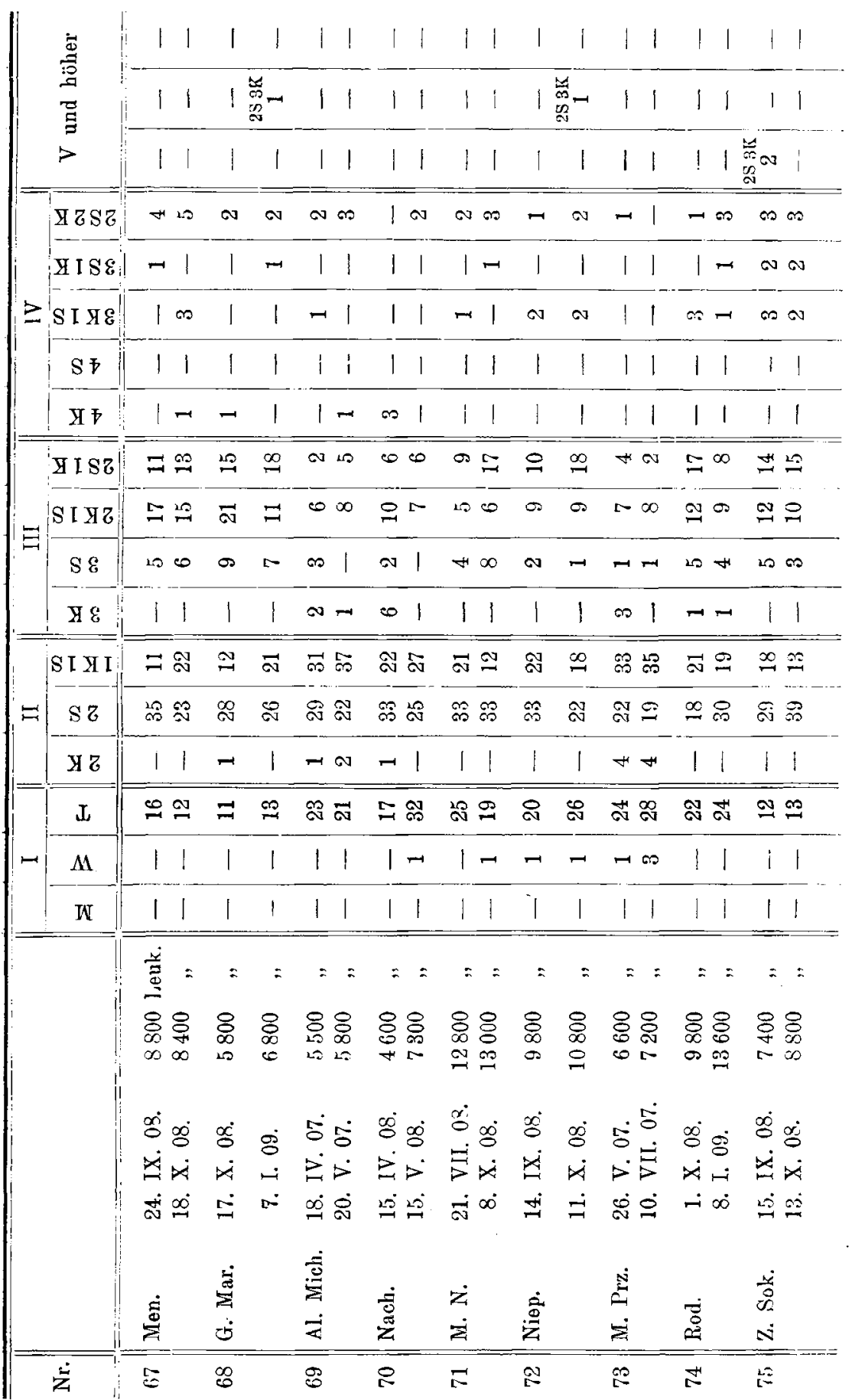




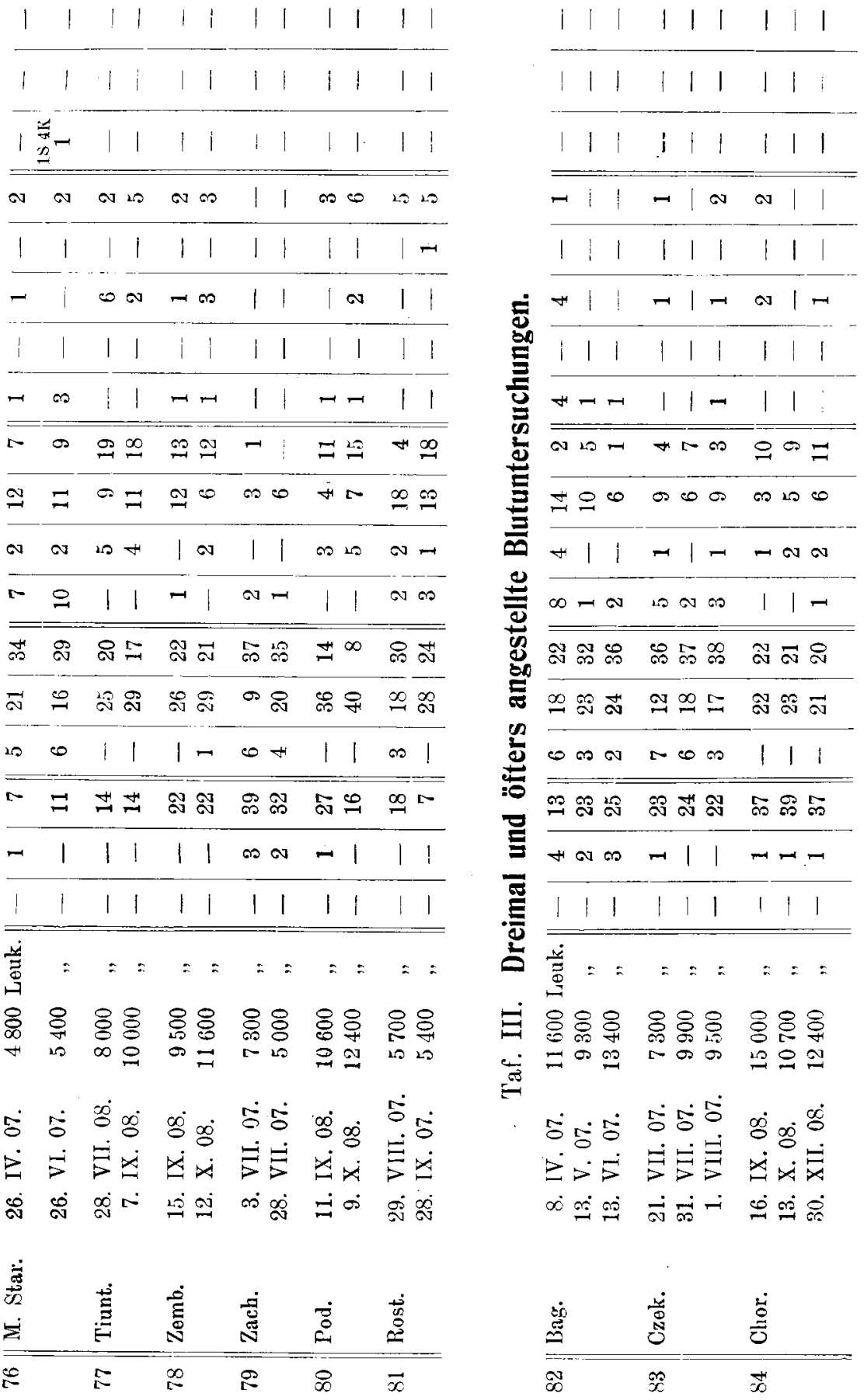




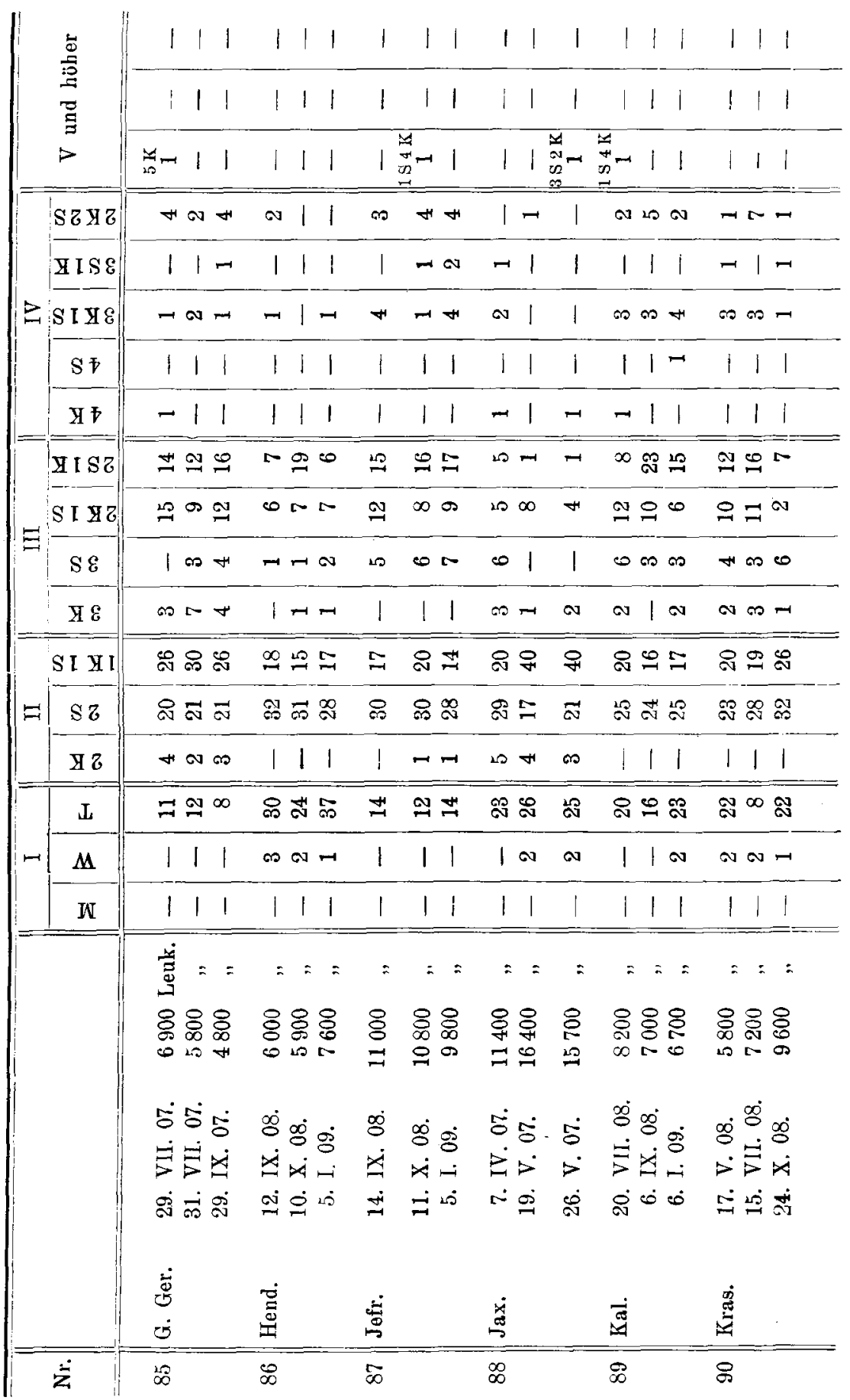




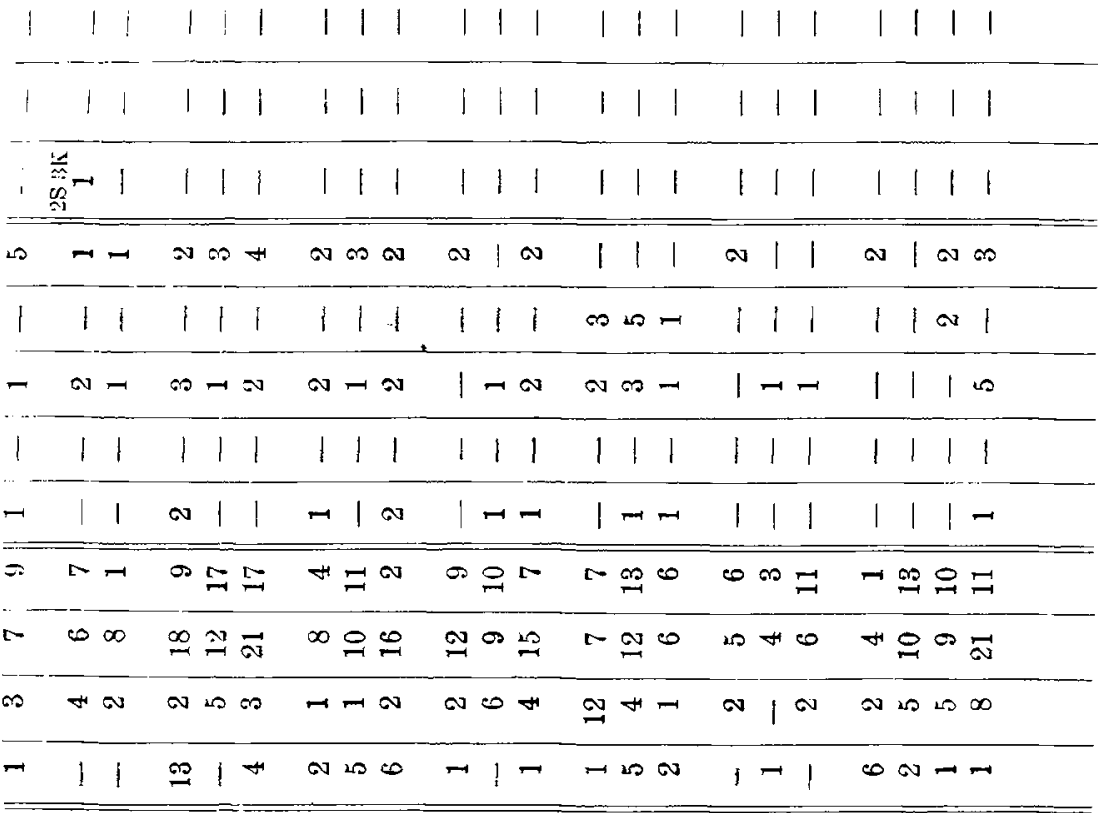

๙

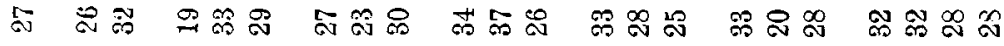

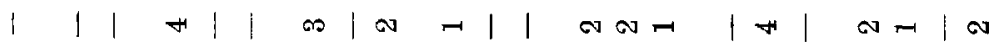

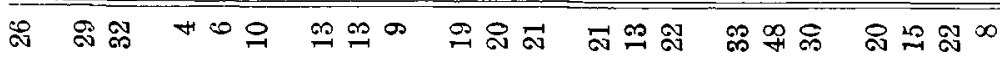

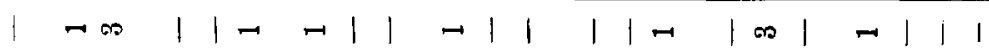

$: 111111111111111111111$

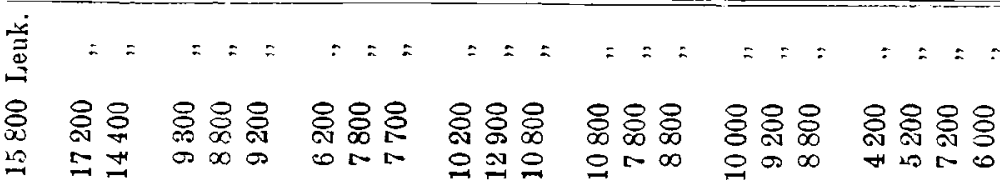

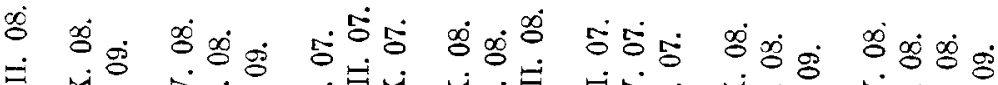

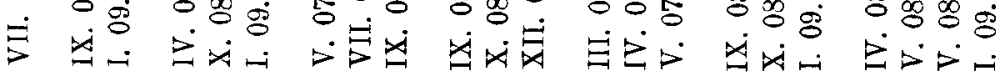
வ்

\begin{tabular}{|c|c|c|c|c|c|c|}
\hline 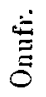 & $\ddot{\ddot{0}}$ & 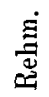 & 芯 & 焉 & $\frac{\dot{x}}{\mathbb{F}}$ & 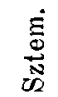 \\
\hline 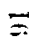 & $\stackrel{g}{\approx}$ & $\stackrel{\mathscr{O}}{\rightrightarrows}$ & $\ddot{\sigma}$ & 29 & $\mathscr{8}$ & $\tilde{\sigma}$ \\
\hline
\end{tabular}




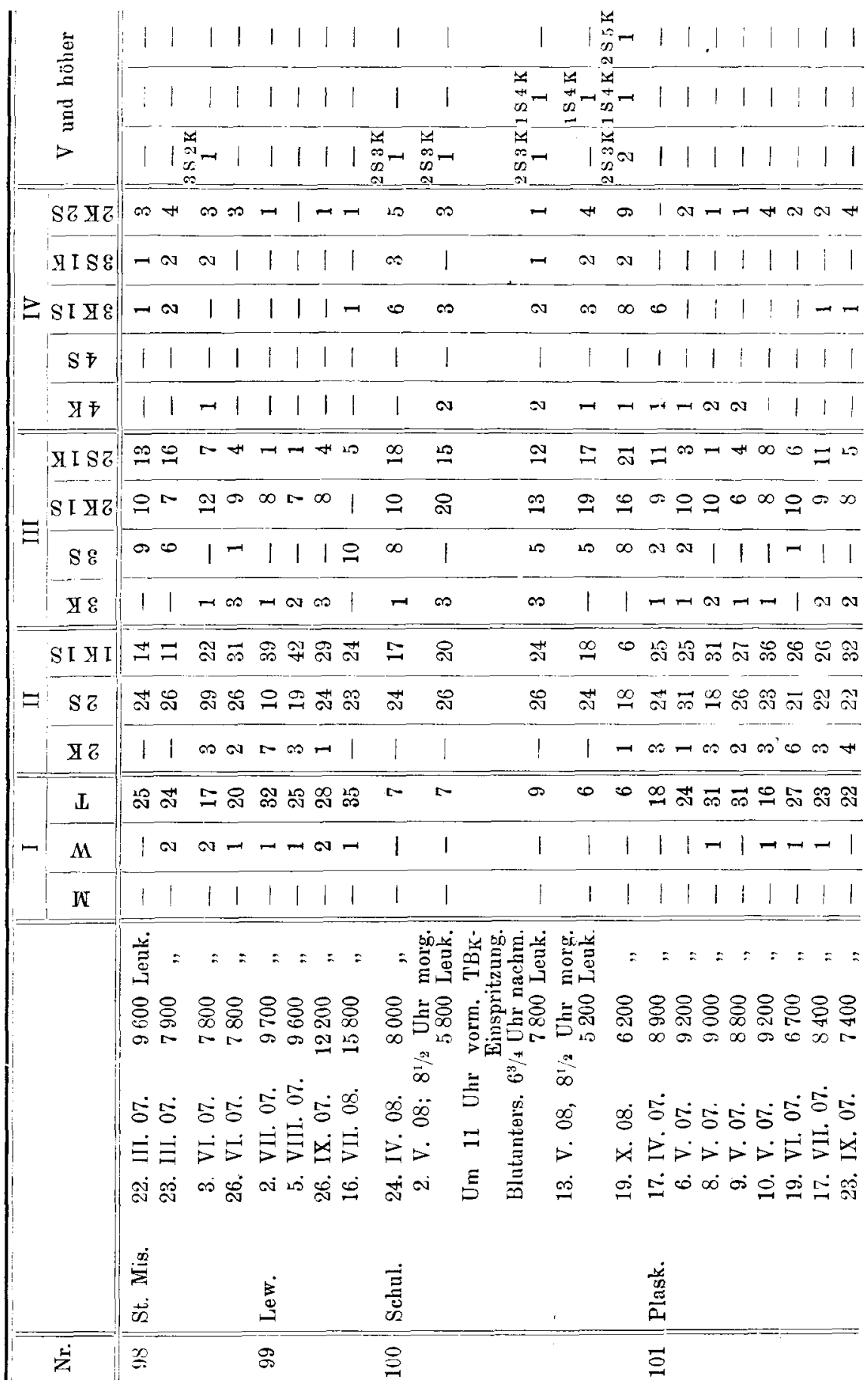




\begin{tabular}{|c|c|c|c|c|c|c|c|c|c|c|c|c|}
\hline & 1 & | & $\because$ & 1 & ! & 1 & | & 4 & ! & | & 1 & $\begin{array}{lllll}1 & 1 & 1 & 1 & 1\end{array}$ \\
\hline 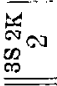 & 1 & ! & & & $\begin{array}{l}y_{n}^{4} \\
\text { on } \\
m\end{array}$ & 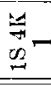 & | & 1 & T & 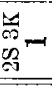 & 1 & 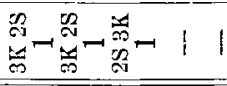 \\
\hline$\infty$ & $\infty$ & $\infty$ & $\forall$ & $\infty$ & $\infty$ & $\dot{\nabla}$ & 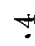 & $H$ & .0 & 10 & s & $00 \infty \mathrm{cot}$ \\
\hline- & $\infty$ & $\infty$ & - & 1 & $\infty$ & 1 & I & 1 & 1 & 1 & | & $11-11$ \\
\hline 1 & 1 & 10 & $\theta$ & $\infty$ & or & 10 & - & $\infty$ & $\neg$ & $\infty$ & $\rightarrow$ & $=\quad-\quad$ a 17 \\
\hline or & $\rightarrow$ & I & 1 & 1 & 1 & 1 & 1 & 1 & $i$ & 1 & 1 & 11111 \\
\hline 1 & 1 & $\infty$ & - & H & 1 & $\infty$ & - & 1 & - & os & - & $+-\rightarrow-\infty$ \\
\hline 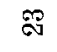 & 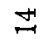 & $\infty$ & \pm & $\infty$ & $\infty$ & $\mathscr{m}$ & $\infty$ & $\stackrel{0}{2}$ & 은 & $\sigma$ & $\infty$ & $\stackrel{\infty}{\sim} \cong \oplus \infty$ \\
\hline 20 & $H$ & $\stackrel{2}{\sim}$ & ת & $\stackrel{\infty}{\sim}$ & $\stackrel{9}{-}$ & 픈 & $\stackrel{\infty}{=}$ & $\stackrel{0}{1}$ & $\stackrel{0}{=}$ & 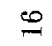 & 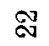 & $\vec{\nabla} \stackrel{\infty}{\sim} \underset{\sim}{\infty}$ \\
\hline 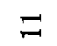 & 国 & 20 & o & 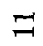 & 0 & $\forall$ & $\infty$ & - & 1 & $\infty$ & $\infty$ & $\infty \pi \infty \infty$ \\
\hline$!$ & 1 & $\infty$ & - & $\infty$ & -1 & $\infty$ & r & 20 & 25 & $\forall$ & $\infty$ & $100 \infty 000$ \\
\hline$\infty$ & $\infty$ & $\stackrel{N}{\sim}$ & $\simeq$ & $\stackrel{\mathscr{1}}{\longleftarrow}$ & 㖗 & $\stackrel{9}{5}$ & on & $\stackrel{2}{=}$ & $\mathscr{B}$ & 8 & 8 & $\stackrel{ \pm}{\vec{\sigma}} \overline{\mathrm{N}} \overline{\mathrm{N}}$ \\
\hline 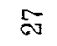 & 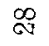 & 守 & 5 & $\mathscr{P}$ & 고 & $\mathscr{Z}$ & 20 & 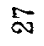 & $\overrightarrow{0}$ & $\stackrel{H}{\infty}$ & $\approx$ & 요 9 요용 \\
\hline 1 & 1 & - & $\infty$ & $\infty$ & -1 & - & 20 & - & $\infty$ & $\infty$ & 1 & 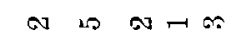 \\
\hline$\stackrel{\infty}{=}$ & $\stackrel{2}{-}$ & $\Xi$ & $\infty$ & 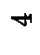 & $\infty$ & $\infty$ & $\Xi$ & $\infty$ & $\infty$ & $\stackrel{9}{\sim}$ & $\stackrel{9}{=}$ & 0 o 0 어 0 \\
\hline 1 & $\rightarrow$ & 1 & 1 & $-r$ & I & 1 & $\rightarrow$ & \} & 1 & I & 1 & 11111 \\
\hline 1 & 1 & 1 & 1 & 1 & I & I & 1 & 1 & 1 & 1 & 1 & 11111 \\
\hline
\end{tabular}

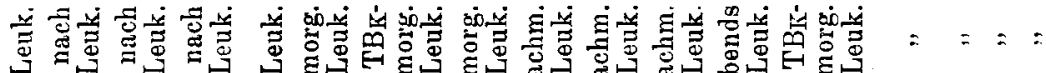
.'.

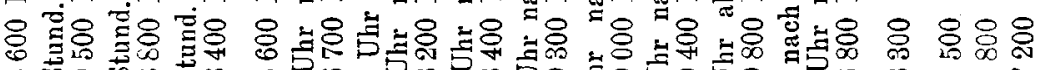

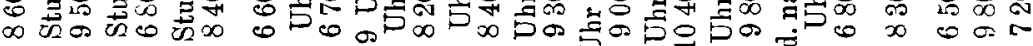

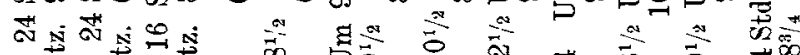

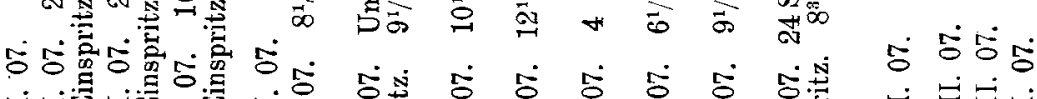

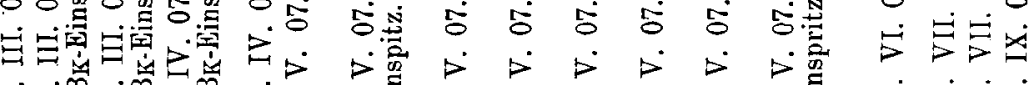

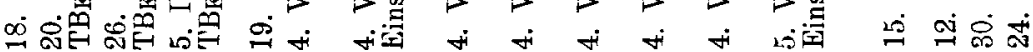

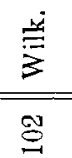

